\title{
Tweety-homolog (Ttyh) Family Encodes the Pore-forming Subunits of the Swelling-dependent Volume-regulated Anion Channel $\left(\mathrm{VRAC}_{\text {swell }}\right)$ in the Brain
}

\author{
Young-Eun Han ${ }^{1,2,3}$, Jea Kwon ${ }^{1,3,4}$, Joungha Won ${ }^{1,3,5}$, Heeyoung An ${ }^{1,3,4}$, \\ Minwoo Wendy Jang ${ }^{1,3,4}$, Junsung Woo ${ }^{3}$, Je Sun Lee ${ }^{6}$, Min Gu Park ${ }^{1,3,4}$, \\ Bo-Eun Yoon ${ }^{7}$, Seung Eun Lee ${ }^{8}$, Eun Mi Hwang ${ }^{3}$, Jae-Young Jung ${ }^{2,3}$, \\ Hyungju Park ${ }^{6}$, Soo-Jin $\mathrm{Oh}^{3,9}$ and C. Justin Lee $\mathrm{e}^{1,2,3 *}$
}

${ }^{1}$ Center for Cognition and Sociality, Institute for Basic Science, Daejeon 34126, ${ }^{2}$ Department of Neuroscience, Division of Bio-Medical Science \& Technology, KIST School, Korea University of Science and Technology, Seoul 02792, ${ }^{3}$ Center for Glia-Neuron Interaction, Korea Institute of Science and Technology (KIST), Seoul 02792, ${ }^{4}$ KU-KIST, Graduate School of Converging Science and Technology, Korea University, Seoul, 02841, ${ }^{5}$ Department of Biological Sciences, Korea Advanced Institute of Science and Technology (KAIST), Daejeon 34141, ${ }^{6}$ Molecular Neurobiology Laboratory, Dept. of Structure and Function of Neural Network, Korea Brain Research Institute, Daegu 41068, ${ }^{7}$ Department of molecular biology, Dankook University, Cheonan 31116, ${ }^{8}$ Virus Facility, Research Animal Resource Center, Korea Institute of Science and Technology (KIST), Seoul 02792, ${ }^{9}$ Convergence Research Center for Diagnosis, Treatment and Care System of Dementia, Korea Institute of Science and Technology (KIST), Seoul 02792, Korea

In the brain, a reduction in extracellular osmolality causes water-influx and swelling, which subsequently triggers $\mathrm{Cl}^{-}$- and osmolytes-efflux via volume-regulated anion channel (VRAC). Although LRRC8 family has been recently proposed as the pore-forming VRAC which is activated by low cytoplasmic ionic strength but not by swelling, the molecular identity of the pore-forming swellingdependent VRAC $\left(V_{\text {RAC }}\right.$ swell $)$ remains unclear. Here we identify and characterize Tweety-homologs (TTYH1, TTYH2, TTYH3) as the major $\mathrm{VRAC}_{\text {swell }}$ in astrocytes. Gene-silencing of all Ttyh1/2/3 eliminated hypo-osmotic-solution-induced $\mathrm{Cl}^{-}$conductance $\left(\mathrm{I}_{\mathrm{Cl} . \text { swell }}\right)$ in cultured and hippocampal astrocytes. When heterologously expressed in HEK293T or CHO-K1 cells, each TTYH isoform showed a significant $\mathrm{I}_{\mathrm{Cl}, \mathrm{swell}}$ with similar aquaporin-4 dependency, pharmacological properties and glutamate permeability as $\mathrm{I}_{\text {Cl.swell }}$ observed in native astrocytes. Mutagenesis-based structure-activity analysis revealed that positively charged arginine residue at 165 in TTYH1 and 164 in TTYH2 is critical for the formation of the channel-pore. Our results demonstrate that TTYH family confers the bona fide $\mathrm{VRAC}_{\text {swell }}$ in the brain.

Key words: Volume-regulated anion channel, VRAC, Tweety-homolog, Ttyh, Volume regulation

Received April 16,2019, Revised April 23,2019, Accepted April 25, 2019

* To whom correspondence should be addressed.

TEL: 82-42-878-9150, FAX: 82-42-878-9151, e-mail: cjl@ibs.re.kr

Copyright $\odot$ Experimental Neurobiology 2019.

www.enjournal.org
This is an Open Access article distributed under the terms of the Creative Commons Attribution Non-Commercial License (http://creativecommons.org/licenses/by-nc/4.0) which permits unrestricted non-commercial use, distribution, and reproduction in any medium, provided the original work is properly cited. 


\section{INTRODUCTION}

Brain volume regulation is a homeostatic process in which the ionic and osmotic balance is maintained by water movement. It is critical for proper function and health of the nervous system and is tightly controlled by a specific cell type called astrocytes due to their high and exclusive expression of the water channel, aquaporin-4 (AQP4) $[1,2]$. The increase of intracellular or decrease of extracellular ionic- and organic-osmolytes initiates water-influx through AQP4 and swelling, which triggers an efflux of $\mathrm{Cl}^{-}$and osmolytes via volume-regulated anion channel $\left(\mathrm{VRAC}_{\text {swell }}\right)$, followed by a water-efflux to restore volume. The latter process is called regulatory volume decrease (RVD) [3-5]. The astrocytic $\mathrm{VRAC}_{\text {swell }}$ has been initially characterized as an intracellular $\mathrm{Ca}^{2+}$-independent and kinase inhibitor-sensitive channel [6]. It has been subsequently shown that several organic osmolytes, notably glutamate and taurine which act as neurotransmitters, are released via the astrocytic VRAC $_{\text {swell }}[7-10]$. Taurine, the most abundant osmolyte has been shown to regulate the glycinergic neurotransmission in the hypothalamus [11]. Moreover, VRAC $_{\text {swell }}$ and the released osmolytes have been implicated in several pathophysiological conditions such as cerebral edema following excessive oxidative stress, ischemia, traumatic brain injury and glioma [12-16]. VRAC $_{\text {swell }}$ is also associated with many other general functions including regulation of cell cycle, apoptosis, proliferation and cellular mobility [17, 18]. Reduction of $\mathrm{VRAC}_{\text {swell }}$ and impairment of apoptotic volume decrease have been linked to a multi-drug resistance (MDR) to chemotherapy in several cancer cells $[19,20]$. Although the pathophysiological functions of the astrocytic $\mathrm{VRAC}_{\text {swell }}$ and the released osmolytes are becoming increasingly highlighted, the precise molecular and cellular mechanisms of $\mathrm{VRAC}_{\text {swell }}$ activation and related functions are still poorly understood due to the lack of molecular identity of the astrocytic VRAC $\mathrm{C}_{\text {swell }}$.

Over the years, many $\mathrm{Cl}^{-}$channels and transmembrane proteins have been proposed as the molecular identity of $\mathrm{VRAC}_{\text {swell }}$ but tested with no success [17, 21-24]. Since 2014, LRRC8A has been proposed as a necessary component of $\mathrm{VRAC}_{\text {swell }}$ in various cell lines by providing evidence of the reduction of $\mathrm{I}_{\mathrm{Cl}, \text { swell }}$ with $\operatorname{Lrrc} 8 \mathrm{a}$ siRNA $[25,26]$. Unexpectedly, reconstitution of the LRRC8Acontaining complex into lipid bilayers was sufficient to form anion channels activated by low intracellular ionic strength $(\Gamma)$ rather than cell swelling itself [27]. Moreover, an overexpression of LRRC8 isoforms not only failed to induce larger $\mathrm{I}_{\mathrm{Cl} \text {,swell }}$ over the endogenous levels in various cell line such as HEK293T, HeLa cells $[25,26]$, but also failed to restore $\operatorname{VRAC}_{\text {swell }}$ activity in cisplatinresistant KCP-4 cells [28]. These results indicate that LRRC8A is not sufficient for VRAC $_{\text {swell }}$ in HEK293T, HeLa and KCP-4 cells.
In a very recent study, the crystal structure of the LRRC8 family consisting of a transmembrane pore domain activated at low cytoplasmic $\Gamma$ has been determined [29], indicating that LRRC8 family is the VRAC activated by the lower cytosolic $\Gamma\left(V_{R A C}\right)$, rather than $V_{R A C}$ swell. Therefore, these previous findings strongly suggest that there exists a separate molecular component for $\mathrm{VRAC}_{\text {swell }}$ in astrocyte.

Consistently, it has been clear that LRRC8-mediated $\mathrm{VRAC}_{\Gamma}$ and the astrocytic $V_{R A C}$ swell do not share the same biophysical and biochemical properties. LRRC8-mediated VRAC F $_{\mathrm{T}}$ in HEK293T and HeLa cells were reported to be $\mathrm{Ca}^{2+}$-dependent as evidenced by the sensitivity to both extracellular zero $\mathrm{Ca}^{2+}$ and intracellular BAPTA [30,31]. Moreover, a G protein-coupled receptor (GPCR)mediated activation of astrocytic VRAC was also shown to be dependent on the local $\mathrm{Ca}^{2+}$ in nanodomains [32]. In contrast, the swelling-activated VRAC, which was firstly reported in human epithelial cells (intestine 407), was demonstrated to be totally independent of $\mathrm{Ca}^{2+}[5]$. More importantly, astrocytic $\mathrm{VRAC}_{\text {swell }}$ was shown to be $\mathrm{Ca}^{2+}$-independent [6]. These results suggested that there exist two-types of VRACs in astrocytes: $\mathrm{Ca}^{2+}$-dependent and $\mathrm{Ca}^{2+}$-independent components of VRAC. In addition, there has been no evidence that LRRC8-mediated $\mathrm{VRAC}_{\Gamma}$ is sensitive to kinase inhibitors, which happens to be a unique property of the astrocytic $\operatorname{VRAC}_{\text {swell }}[6]$. Furthermore, the glutamate permeability ratio, $\mathrm{P}_{\mathrm{glu}} / \mathrm{P}_{\mathrm{Cl}}$, of LRRC8-mediated $\mathrm{VRAC}_{\Gamma}$ was previously reported as near 0.2 [33]. In contrast, the astrocytic $\mathrm{VRAC}_{\text {swell }}$ has been directly shown to display a higher glutamate permeability [8]. Interestingly, the glutamate- and GABA-permeable $\mathrm{Ca}^{2+}$-activated anion channel BEST1 [34, 35], but not LRRC8A, was shown to encode Aqp4-dependent $\mathrm{VRAC}_{\text {swell }}$ in retinal pigment epithelial cells differentiated from human-induced pluripotent stem cells (hiPSC-RPE) [31,36], suggesting that anion channels other than LRRC8A could be responsible for the astrocytic $\mathrm{VRAC}_{\text {swell }}$. More importantly, mechanically-induced ATP release in astrocyte was shown to be mediated possibly by $\mathrm{VRAC}_{\text {swell }}$ as evidenced by the sensitivity to a known VRAC inhibitor, DCPIB [37]. However, this was not impaired by gene-silencing of LRRC8A, suggesting an involvement of other unidentified component of $\mathrm{VRAC}_{\text {swell }}$ [37]. Therefore, the molecular identity of the astrocytic $V_{R A C}$ swell still remains unknown.

Previous studies reported that the maxi-chloride channels share the common physiological, biophysical and pharmacological pro-

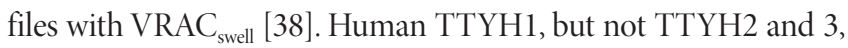
was initially described as putative maxi-chloride anion channels, activated by hypo-osmotic solution (HOS) [39], which was disproven later [40]. Recently, TTYH1 was confirmed to be a potent regulator of tumor microtubule morphology, invasion, and prolif- 
eration of glioma, which are the known functions of $\mathrm{VRAC}_{\text {swell }}[41]$. Brain transcriptome analysis by RNA sequencing showed that in astrocytes TTYH1 and 3 were the top $49^{\text {th }}$ and $94^{\text {th }}$ among 22,458 genes ranked by expression level [42]. Furthermore, TTYH1/2/3 showed 11-, 12-, and 3-fold higher mRNA level in astrocyte compared to neuron in the brain [42]. Therefore, TTYH1/2/3 should be considered as potential candidates of the astrocytic $\mathrm{VRAC}_{\text {swell }}$.

In this study, we set out to determine the true molecular identity of the astrocytic $\mathrm{VRAC}_{\text {swell }}$, activated by AQP4-dependent swelling. Many previous studies of $\mathrm{VRAC}_{\Gamma}$ and $\mathrm{VRAC}_{\text {swell }}$ have used external and internal solutions that contained cations such as $\mathrm{Na}^{+}, \mathrm{K}^{+}$, and $\mathrm{Cs}^{+}$, which might have allowed the investigators to inadvertently record currents contaminated by cations. We have utilized a special recipe of external and internal solutions consisting only $\mathrm{Cl}^{-}$as the permeating ion to eliminate any contribution of cations $\mathrm{Na}^{+}, \mathrm{K}^{+}$and to minimize $\mathrm{Cs}^{+}$for the recording of genuine $\mathrm{I}_{\mathrm{Cl}, \mathrm{swell}}$, as previously described for the recording of $\mathrm{VRAC}_{\text {swell }}$ current in cultured astrocyte [6]. We have identified and characterized TTYH1/2/3, not LRRC8A nor BEST1, as the pore-forming subunits of the astrocytic $V_{R A C}$ swell.

\section{MATERIALS AND METHODS}

\section{Animals and housing}

C57BL/6J mice and hGFAP-CreERT2 were used at $8 \sim 10$ weeks of age. The hGFAP-CreERT2 mice are inducible transgenic mice under control of human GFAP promoter and estrogen. All mice were kept on a 12 hours light-dark cycle in a specific-pathogenfree facility with controlled temperature and humidity and had free access to food and water. All experimental procedures were conducted according to protocols approved by the directives of the Institutional Animal Care and Use Committee of KIST (Seoul, Republic of Korea).

\section{Primary mouse astrocyte culture}

Primary cultured astrocytes were prepared from cortex of C57BL/6 mouse pups (P0-P2) as described [37]. The cerebral cortex was dissected from the brain and adherent meninges were removed, minced and dissociated into single cell suspension by trituration. Cells were cultured in Dulbeccos modified Eaglés medium (DMEM, \#10-013, Corning) supplemented with (in mM) 25 glucose, 4 L-glutamine, 1 sodium pyruvate, $10 \%$ heat-inactivated horse serum (\#260500-088, Gibco), 10\% heat-inactivated fetal bovine serum (\#10082-147, Gibco) and 10,000 units/ml penicillinstreptomycin (\#15140-122, Gibco). Cultures were maintained at $37^{\circ} \mathrm{C}$ in a humidified $5 \% \mathrm{CO}_{2}$ incubator. On DIV3, cells were vigorously washed with repeated pipetting and the media was replaced to get rid of debris and other floating cell types. During maintaining the culture before use, the media was replaced every 3 4 days. For gene-silencing experiments with primary cultured astrocytes, various shRNA vectors were electroporated (Neon Transfection system kit; \#MPK10096, Invitrogen) into trypsinized cultured astrocytes 4 days before the experimental day and replated onto culture dish. One day before the experimental day (for recording $\mathrm{I}_{\mathrm{d}, \text { swell }}$, DIV21 primary astrocyte culture were used), cells were replated onto cover-glass coated with $0.1 \mathrm{mg} / \mathrm{ml}$ Poly DLysine (PDL, \#P6407, Sigma-Aldrich).

\section{Cell lines culture}

Human embryonic kidney 293T (HEK293T) and Chinese hamster ovary-K1 (CHO-K1, referred as $\mathrm{CHO}$ ) cells were purchased from ATCC (\#CRL-3216, ATCC) and the Korean Cell Line Bank (Seoul National University, Republic of Korea), respectively. All cell lines have been tested for mycoplasma contamination. HEK293T cells and CHO cells were cultured in DMEM (\#10-013, Corning) and F-12 (\#21127-022, Gibco), respectively. Both media were supplemented with (in mM) 25 glucose, 4 L-glutamine, 1 sodium pyruvate, $10 \%$ heat-inactivated fetal bovine serum (\#10082-147, Gibco) and 10,000 units/ml penicillin-streptomycin (\#15140-122, Gibco). Cell lines were maintained at $37^{\circ} \mathrm{C}$ in a humidified atmosphere of 95\% air and 5\% $\mathrm{CO}_{2} .18$ hours before the experimental day, cells were transfected with DNA clone by transfection reagent (Effectene, \#301425, Qiagen). On experiment day, the transfected cells were replated onto cover-glass for electrophysiological recordings. For immunocytochemistry, HEK293T cells were plated onto PDL coated cover-glass, and transfected with DNA clone 20 hours before fixation.

\section{shRNA vector construction}

Various kinds of shRNA were synthesized as for following: Two kinds of oligos were purchased (Sequence of oligos; [phos] 5'-t [sense sequence of target] ttcaagaga [reverse complement sequence of target] tttttc- $3^{\prime}$ and [phos] 5 - tcgagaaaaaa [sense sequence of target] tctcttgaa [reverse complement sequence of target] a-3'). The sequence information for control shRNA and various candidates of shRNA are listed in Table 1.Two oligos were annealed with annealing buffer (in mM; 200 potassium acetate, 60 HEPES-KOH, 4 Mg-acetate, $\mathrm{pH} 7.3$ was adjusted by $\mathrm{KOH}$ ) and incubated at $95^{\circ} \mathrm{C}$ for $5 \mathrm{~min}$ and $70^{\circ} \mathrm{C}$ for $10 \mathrm{~min}$. The annealed double-stranded oligo was inserted into HpaI-XhoI restriction enzyme sites of pSicoR lentiviral vector [44] (\#11579, Addgene) and verified by sequencing. The shRNA containing pSicoR vectors were electroporated into cultured astrocytes. In experiments using triple combination of TTYH shRNA, we used either (pSicoR-Ttyh1-shRNA-GFP, 
Table 1. List of shRNA and Knock-down percentages

\begin{tabular}{|c|c|c|c|c|c|}
\hline Gene & Species & Accession \# & Target sequences & Knock-down \% & Test \\
\hline $\begin{array}{l}\text { Control } \\
\text { Aqp4 }\end{array}$ & Mus musculus & $\begin{array}{l}\text { This paper } \\
\text { NM_001308641 } \\
\text { NM_001308642 } \\
\text { NM_001308643 } \\
\text { NM_001308644 } \\
\text { NM_001308645 } \\
\text { NM_001308646 } \\
\text { NM_001308647 } \\
\text { NM_001317729 } \\
\text { NM_009700 }\end{array}$ & $\begin{array}{l}\text { TCGCATAGCGTATGCCGTT } \\
\text { GCACACGAAAGATCAGCATCG }\end{array}$ & $\begin{array}{l}\text { N/A } \\
87.22 \\
\text { verified in } \\
\text { Woo et al., } 2017\end{array}$ & $\begin{array}{l}\text { in heterologous system by } \\
\text { performing RT-PCR }\end{array}$ \\
\hline $\begin{array}{l}m L r r c 8 a \\
m / h L r r c 8 a\end{array}$ & $\begin{array}{l}\text { Mus musculus } \\
\text { Homo sapiens (h) } \\
\text { Mus musculus (m) }\end{array}$ & $\begin{array}{l}\text { NM_177725 } \\
\text { NM_001127244 (h) } \\
\text { NM_001127245(h) } \\
\text { NM_019594(h) } \\
\text { NM_177725(m) }\end{array}$ & $\begin{array}{l}\text { GCCTGCATTGGTTTGCCAAGT } \\
\text { CCATCATCAAGGTGATCAA } \\
\text { GCACAACATCAAGTTCGACGT }\end{array}$ & $\begin{array}{l}97.33 \\
93.75\end{array}$ & $\begin{array}{l}\text { in heterologous system by } \\
\text { performing Western-blot }\end{array}$ \\
\hline $\operatorname{Lrrc} 8 \mathrm{c}$ & Mus musculus & NM_133897 & GCTTCCAGCACTTGAGAAAGC & $44.52 \pm 5.28$ & $\begin{array}{l}\text { in cultured mouse cortical } \\
\text { astrocytes by performing } \\
\text { RT-PCR }\end{array}$ \\
\hline Best1 & Mus musculus & NM_011913 & TTGCCAACTTGTCAATGAA & $\begin{array}{l}\text { verified in } \\
\text { Park et al., } 2009\end{array}$ & verified in Park et al., 2009 \\
\hline Ttyhl & Mus musculus & $\begin{array}{l}\text { NM_001001454 } \\
\text { NM_001109765 } \\
\text { NM_001305822 } \\
\text { NM_021324 }\end{array}$ & GCACAGAAGCCCTTGTTATCC & $90.84 \pm 0.53$ & $\begin{array}{l}\text { in heterologous system by } \\
\text { performing RT-PCR }\end{array}$ \\
\hline Ttyh2 & Mus musculus & NM_053273 & GCATCTGCTATGATGGCATTG & $70.53 \pm 5.45$ & \\
\hline Ttyh3 & Mus musculus & $\begin{array}{l}\text { NM_001308040 } \\
\text { NM_175274 }\end{array}$ & GCATTGCAGTGGGATTCTACG & $87.41 \pm 3.66$ & \\
\hline
\end{tabular}

Stereotaxic surgery for virus delivery

pSicoR-Ttyh2-shRNA-mcherry and pSicoR-Ttyh3 shRNA-mcherry) or (pSicoR-scrambled-shRNA-GFP and pSicoR-scrambledshRNA-mcherry). The sequence of each shRNAs are listed in the Table 1.

\section{Stereotaxic surgery for virus delivery}

The 7 9 weeks old male mice were anesthetized with 2\% tribromoethanol (Avertin, $20 \mu \mathrm{l} / \mathrm{g}$ ) and placed in a stereotaxic frame. The scalp was incised and exposed the skull. The connective tissue was gently scraped away. Stereotaxic coordinates were: AP: -1.7 mm; L: $1.7 \mathrm{~mm}$; and DVL:-1.85 mm, according to Allen Mouse Brain Atlas (http://www.brain-map.org). The cocktail of lentiviruses carrying either (pSicoR-Ttyh1-shRNA-GFP, pSicoRTtyh2-shRNA-mcherry, and pSicoR-Ttyh3-shRNA-mcherry) or (pSicoR-scrambled-shRNA-GFP and pSicoR-scrambled-shRNAmcherry) were bilaterally injected into hippocampal CA1 stratum radiatum of naïve $\mathrm{C} 57 \mathrm{BL} / 6 \mathrm{~J}$ mice for slice patch-clamp recording or tamoxifen-treated hGFAP-creERT2 mice for intrinsic optical signal (IOS) imaging. The adeno-associated virus (AAV) of Lentivirus carrying pSicoR-Ttyhl-shRNA-GFP or scrambled-shRNAGFP was also injected into the CA1 stratum radiatum of naïve
C57BL/6J mice for confirming the knock-down efficiency with immunohistochemistry. 10 14 days after virus delivery by stereotaxic injection, the mice were sacrificed for next experiments at $9 \sim 10$ weeks of age.

\section{Astrocyte-specific rescue by tamoxifen-driven action of Cre- recombinase}

The tamoxifen-inducible Cre-mediated recombination is expected to result in deletion of the floxed sequences. To activate Cre recombinase, 7 9 weeks-old male mice were administrated with tamoxifen (\#T5648, Sigma-Aldrich) once a day (200 mg per kg of body weight, intraperitoneal) for 7 days. Tamoxifen was dissolved in sunflower oil (\#1642347, Sigma-Aldrich) with 10\% ethanol at a final concentration of $20 \mathrm{mg}$ per milliliter at room temperature, and stored at $4{ }^{\circ} \mathrm{C}$ in the dark. The shRNA is floxed with loxP sites in the pSicoR construct, which is cleaved by Cre-expression [44]. The cocktail of lentiviruses carrying pSicoR-Ttyh1-shRNAGFP, pSicoR-Ttyh2-shRNA-mcherry and pSicoR-Ttyh3-shRNAmcherry were injected into CA1 stratum radiatum of the hippocampus in tamoxifen-treated hGFAP-creERT2 transgenic mice, which allowed us to achieve astrocyte-specific recovery of TTYH 
family expression in the hippocampal CA1 stratum radiatum.

\section{Construction of Ttyh1-shRNA-insensitive-GFP vector}

The design for Ttyh1-shRNA-insensitive-GFP clone construction was done by changing every third single nucleotide of Ttyh1 shRNA target site to another nucleotide that makes same amino acid due to the codon redundancy (Ttyhl-shRNA target sequence- 5'- GCACAGAAGCCCTTGTTATCC -3'; shRNAinsensitive sequence- 5'-GCGCAAAAACCTTTATTGTCA-3' included 7 mismatches, also described in Fig. 2B). The site-directed mutagenesis kit was used for the construction of Ttyh1-shRNAinsensitive-GFP vector (Ezchange ${ }^{\mathrm{TM}}$ site-directed mutagenesis kit, EZ400, Enzynomics). The sequence information of oligomers for cloning of mutants clone are listed in Supplemental Table 2.

\section{Construction of truncation and single amino acid mutant vector}

All truncation mutant and single amino acid mutants of TTYH1 were constructed in shRNA-insensitive TTYH1 tagged with GFAP clone (Ttyhl shRNA-insensitive-EGFP). Also, a single amino acid mutant of TTYH2 or TTYH3 were constructed in TTYH2 or TTYH3-IRES2-EGFP clone. All truncations, single amino acid mutants, and shRNA insensitive clones were made by site-directed mutagenesis kit (Ezchange ${ }^{\mathrm{TM}}$ site-directed mutagenesis kit, EZ400, Enzynomics).

\section{Drugs and chemicals}

4-(2-butyl-6,7-dichloro-2-cyclopentylindan-1-on-5-yl)oxybutyric acid (DCPIB), 2-(2-Amino-3-methoxyphenyl)-4H1-benzopyran-4-one (PD98059) were purchased from Tocris (\#1540, 1213). 4,5,7-Trihydroxyisoflavone, 5,7-Dihydroxy-3-(4hydroxyphenyl)-4H-1-benzopyran-4-one (Genistein) was purchased from Sigma-Aldrich (\#G6649). Other chemicals used for recording solution of electrophysiology and intrinsic optical signal imaging were purchased from Sigma-Aldrich.

\section{Electrophysiology and solutions}

For VRAC current (herein defined as $\mathrm{Cl}^{-}$current induced by hypo-osmotic stimulation, $\left.\mathrm{I}_{\mathrm{d}, \mathrm{swell}}\right)$ recording, primary cultured cortical astrocyte or transfected HEK292T or CHO cells, and acute hippocampal slices from 8 10 weeks mice were used for in vitro and ex vivo (slice) whole cell patch clamp recording, respectively. The preparation procedures with cultured coverslip and hippocampal slices followed a previous report [43]. In both in vitro and ex vivo whole cell patch clamp recording, we use the same internal and external solution; isotonic (ISO), hypo-osmotic solution (HOS). In case of ex vivo whole-cell patch clamp recording, the slices were left to recover for at least 1 hour before recording in oxygenated $\left(95 \% \mathrm{O}_{2}\right.$ and $\left.5 \% \mathrm{CO}_{2}\right)$ artificial cerebrospinal fluid (aCSF) containing (in mM) $130 \mathrm{NaCl}, 24 \mathrm{NaHCO}_{3}, 3.5 \mathrm{KCl}, 1.25$ $\mathrm{NaH}_{2} \mathrm{PO}_{4}, 1 \mathrm{CaCl}_{2}, 3 \mathrm{MgCl}_{2}$ and 10 glucose ( $\mathrm{pH} 7.4$ ) at room temperature. After 1 hour, the slices were placed on a chamber with an aCSF solution. After complete rupture of the cell membrane, the external aCSF was changed to standard ISO solution for baseline recording.

Standard external bath solutions of both ISO and HOS for VRAC $_{\text {swell }}$ were composed of (in mM): 70 Tris- $\mathrm{HCl}, 1.5 \mathrm{CaCl}_{2}, 10$ HEPES, and 10 glucose, 5 TEA-Cl, $5 \mathrm{BaCl}_{2}$ and adjusted to $\mathrm{pH} 7.3$ with $\mathrm{CsOH}$, as previously described [6]. The osmolality of each solution was adjusted with sucrose: $100 \mathrm{mM}$ sucrose for 280 290 mOsm (for ISO) and $30 \mathrm{mM}$ sucrose for 220 230 mOsm (for HOS), Solution osmolality was confirmed by a vapor pressure osmometer (Vapro osmometer \#5600, Wescor). The external solution of both $\mathrm{ISO}(\mathrm{NaCl})$ and $\mathrm{HOS}(\mathrm{NaCl})$ for recording of LRRC8-mediated $\mathrm{VRAC}_{\Gamma}$ was composed of (in $\mathrm{mM}$ ) : $150 \mathrm{NaCl}$ for ISO(NaCl), $105 \mathrm{NaCl}$ for $\mathrm{HOS}(\mathrm{NaCl})$, respectively, $6 \mathrm{KCl}, 1$ $\mathrm{MgCl}_{2}, 1.5 \mathrm{CaCl}_{2}, 10$ Glucose, 10 HEPES, adjusted to $\mathrm{pH} 7.4$ with $\mathrm{NaOH}$. The solution osmolality is $320 \mathrm{mOm}$ for ISO $(\mathrm{NaCl})$ and $240 \mathrm{mOsm}$ for $\mathrm{HOS}(\mathrm{NaCl})$. For $\mathrm{Ca}^{2+}$ dependency with TTYH mediated $\mathrm{I}_{\mathrm{Cl}, \text { swell }}, 1.5 \mathrm{mM} \mathrm{CaCl}_{2}$ is changed to $0.15 \mathrm{mM} \mathrm{CaCl}_{2}$ for all external bath solution. TEA-Cl and $\mathrm{BaCl}_{2}$ were added to eliminate the potassium currents enabling selective recording of $\mathrm{Cl}^{-}$ current. For glutamate permeability experiments, $70 \mathrm{mM}$ Tris-Cl containing HOS external solution was substituted for $70 \mathrm{mM}$ Trisbase and $70 \mathrm{mM}$ glutamate (glutamate containing HOS, gHOS) to

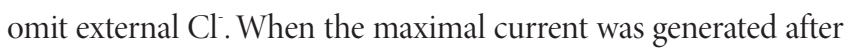
standard HOS treatment, the standard HOS $(70 \mathrm{mM}$ Tris-Cl) was changed to gHOS (70 mM Tris-glutamate). The reversal potentials from both standard HOS (70mM Tris-Cl) and gHOS (70mM Tris-glutamate) were measured to calculate the ratio of glutamate permeability (detailed description in the analysis of electrophysiological data).

For the recording of various anion ( $\mathrm{SCN}^{-}, \mathrm{I}^{-}, \mathrm{Br}^{-}$, and $\mathrm{F}$ ) permeability, $105 \mathrm{mM}$ of $\mathrm{NaCl}$ in $\mathrm{HOS}(\mathrm{NaCl})$ was changed to the same concentration, $105 \mathrm{mM}$ of $\mathrm{NaSCN}, \mathrm{NaI}, \mathrm{NaBr}$, and $\mathrm{NaF}$ at the maximal conductance of $\mathrm{VRAC}_{\text {swell }}$ or $\mathrm{VRAC}_{\Gamma}$ recording. The reversal potentials from each $\mathrm{HOS}(\mathrm{NaCl})(105 \mathrm{mM} \mathrm{NaCl})$ and $\mathrm{HOS}(\mathrm{NaX})$ (105mM NaSCN, $\mathrm{NaI}, \mathrm{NaBr}$, and $\mathrm{NaF}$ ) were measured to calculate ratio of ion permeability (The calculating equation for of relative anion permeability is the same with glutamate permeability, detailed description in analysis of electrophysiological data).

Standard internal solution for $\mathrm{VRAC}_{\text {swell }}$ was composed of (in mM) : 60 Trizma-HCl, 70 Trizma-base, 70 Aspartic acid, 15 HEPES, $0.4 \mathrm{CaCl}_{2}, 1 \mathrm{MgCl}_{2}, 4 \mathrm{Mg}$-ATP, $0.5 \mathrm{Na}-\mathrm{GTP}$, and 1 EGTA, 
Table 2. Comparison of external and internal solutions in the current study and other previous studies

\begin{tabular}{|c|c|c|c|c|c|c|c|}
\hline \multirow[t]{2}{*}{ Solution } & \multirow[t]{2}{*}{$\begin{array}{l}\text { Constituents } \\
\text { (in } \mathrm{mM} \text { ) }\end{array}$} & \multicolumn{2}{|c|}{$\begin{array}{c}\text { Current study } \\
\text { (same as Valérie Crépel et. al., } \\
\text { J. Neurosci (1998)) }\end{array}$} & \multicolumn{2}{|c|}{$\begin{array}{c}\text { Felizia K. Voss et. al., Sci- } \\
\text { ence (2014) }\end{array}$} & \multicolumn{2}{|c|}{ Zhaozhu Qiu et. al., Cell (2014) } \\
\hline & & ISO & HOS & ISO & HOS & ISO & HOS \\
\hline \multirow[t]{11}{*}{ External } & Tris.Cl & 70 & 70 & - & - & - & - \\
\hline & $\mathrm{Na} \cdot \mathrm{Cl}$ & - & - & 150 & 105 & 90 & 90 \\
\hline & $\mathrm{K} \cdot \mathrm{Cl}$ & - & - & 6 & 6 & 2 & 2 \\
\hline & $\mathrm{Mg} \cdot \mathrm{Cl}_{2}$ & - & - & 1 & 1 & 1 & 1 \\
\hline & $\mathrm{Ca} \cdot \mathrm{Cl}_{2}$ & 1.5 & 1.5 & 1.5 & 1.5 & 1 & 1 \\
\hline & HEPES & 10 & 10 & 10 & 10 & 10 & 10 \\
\hline & Glucose & 10 & 10 & 10 & 10 & - & - \\
\hline & TEA.Cl & 5 & 5 & - & - & - & - \\
\hline & $\mathrm{Ba} \cdot \mathrm{Cl}_{2}$ & 5 & 5 & - & - & - & - \\
\hline & Osmolarity & $\begin{array}{l}\text { Adding sucrose } \\
\text { up to } 290 \mathrm{mOsm}\end{array}$ & $\begin{array}{l}\text { Adding sucrose } \\
\text { up to } 220 \mathrm{mOsm}\end{array}$ & - & - & Mannitol 110 & Mannitol 10-60 \\
\hline & $\mathrm{pH}$ & \multicolumn{2}{|c|}{ pH7.3 by $\mathrm{CsOH}$} & \multicolumn{2}{|c|}{ pH7.4 by $\mathrm{NaOH}$} & \multicolumn{2}{|c|}{ pH7.4 by $\mathrm{NaOH}$} \\
\hline \multirow[t]{11}{*}{ Internal } & Tris.Cl & \multicolumn{2}{|c|}{60} & \multicolumn{2}{|c|}{-} & \multicolumn{2}{|c|}{-} \\
\hline & Tris-Aspartate & \multicolumn{2}{|c|}{70} & \multicolumn{2}{|c|}{ - } & \multicolumn{2}{|c|}{-} \\
\hline & Cs.Cl & \multicolumn{2}{|c|}{ - } & \multicolumn{2}{|c|}{40} & \multicolumn{2}{|c|}{133} \\
\hline & Cs.MeS & \multicolumn{2}{|c|}{ - } & \multicolumn{2}{|c|}{100} & \multicolumn{2}{|c|}{-} \\
\hline & HEPES & \multicolumn{2}{|c|}{15} & \multicolumn{2}{|c|}{10} & \multicolumn{2}{|c|}{10} \\
\hline & $\mathrm{Ca} \cdot \mathrm{Cl}_{2}$ & \multicolumn{2}{|c|}{0.4} & \multicolumn{2}{|c|}{1.9} & \multicolumn{2}{|c|}{2} \\
\hline & $\mathrm{Mg} \cdot \mathrm{Cl}_{2}$ & \multicolumn{2}{|c|}{1} & \multicolumn{2}{|c|}{1} & \multicolumn{2}{|c|}{1} \\
\hline & EGTA & \multicolumn{2}{|c|}{1} & \multicolumn{2}{|c|}{5} & & 5 \\
\hline & ATP & & & & & & 4 \\
\hline & GTP & & .5 & & & & 0.5 \\
\hline & $\mathrm{pH}$ & $\mathrm{pH} 7.25$ & y $\mathrm{CsOH}$ & $\mathrm{pH}$ & $\mathrm{OH}$ & pH7.2 & $\mathrm{y} \mathrm{CsOH}$ \\
\hline
\end{tabular}

adjusted to $\mathrm{pH} 7.25$ with $\mathrm{CsOH}$, as previously described [6].

The internal solution for recording of LRRC8-mediated $\mathrm{VRAC}_{\Gamma}$ was composed of (in $\mathrm{mM}$ ) : $40 \mathrm{CsCl}, 100 \mathrm{CsMeS}, 1 \mathrm{MgCl}_{2}, 1.9$ $\mathrm{CaCl}_{2}$, 5 EGTA, 4 Na2ATP, 10 HEPES, adjusted to $\mathrm{pH} 7.2$ with $\mathrm{CsOH}$, as previously described(Voss et al., 2014). For $\mathrm{Ca}^{2+}$ free experiment, 1mM EGTA was replaced into 20mM BAPTA which leads $100 \mathrm{nM}$ free $\mathrm{Ca}^{2+}$ to be reduced by $10 \mathrm{nM}$. Patch pipettes had tip resistances of $5 \sim 8 \mathrm{M} \Omega$ when filled with internal solution. Pipettes were pulled from borosilicate thin-wall glass capillaries (TW150F-4, World Precision Instruments) with the micropipette puller (P-97, Sutter Instrument). Unlike other previous studies [25, 26], we used Tris $\cdot \mathrm{Cl}$-based external solution without $\mathrm{Na}^{+}$and $\mathrm{K}^{+}$ and minimal level of $\mathrm{Cs}^{+}(15 \mathrm{mM}$ of $\mathrm{CsOH}$ for $\mathrm{pH}$ adjustment of external solution), and Tris $\cdot \mathrm{Cl}$-based internal solution to eliminate any contribution of $\mathrm{Na}^{+}, \mathrm{K}^{+}$and to minimize $\mathrm{Cs}^{+}$to $\mathrm{I}_{\mathrm{Cl} \text { swell. }}$. This is particularly important for isolating the anionic current (See Table 2).

For substituted-cysteine accessibility method (SCAM), 10 amino acids in TTYH1 (from V161 to A170) were each substituted with cysteine residue. The cysteine mutant of TTYH1 or TTYH1-WT were co-transfected with AQP4 in HEK29T cells. The standard bath solution of HOS containing MTSES $(100 \mathrm{mM})$ was applied at the maximal $\mathrm{I}_{\mathrm{Cl}, \text { swell }}$. The percent block was determined.

To test the dominant negative function of TTYH1-R165A, pEGFP-N1-TTYH1-WT and pEGFP-N1-TTYH1-R165A were co-expressed with mAQP4-M1-mcherry in HEK293Tcells. The total DNA amount of TTYH1 (WT or R165A) is $2 \mathrm{mg}$ and AQP4 is $750 \mathrm{ng}$. The relative amount of R165A to WT is varied with 1:0, $0.75: 0.25,0.5: 0.5,0.25: 0.75$, and 0:1. The maximal current of $\mathrm{I}_{\mathrm{Cl} \text {,swell }}$ was recorded in each condition by treatment of a standard solution of HOS.

To identify shRNA-transfected or infected astrocytes from primary cultures or hippocampal slices, GFP or mcherry fluorescence was used (Fig. 10D and 11J), which were driven under CMV promoter in pSicoR vector construct (Fig. 11I). In the case of hippocampal slices, astrocytes were distinguished by electrophysiological properties such as low membrane resistance $(\mathrm{Rm})$, low resting membrane potential after rupturing. The whole cell configuration was achieved by rupturing the cell membrane with suction after achieving a giga-seal. Holding voltage was $-60 \mathrm{mV}$. Stability and quality of the patch were determined by monitoring the cell parameters: Rm, cell capacitance $(\mathrm{Cm})$, and series resistance $(\mathrm{Ra})$.

The episodic ramp protocol (+100 mV to $-100 \mathrm{mV}, 1000 \mathrm{~ms}, 15 \mathrm{~s}$ interval) for measurement of the maximal conductance of $\mathrm{VRAC}_{\text {swell }}$ 
and $\mathrm{VRAC}_{\Gamma}$ and the current step protocol (from-100 $\mathrm{mV}$ to +140 $\mathrm{mV}$ with $20 \mathrm{mV}$ step) for measurement of the voltage-dependent inactivation of $\mathrm{VRAC}_{\text {swell }}$ and $\mathrm{VRAC}_{\Gamma}$ were given and recorded with a Digidata 1322A interface and pClamp10 software (Molecular Devices). A continuous gap-free recording was simultaneously conducted with Minidigi digitizer and Axoscope10 software (Axon Instruments).

\section{Analysis of electrophysiological data}

For drawing the $\mathrm{I} \sim \mathrm{V}$ curve for $\mathrm{I}_{\mathrm{Cl} \text {,swell }}$, the averaged mean value and standard error of mean (SEM) at every $5 \mathrm{mV}$ are plotted. The current density $(\mathrm{pA} / \mathrm{pF})$ of $\mathrm{I}_{\mathrm{Cl} \text {,swell }}$ was measured by subtraction of maximal $\mathrm{Cl}^{-}$current (average of maximal 4weeps in HOS treatment) from basal $\mathrm{Cl}^{-}$current (average 4weeps of ISO treatment, $1 \mathrm{~min}$ before HOS treatment) divided by the capacitance of the membrane $(\mathrm{Cm})$, and measured the amplitude of current density (pA/pF, from - $100 \mathrm{mV}$ to $100 \mathrm{mV}$ ) by $\mathrm{I}_{\mathrm{Cl} \text {,swell (at } 100 \mathrm{mV} \text { ) }}-\mathrm{I}_{\mathrm{Cl} \text {,swell (at - } 100}$ $\mathrm{mV}$ ). Rectification index was defined here as the following equation.

$$
\text { Rectification index }=\left|\frac{I_{c^{l}, \text { swell }} \mid-100 \mathrm{mV}}{I_{c^{l}, \text { swell }} \mid+100 \mathrm{mV}}\right|
$$

To examine the glutamate permeability $\left(\mathrm{P}_{\mathrm{Glu}}\right)$ of VRACs, we measured the reversal potential shift of $\mathrm{I}_{\mathrm{Cl} \text { swell }}$ caused by external solution change from standard HOS solution $(70 \mathrm{mM}$ Tris- $\mathrm{Cl})$ to gHOS (70 mM Tris-glutamate) solution, which was corrected for junction potential $(9.4 \mathrm{mV})$. The detailed composition of the gHOS solution is described above. The reversal potential of $\mathrm{I}_{\mathrm{Cl}, \text { swell }}$ was calculated with following Goldman-Hodgkin-Katz (GHK) equation.

$$
E_{r e v}=\frac{R T}{F} * \ln \left(\frac{P_{c l}\left[C l^{-}\right]_{i}+P_{g l u}[g l u]_{i}}{P_{c l}\left[C l^{-}\right]_{o}+P_{g l u}[g l u]_{o}}\right)
$$

With this equation, reversal potential difference $\left(\Delta E_{\text {rev }}\right)$ was calculated as (previously also shown in $[35,45]$ ).

$$
\begin{gathered}
\Delta E_{r e v}=\frac{R T}{F} * \ln \left(\frac{P_{c l}\left[C l^{-}\right]_{i}+P_{g l u}[g l u]_{i}}{P_{c l}\left[C l^{-}\right]_{H O S}+P_{g l u}[g l u]_{H O S}}\right) \\
-\frac{R T}{F} * \ln \left(\frac{P_{c l}\left[C l^{-}\right]_{i}+P_{g l u}[g l u]_{i}}{P_{c l}\left[C l^{-}\right]_{g H O S}+P_{g l u}[g l u]_{g H O S}}\right)
\end{gathered}
$$

The 'ì and 'o' indicates internal and external solution respectively. HOS and gHOS represent standard hypo-osmotic stimulation condition and glutamate containing HOS condition respectively.

\section{Intrinsic optical signal imaging}

For IOS imaging devices, Infrared (IR) light source with optical filter (775 nm wavelength, Omega Filters) was used for transillumination of brain slices and these optical signals were obtained as IOS images using a microscope (BX50WI, Olympus) equipped with a CCD camera (ORCA-R2, Hamamatsu). Imaging Workbench software (INDEC Biosystems) was used for image acquisition and image analysis.

For the detailed procedure of experiments, we first prepared mouse brain hippocampal slices (described in the methods for electrophysiology). Next, we fixed hippocampal slice into the recording chamber and positioned electrical stimulator in the CA1 stratum radiatum region. We determined the region of interest (ROI) by calculating 1.5 2\% increase in IOS by single pulse electrical stimulation $(20 \mathrm{~Hz}, 1 \mathrm{sec}, 200 \sim 300 \mathrm{~mA})$. Images were acquired every 1 second and after stabilization of the IOS signal, we acquired $10 \mathrm{~min}$ baseline IOS transmittance $\left(\mathrm{T}_{\text {base }}\right)$. Next, we applied 1Hz-30min electrical stimulation (which has been previously shown to induce activity-dependent cell swelling [2]) and acquired two IOS indexes required for analysis: maximum IOS transmittance $\left(\mathrm{T}_{\max }\right)$ and final IOS transmittance $\left(\mathrm{T}_{\text {end }}\right)$. With these defined indicators, we calculated the induced maximal volume increase (b) and regulated volume decrease (a) as $\mathrm{T}_{\max }-\mathrm{T}_{\text {base }}$ and $\mathrm{T}_{\max }-\mathrm{T}_{\text {end }}$ respectively (Fig. $11 \mathrm{C}, \mathrm{E}$, and J). Finally, the percentage of regulated volume decrease (RVD\%) was calculated by

$$
R V D \%=\frac{a}{b} * 100
$$

\section{Quantitative real-time PCR and reverse transcription PCR}

Gene silencing test with shRNAs that target VRAC candidates including Best1, Ttyh1,2 and 3,LRRC8A and $C$ were tested by quantitative real-time PCR (qRT-PCR). All shRNAs were electroporated into cultured cortical astrocytes. Approximately 3 days after electroporation, total RNA was extracted by using RNA isolation kit (RNeasy Mini Kit, \#74104, Qiagen). cDNA was synthesized by using reverse transcriptase (SuperScript III reverse transcriptase, \# 18080-044, Invitrogen). For qRT-PCR, SYBR-green (SYBR Green PCR master mix, \#4309155, Applied Biosystems) were used. Primers for qRT-PCR for each gene were listed in Supplemental Table 2.

\section{Western blot and surface biotinylation assay}

The knock-down efficiency of $m L r r c 8$ a shRNA or $m / h$ Lrrc8a shRNA was confirmed by performing western blot. mLRRC8AGFP with control or mLrrc8a shRNA or $m / h$ Lrrc8a shRNAmcherry were co-transfected with HEK293T cells. After the $30 \mathrm{hr}$, the transfected HEK293T cells were lysed with RIPA buffer (\#R4100, GenDEPOT) containing protease inhibitor cocktail 
(\#P3100, GenDEPOT). $30 \mu \mathrm{g}$ of protein lysates were separated by protein electrophoresis using protein gels (\#4561084, BIORAD) and blotted onto PVDF membranes (\#1704156, BIORAD). The blots were incubated overnight at $4{ }^{\circ} \mathrm{C}$ with chicken anti-GFP (1:5000, \#AB13970, Abcam) and rabbit anti-b-actin (1:5000, \#AB133626, Abcam). Blots were then washed and incubated with horseradish peroxidase-conjugated rabbit anti-chicken $\operatorname{IgY}$ (1:3000, \#AP162P, Millipore), goat anti-rabbit IgG (1:3000, \#AB6721, Abcam), respectively. The immunoreactivity with enhanced chemiluminescence (GE Healthcare Life Sciences). The band intensity was acquired by ImageQuant LAS 4000 (GE Healthcare) and quantified using ImageJ software (NIH). For surface biotinylation, wild-type, several truncated mutant or single amino acid mutants of mTTYH1-EGFP with AQP4 overexpressing HEK293T cells were incubated at $4^{\circ} \mathrm{C}$ and washed three times with PBS. Surface-expressed proteins were then biotinylated in PBS containing Ez-link sulfo-NHS-LC-Biotin (Thermo 21335) for $30 \mathrm{~min}$. After biotinylation, cells were washed with quenching buffer (100 mM glycine in PBS) to remove excess biotin and then washed three times with PBS. The cells were then lysed and incubated with high capacity NeutrAvidin-Agarose Resin (Thermo 29204). After three washes with lysis buffer, bound proteins were eluted by SDS sample buffer and subjected to western blot analysis. Primary antibody was rabbit anti-GFP (Millipore, AB3080). The secondary antibody was Donkey anti-rabbit HRP (Amersham, NA9340).

\section{Immunocytochemistry}

To determine whether the direction of N-, C-terminus, and Loop1 of TTYH1 are located in the cytosolic or extracellular side, HEK293T cells were transfected with TTYH1-EGFP or TTYH1GFP (Loop1-FLAG), grown on coverslips for 24 hours. The cells were fixed in $4 \%$ paraformaldehyde for $30 \mathrm{~min}$ at room temperature. The permeabilized group are treated PBS with 3\% Triton $\mathrm{X}-100$ for $5 \mathrm{~min}$ and the non-permeabilized group is treated PBS for $5 \mathrm{~min}$. Non-specific binding was prevented with 1-hour incubation in $2 \%$ donkey serums. Cells were incubated the rabbit anti-Ttyh1 (for N-terminus of TTYH1, \#NBP1-59909, Novus Biologicals), anti-GFP (for C-terminus of TTYH1, \#ab13970, Abcam), and anti-FLAG (for Loop1 of TTTYH1, \#F1804, SigmaAldrich) primary antibodies for overnight at $4^{\circ} \mathrm{C}$. After washing, DyLight 594-conjugated secondary antibody (Jackson lab, 1:400) was added and incubated for 2 hours at room temperature. The cells were washed and mounted, and then observed under a Nikon A1 confocal microscope.

\section{Immunohistochemistry}

Mice under anesthesia with 2\% tribromoethanol (avertine, $20 \mu \mathrm{l} /$ g) and were trans-cardially perfused with $0.9 \%$ saline followed by $4 \%$ PFA, and then the brains were removed. The dissected brains were post-fixed with $4 \%$ PFA at $4{ }^{\circ} \mathrm{C}$ for 18 24 hours and dehydrated with $30 \%$ sucrose at $4{ }^{\circ} \mathrm{C}$ for 48 hours. For immunostaining, brain sections with a thickness of $30 \mu \mathrm{m}$ were cut using a cryostat, blocked with the serum (donkey serum 2\%, goat serum 2\%, the solution including $0.3 \%$ Triton X-100) of the appropriate species for 1 hour and then treated with primary antibodies, including rabbit anti-TTYH1 (1:200, \#NBP1-59909, Novus Biologicals), chicken anti-GFAP (1:500, \#ab5541, Millipore), mouse anit-NeuN (1:500, \#MAB377, Millipore), DAPI (1:5000, \#46190, Chemicon). During over-night. The next day, tissues were rinsed 3 times with $0.1 \mathrm{M}$ PBS and subsequently incubated with secondary antibodies conjugated with Alexa Fluor 488, 594 and 647 for 1 hour 30 min. After treating with secondary antibodies, the tissues were washed out with PBS including DAPI staining in the second washing step. After three rinses in PBS, the sections were mounted on slide glasses. Images were acquired on a Nikon Al confocal microscope.

\section{Analysis of immunohistochemistry}

Statistical analyses were performed using ImageJ software (NIH Image). For analyzing the knock-down efficiency of AAV-virus containing control or Ttyh1/2/3 shRNA, we measured the TTYH1 intensity in the binary image of GFAP positive $(+)$ cells. The statistical analysis of TTYH1 intensity in GFAP $(+)$ cells between control and Ttyh1/2/3 shRNA groups were analyzed with the twotailed Mann-Whitney t-test.

\section{Bioinformatics and statistical analysis}

Publically available brain RNA-seq data sets [42] of VRAC candidates such as TTYH, LRRC8, BEST family were used in Fig. 1D (https://web.stanford.edu/group/barres_lab/brain_rnaseq.html). Multiple alignments of amino acids were processed from CLUSTAL OMEGA (http://www.ebi.ac.uk/Tools/msa/clustalo/). The dendrogram was drawn by the PHYLIP program. The prediction of the transmembrane domain of TTYH family was processed by TMHMM (http://www.cbs.dtu.dk/services/TMHMM/). The potential phosphorylation site and kinases were predicted by GPS 3.0 (http://gps.biocuckoo.org/online.php). Statistical analysis was performed using GraphPad Prism 7.01 software. $\mathrm{p}<0.05$ was considered statistically significant. No statistical methods were used to predetermine sample size. All statistical analysis results and methods were described in the Supplemental Table 1 for main figures. 


\section{Quantification and statistical analysis}

Statistical parameters including the exact value of $n$, the definition of center, dispersion and precision measures (mean \pm SEM) and statistical significance are reported in the Supplemental Table 1. All data points are tested if the values come from a Gaussian distribution by D'Agostino-Pearson omnibus normality test, and then appropriate statistical methods are applied. In figures, asterisks denote statistical significance as ${ }^{\star}, \mathrm{p}<0.05$; ${ }^{* *}, \mathrm{p}<0.01$; ${ }^{* * *}$, $\mathrm{p}<0.001{ }^{* * * *}, \mathrm{p}<0.000$, as well as non-significance with NS, $\mathrm{p}>0.05$. Statistical analysis was performed in GraphPad PRISM 7.
A

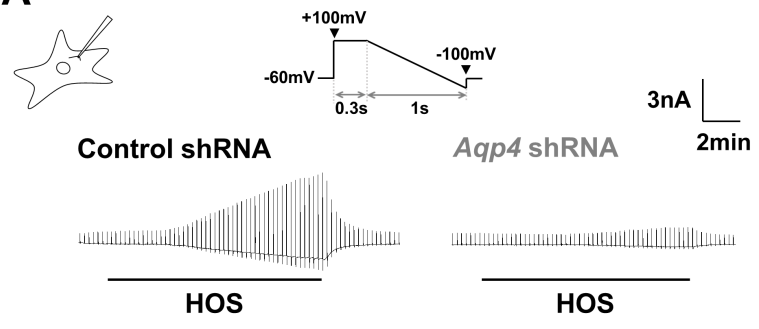

E

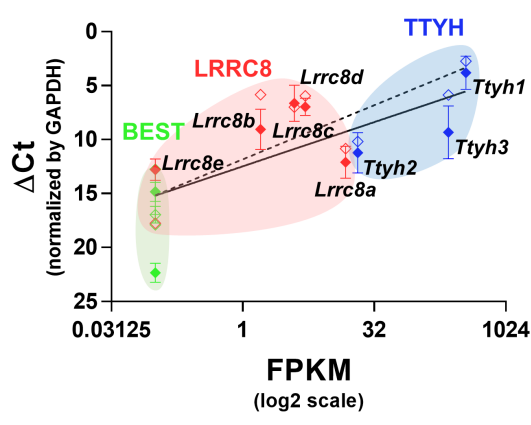

- Cultured astrocytes

$-y=-2.719 x+12.46, R^{2}=0.428$

$\diamond$ Hippocampal tissue

$y=-3.329 x+11.82, R^{2}=0.682$
B

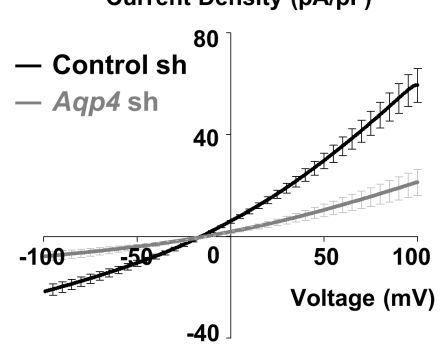

C

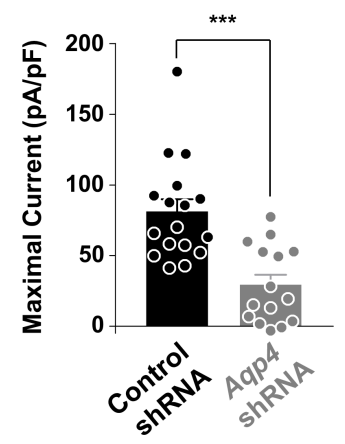

$\mathbf{F}$
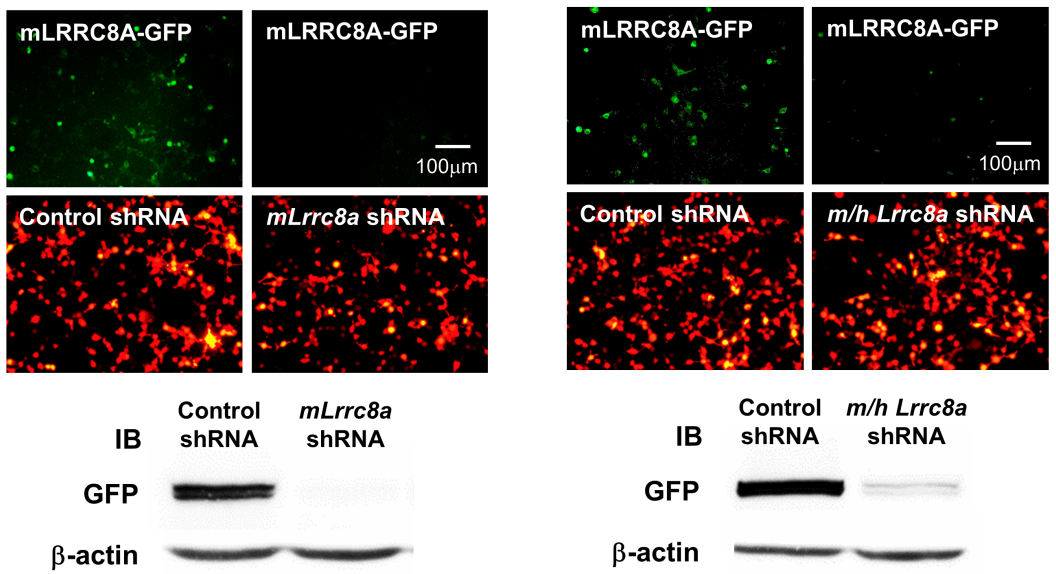

Fig. 1. Neither Lrrc8a nor Best1 encodes the pore-forming subunit of astrocytic VRAC swell $_{\text {. }}$ (A) Representative HOS-induced current (ICl, swell $_{\text {inecord- }}$ ings from control shRNA and Aqp4 shRNA-expressing cultured astrocytes. Inset (left): schematic diagram of whole-cell patch-clamp recording in primary cultured astrocyte. Inset (right): schematic diagram of ramp protocol from $+100 \mathrm{mV}$ to $-100 \mathrm{mV}$. (B) Averaged $\mathrm{I} \sim \mathrm{V}$ curves for $\mathrm{I}_{\mathrm{Cl}, \mathrm{swell}}$ in control shRNA (black) and Aqp4 shRNA (grey). (C) Summary bar graph showing the maximal amplitude of $\mathrm{I}_{\mathrm{Cl} \text {,swell }}$ from $+100 \mathrm{mV}$ to $-100 \mathrm{mV}$. Data are represented as mean \pm SEM ( $\mathrm{n}=17$ for control shRNA and $\mathrm{n}=15$ for $A q p 4$ shRNA; ${ }^{* * *} \mathrm{p}<0.001$, Mann-Whitney test). (D) Inverse correlation between the $\Delta \mathrm{Ct}$ value normalized by GAPDH measured by quantitative real-time quantitative PCR (qPCR) using cDNAs from hippocampal tissue (empty diamond), cultured cortical astrocytes (filled diamond) and FPKM value by RNA-sequencing that was previously shown in previous study (Zhang et al., 2014) to check relative mRNA expression of VRAC candidates such as Ttyh (Ttyh1, Ttyh2 and Ttyh3), Lrrc8 (Lrrc8a, Lrrc8b, Lrrc8c, Lrrc8d and Lrrc8e), and Best (Best1, Best2 and Best3) family. Data are represented as mean \pm SEM of $\Delta$ Ct normalized by GAPDH ( $\mathrm{n}=3$ for cultured astrocytes and $\mathrm{n}=2$ for hippocampal slices; $\mathrm{R}^{2}=0.428$ for cultured astrocytes and $\mathrm{R}^{2}=0.682$ for hippocampal slices; nonlinear regression). (E, F) Upper panels, fluorescence images of mLRRC8A-GFP and control or $m L$ rrc8a or $m / h L r r c 8 a$ shRNA-mcherry co-expressing HEK293T cells. Bottom panels, western blot results confirming the efficiency for $m L r r c 8$ a shRNA or $m / h$ Lrrc8a shRNA compare to control shRNA in mLRRC8A-overexpressed HEK293T cells. (G) Representative $\mathrm{I}_{\mathrm{Cl} \text {,swell }}$ recordings from control shRNA, Lrrc8a shRNA, Lrrc 8c shRNA and both Lrrc8a and $c$ shRNAs-expressing cultured astrocytes. (H) Averaged $\mathrm{I} \sim \mathrm{V}$ curves for $\mathrm{I}_{\mathrm{Cl} \text { swell }}$ in control shRNA (black), Lrrc8a shRNA (orange), Lrrc8c shRNA (green) and both Lrrc8a and c shRNAs (sky blue). (I) Summary bar graph showing the maximal amplitude of $\mathrm{I}_{\mathrm{Cl}, \text { swell }}$ from $+100 \mathrm{mV}$ to $-100 \mathrm{mV}$. Data are represented as mean $\pm \mathrm{SEM}(\mathrm{n}=11$ for control shRNA, $\mathrm{n}=9$ for Lrrc8a shRNA, $\mathrm{n}=8$ for $\operatorname{Lrc} 8 \mathrm{c}$ shRNA, and $\mathrm{n}=9$ for Lrrc8a/c shRNA; NS $>0.05$, ordinary one-way ANOVA). (J-L) Representative traces, averaged I V curves and summary bar graphs of maximal $\mathrm{I}_{\mathrm{Cl} \text { swell }}$ currents from control or BEST1 KO mice in cultured astrocytes ( $\mathrm{n}=14$ for WT and $\mathrm{n}=10$ for BEST1 $\mathrm{KO}$; NS $>0.05$, Mann-Whitney test). (M O) Representative traces, averaged I V curves and summary bar graphs of maximal $\mathrm{I}_{\mathrm{Cl} \text { swell }}$ currents from control $(n=11)$ or BEST1 shRNA expressing condition $(n=10)$ in cultured astrocytes $(n=11$ for control shRNA and $n=10$ for Best 1 shRNA; NS: $p>0.05$, Twotailed unpaired t-test). 


\section{RESULTS}

\section{Neither Lrrc8a nor Best1 encodes the astrocytic VRAC $C_{\text {swell }}$}

Previous studies suggested that water movement via AQP4 is critical for an initial volume increase which then somehow triggers an opening of $\mathrm{VRAC}_{\text {swell }}$ in astrocytes [46]. To test the requirement of AQP4 for activation of $\mathrm{VRAC}_{\text {swell }}$, we recorded $\mathrm{I}_{\mathrm{Cl} \text {,swell }}$ under voltage-clamp configuration from cultured mouse astrocytes expressing either control or Aqp4 shRNA. To isolate genuine $\mathrm{I}_{\mathrm{Cl}, \mathrm{swell}}$ without any current contaminated by cations, we used a special recipe of intracellular and extracellular solutions as previously described (see Table 2 in Materials and Methods) [6]. HOS-treatment caused a slow onset of $\mathrm{Cl}^{-}$conductance increase as a series of vertical lines representing the current trace in response to a periodic voltage ramp from $+100 \mathrm{mV}$ to $-100 \mathrm{mV}$ (Fig. $1 \mathrm{~A}$ inset). We found that the $\mathrm{I}_{\mathrm{Cl}, \text { swell }}$ was mostly abolished by Aqp4 shRNA (Fig. 1A C, see Table 1 in Materials and Methods). Consistent with previous reports [46], these results indicate that astrocytes regulate their volume with water movement through AQP4.

Previously, two groups concurrently reported that LRRC8A is an essential component of $\mathrm{VRAC}_{\Gamma}$ in various cell lines [25-27]. Thus, we tested whether LRRC8A is the major component of $V_{R A C}$ swell in astrocytes. We developed a specific shRNA for $L r r c 8 a$ and $L r$ $r c 8 c$, which shows relatively higher mRNA expression than other Lrrc8 isoforms in cultured astrocytes (Fig. 1D F, see Table 1 in Materials and Methods). We observed that the maximal amplitude of $\mathrm{I}_{\mathrm{Cl}, \mathrm{swell}}$ was not affected by LrrcBa shRNA or Lrrc8c shRNA or both (Fig. 1G I). Taken together, these results indicate that LR-
G
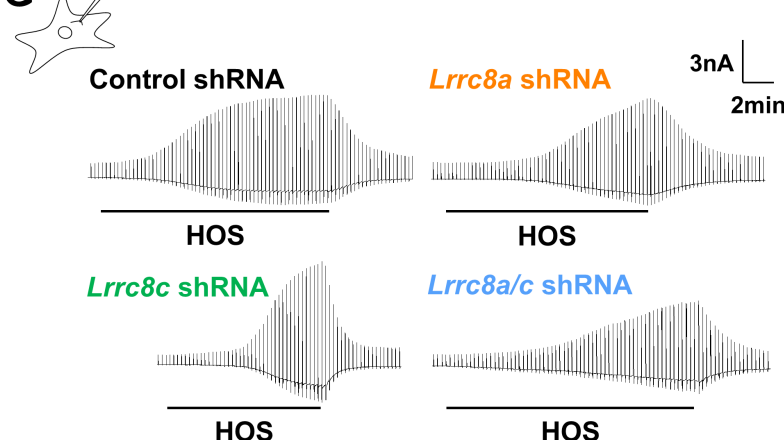

Lrrc8a/c shRNA

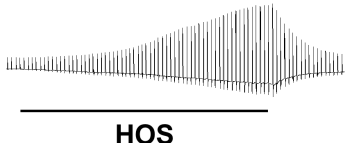

$\mathbf{J}$

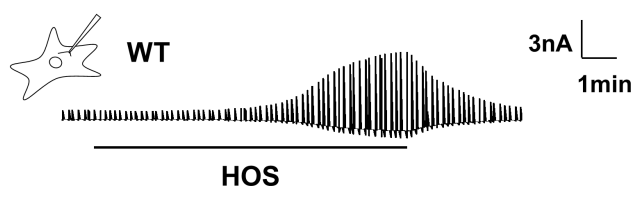

BEST1 KO

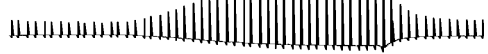

HOS

M
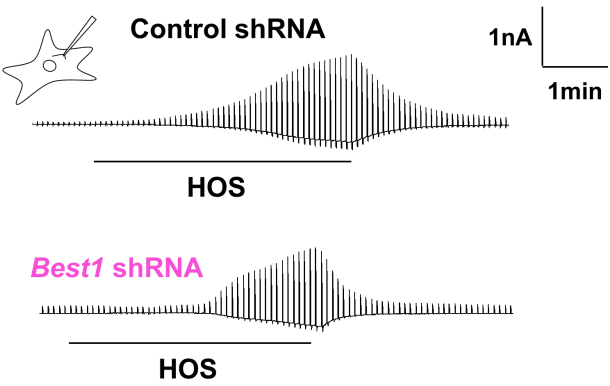

H

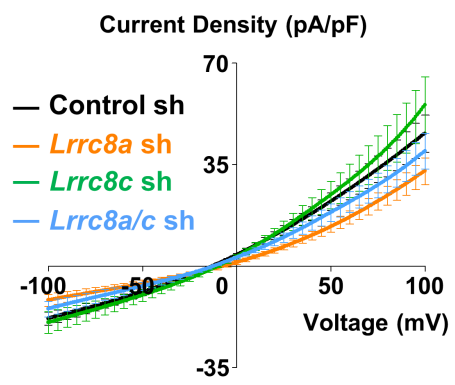

K

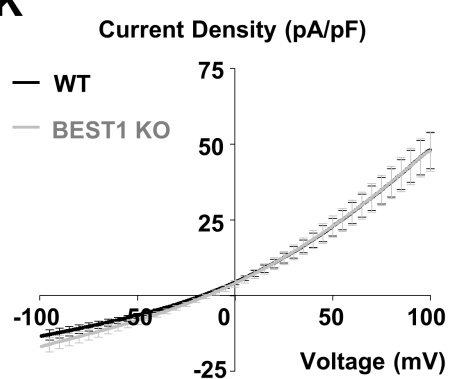

$\mathbf{N}$

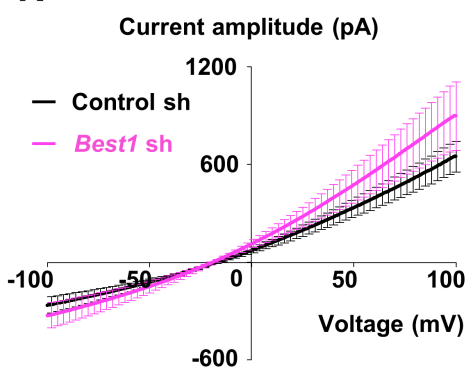

I

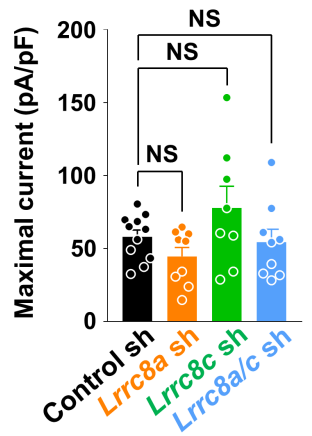

$\mathbf{L}$

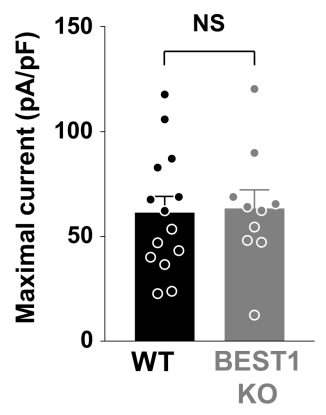

0

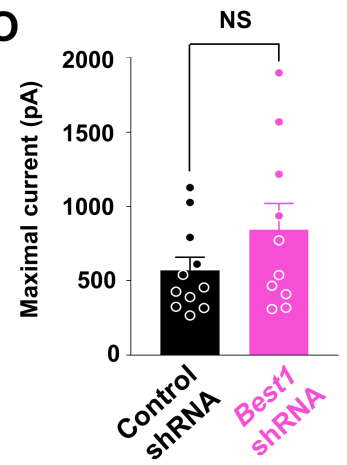

Fig. 1. Continued. 
RC8A and $\mathrm{C}$ do not contribute majorly to the astrocytic $\mathrm{VRAC}_{\text {swell. }}$. It has been subsequently contended that BEST1, not LRRC8A, is indispensable for volume regulation in hiPSC-RPE cells [36]. Over the years, we have extensively characterized BEST1 as a $\mathrm{Ca}^{2+}$ activated anion channel, localized at peri-synaptic sites of the hippocampal astrocytes, functioning as the glutamate- and GABApermeable channel in cerebellum and hippocampus, respectively [47]. To test whether there is any contribution of BEST1 in the astrocytic $\mathrm{VRAC}_{\text {swell }}$, we utilized previously characterized BEST1 knockout mouse [48] and Best 1 shRNA [45]. We observed that $\mathrm{I}_{\mathrm{Cl}, \mathrm{swell}}$ was normally generated in either cultured astrocytes from BEST1 knockout mice or in Best1 shRNA expressing astrocytes (Fig. 1J O), eliminating the possibility that BEST1 contributes to the astrocytic $V_{R A C}$ swell. Taken together, the astrocytic $V_{R A C}$ swell is not encoded by Lrrc 8 a or Best 1 .

\section{Ttyh family of genes encode the essential components of the astrocytic VRAC $C_{\text {swell }}$}

We next focused on Ttyh family as the candidate genes for $\mathrm{VRAC}_{\text {swell }}$. Firstly, we confirmed that cultured astrocytes show much higher mRNA expression of Tty $1 / 2 / 3$, compared to other $\mathrm{VRAC}_{\text {swell }}$ candidates such as Lrrc8 and Bestrophin family (Fig. 1D), as previously reported [42]. Thus, we developed and tested the Ttyh isoform-specific shRNAs (Fig. 2A) on the astrocytic $\mathrm{I}_{\mathrm{Cl}, \text { swell }}$. We found that the astrocytic $\mathrm{I}_{\mathrm{Cl}, \text { swell }}$ was almost completely abolished by a combination of all three Tty $h 1 / 2 / 3$ shRNAs, but not by a single Tty hhRNA or any combination of double Ttyh shRNAs (Fig. 2E H). To exclude any possibility of off-target effect by shRNAs, we developed a fully functional shRNA-insensitive clone of TTYH1 (Fig. 2B D). We found that in astrocytes co-expressing all Ttyh1/2/3 shRNAs with shRNA-insensitive form of TTYH1, the $\mathrm{I}_{\mathrm{Cl}, \text { well }}$ was fully recovered to the control level (Fig. $2 \mathrm{G}$ and $2 \mathrm{H}$ ). Taken together, these results indicate that TTYH family are necessary for the astrocytic $\mathrm{VRAC}_{\text {swell }}$ with functional redundancy.

The reduction of $\mathrm{I}_{\mathrm{Cl}, \text { swell }}$ by Ttyh1/2/3 shRNAs might be due to two possibilities: a reduction of the pore-forming subunits of VRAC $_{\text {swell }}$ to reduce the amplitude of $\mathrm{I}_{\mathrm{Cl}, \text { swell }}$ or a reduction of a modulatory protein of $\mathrm{VRAC}_{\text {swell }}$ to reduce the activation kinetics of $\mathrm{I}_{\mathrm{Cl}, \text { swell }}$. To distinguish these two possibilities, we analyzed the current kinetics of $\mathrm{I}_{\mathrm{Cl} \text {,swell }}$ by plotting the average current density of $\mathrm{I}_{\text {Clswell }}$ versus time after HOS treatment (Fig. 2I and 2K). To compare each shRNA condition, we normalized current density by the maximum to calculate the time to reach $50 \%$ of peak (Fig. 2J and $2 \mathrm{~L}$ ). We found that the maximal current density at both $+100 \mathrm{mV}$ and $-100 \mathrm{mV}$ was dramatically decreased in Tty $1 / 2 / 3$ shRNAs expressing astrocytes compared to control shRNA (Fig. 2I). However, the time to reach $50 \%$ of peak was not significantly different
(Fig. 2J, inset), suggesting that the current reduction by Ttyh1/2/3 shRNAs was due to a reduction of the pore-forming $\mathrm{VRAC}_{\text {swell }}$ subunits. In contrast, we found that the maximal current density at both $+100 \mathrm{mV}$ and $-100 \mathrm{mV}$ was not significantly different in Lrrc8a shRNA condition compared to control shRNA (Fig. 2K). However, the time to reach 50\% of peak in Lrrc8a shRNA expressing astrocytes was significantly slower compared to control shRNA condition (Fig. 2L, inset), indicating that Lrrc8a shRNA slows the activation of $\mathrm{VRAC}_{\text {swell }}$ without affecting the maximal amplitude of $\mathrm{I}_{\mathrm{Cl}, \mathrm{swell}}$ - Taken together, these results suggest that TTYH1/2/3 are the essential component of $\mathrm{VRAC}_{\text {swell, }}$, whereas LRRC8A might act as a modulatory channel of $\mathrm{VRAC}_{\text {swell }}$.

\section{Each TTYH1/2/3 isoform is sufficient for VRAC $C_{\text {swell }}$ activity}

To test if each TTYH isoform confers VRAC swell $_{\text {activity, we }}$ transiently expressed each TTYH isoform clone in HEK293T cells together with AQP4 to maximize HOS-induced volume increase and recorded $\mathrm{I}_{\mathrm{Cl}, \text { swell }}$ (Fig. 3A C). We found that each TTYH isoform co-expressed with AQP4 showed significantly increased $\mathrm{I}_{\mathrm{Cl}, \mathrm{swell}} \mathrm{compared}$ to the condition of AQP4 alone (Fig. 3A C), indicating that all three isoforms of TTYH are sufficient for activation of the $\mathrm{I}_{\mathrm{Cl}, \text { swell }}$ in the presence of AQP4 and that each isoform of TTYH family can mediate $\mathrm{VRAC}_{\text {swell }}$ possibly as a homomeric channel. In marked contrast, LRRC8A has been repeatedly shown to be insufficient for $\mathrm{VRAC}_{\text {swell }}$ activity in heterologous expression systems $[25,26,28,31]$. Consistently, we did not observe $\mathrm{I}_{\mathrm{Cl}, \mathrm{swell}}$ in CHO-K1 cells co-expressing LRRC8A and AQP4 (Fig. 3D F), indicating that $\mathrm{LRRC} 8 \mathrm{~A}$ is not sufficient for $\mathrm{VRAC}_{\text {swell. }}$.

The unexpected lack of HOS-induced $\mathrm{I}_{\mathrm{Cl}, \text { swell }}$ in naïve HEK293T cells (Fig. 3A C) was a surprising observation which called for further investigation. In the past, LRRC8A-mediated $V_{R A C}$ in naïve HEK293T cells has been recorded with external solution containing cations such as $\mathrm{Na}^{+}, \mathrm{Cs}^{+}$, or $\mathrm{K}^{+}$(see Table 2 in Materials and Methods). In contrast, the external solutions that we have utilized contain minimal cations as previously described for the recording of astrocytic VRAC [6]. Therefore, we directly tested the two different solutions in native HEK293T cells. By surprise, we found that $\mathrm{I}_{\mathrm{Cl}, \mathrm{swell}}$ was not observed when the native HEK293T cells with endogenous LRRC8A-mediated VRAC $\mathrm{C}_{\Gamma}$ was treated with the HOS which contained minimal cations, whereas a robust $\mathrm{I}_{\mathrm{Cl} \text {,swell }}$ was induced by the $\mathrm{Na}^{+}$-containing HOS (Fig. 3G I), suggesting that an activation of LRRC8A either requires external cation or possesses a sensitivity to Tris. To further confirm whether this $\mathrm{I}_{\mathrm{Cl} \text { lswell }}$ induced by $\mathrm{Na}^{+}$-containing HOS was mediated by LRRC8A, we engineered previously reported Lrrc8a shRNA [49] which targets both human and mouse LRRC8A (Fig. 1F). We found that the $\mathrm{I}_{\text {Clswell }}$ induced by $\mathrm{Na}^{+}$-containing HOS was almost completely eliminated by the $\mathrm{m} /$ 
A

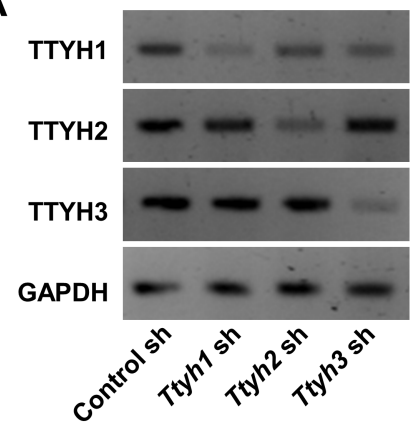

D
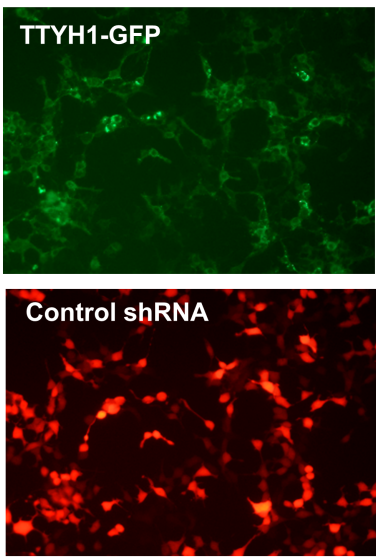

B

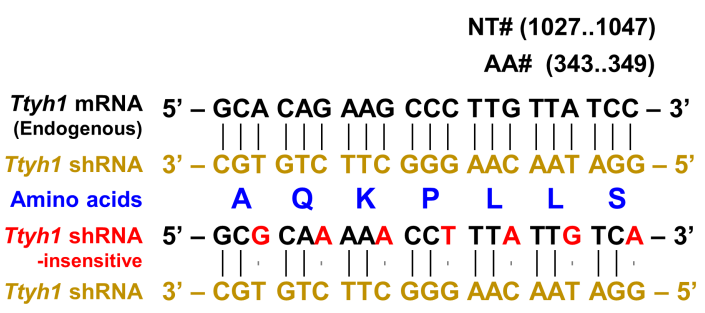

C

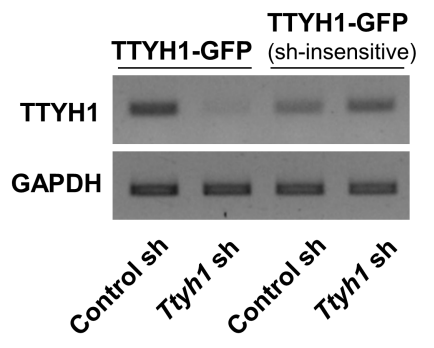

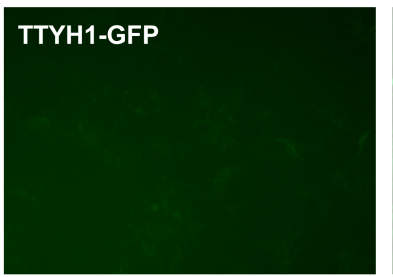

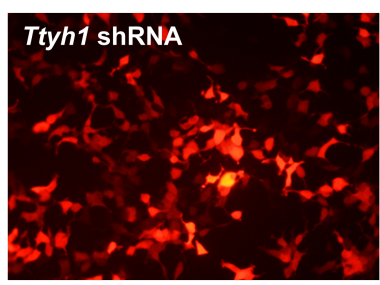

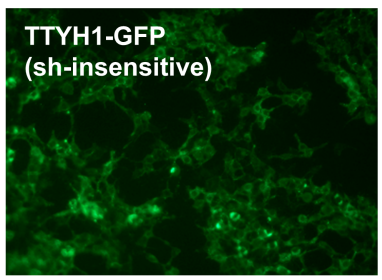

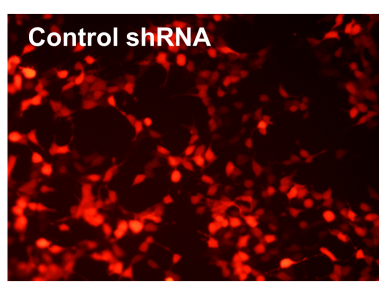

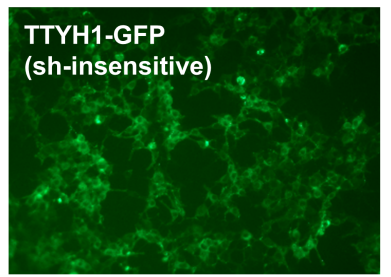

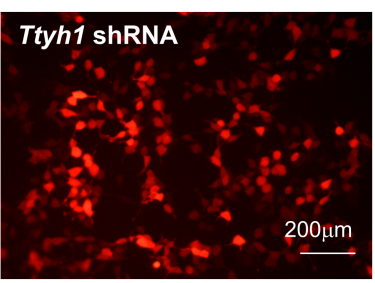

Fig. 2. Ttyh family of genes encode the essential components of the astrocytic VRAC swell $_{\text {. }}$ (A) RT-PCR results confirming the efficiency of each Tty $1 / 2 / 3$ shRNA in cultured astrocytes. Lentivirus containing each pSicoR Ttyh1/2/3 shRNA were infected in cultured astrocytes. (B) Schematic diagram of the design of shRNA-insensitive clone of TTYH1. The upper sequence represents endogenous Ttyhl mRNA sequence that is complemented with Ttyh1 shRNA. The lower sequence represents shRNA-insensitive clone of TTYH1 sequence that is not complemented with Ttyh1 shRNA due to changing every third single nucleotide of Ttyhl shRNA target site to another nucleotide that makes same amino acid due to the codon redundancy. (C) RT-PCR results confirming the efficiency for shRNA-insensitivity using shRNA-insensitive clone of TTYH1 with control or Ttyh1 shRNA compared to TTYH1-GFP with control or Ttyh1 shRNA overexpressing HEK293T cells. (D) Fluorescence images of TTYH1-GFP and shRNA-insensitive clone of TTYH1 with control or Ttyh1 shRNA expressing HEK-293T cells. (E) Representative $\mathrm{I}_{\text {Clswell }}$ from control shRNA, Ttyh1/3 shRNAs, Ttyh1/2/3 shRNAs, Ttyh1/2/3 shRNAs with shRNA-insensitive clone of TTYH1 (Ttyh1 sh-insens.) expressing cultured astrocytes. (F) Summary bar graph showing the maximal amplitude of $\mathrm{I}_{\text {Cl,swell }}$ from $+100 \mathrm{mV}$ to $-100 \mathrm{mV}$ in the presence of single Ttyh shRNA or any combination of double Ttyh shRNAs (T1, T2, T3, $T 1 / 2, T 1 / 3, T 2 / 3$ shRNAs). Data are represented as mean \pm SEM ( $\mathrm{n}=10$ for Naïve, $\mathrm{n}=14$ for $7 \mathrm{mg}$ of control shRNA, $\mathrm{n}=10,12$ and 8 for $7 \mathrm{mg}$ of single Tty 1 , Ttyh2, and Ttyh3 shRNA, $\mathrm{n}=8$ for $14 \mathrm{mg}$ of control shRNA, $\mathrm{n}=10,10$ and 10 for $14 \mathrm{mg}$ of double Ttyh1/2, Ttyh1/3, and Ttyh2/3 shRNAs; NS $>0.05$, Kruskal-Wallis test). (G) Summary bar graph showing the maximal amplitude of $\mathrm{I}_{\mathrm{Cl} \text {,swell }}$ from $+100 \mathrm{mV}$ to $-100 \mathrm{mV}$ in naïve astrocytes and in the presence of control or Ttyh1/2/3 shRNAs and Ttyh1/2/3 shRNAs with shRNA-insensitive clone of TTYH1 expressing cultured astrocytes. Data are represented as mean \pm SEM ( $\mathrm{n}=10$ for Naïve, $\mathrm{n}=11$ for control shRNA, $\mathrm{n}=13$ for Ttyh1/2/3 shRNAs, and $\mathrm{n}=18$ for Ttyh 1/2/3 shRNAs with shRNA-insensitive clone of TTYH1; ${ }^{* *}<0.001, \mathrm{NS}>0.05$, Ordinary one-way ANOVA). (H) Averaged I V curves for $\mathrm{I}_{\text {Cl.swell }}$ in Control shRNA (grey), Ttyh1/2/3 shRNAs $(T 1 / 2 / 3$ shRNAs, blue) and T1/2/3 shRNAs with shRNA-insensitive clone of TTYH1 (Ttyh1 sh-insens; red). (I, K) Averaged current density values at $\pm 100 \mathrm{mV}$ in every minute after HOS treatment in control (black), Ttyh1/2/3 shRNAs (blue) and Lrrc8a (orange) expressing cultured astrocytes. Dot points are represented as mean \pm SEM. Lines (dark grey, sky blue, and orange) between each value were drawn by the fitting of sigmoidal $4^{\text {th }}$ order function. $(\mathrm{n}=11$ for both control shRNA (grey), $\mathrm{n}=13$ for Ttyh1/2/3 shRNA (sky blue), and $\mathrm{n}=9$ for Lrrc 8 a shRNA (orange)). (J, L) Normalized current density from +100 $\mathrm{mV}$ to $-100 \mathrm{mV}$ by maximum current amplitude in every minute after HOS treatment. Dot points are represented as mean \pm SEM. Lines (dark grey, sky blue, and orange) between each value were drawn by the fitting of sigmoidal $4^{\text {th }}$ order function. ( $\mathrm{n}=11$ for both control shRNA (grey), $\mathrm{n}=13 \mathrm{for}$ Tty $1 / 2 / 3$ shRNA (blue), and $\mathrm{n}=9$ for $\operatorname{Lrrc} 8 \mathrm{a}$ shRNA(orange)). Inset: The averaged time to $50 \%$ of peak. Data are represented as mean \pm SEM ( $\mathrm{n}=11$ for both control shRNAs, $\mathrm{n}=13$ for Ttyh1/2/3 shRNA, and $\mathrm{n}=9$ for Lrrc8a shRNA).

h Lrrc8a shRNA and overexpression of TTYH1 and AQP4 along with $\operatorname{Lrrc8a}$ shRNA caused a robust $\mathrm{I}_{\mathrm{Cl}, \text { swell }}$ (Fig. 3J L ), indicating that TTYH1 is sufficient for $\mathrm{VRAC}_{\text {swell }}$ even in the absence of LRRC8A. Furthermore, the same $m / h$ Lrrc8a shRNA did not have any effect on the maximal amplitude of $\mathrm{I}_{\mathrm{Cl} \text {,swell }}$ induced by the HOS which contained minimal cations in astrocytes (Fig. 3M O) as well as in TTYH1 and AQP4 over-expressing HEK293T cells (Fig. $3 \mathrm{P} \sim \mathrm{R})$. These results indicate that LRRC8A-mediated $\mathrm{VRAC}_{\Gamma}$ is 
E

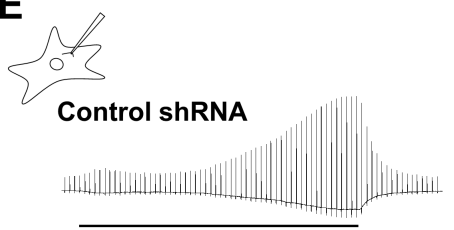

HOS

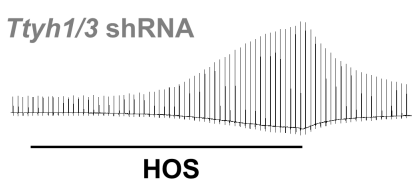

\section{Ttyh1/2/3 shRNA}

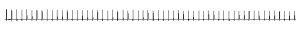

HOS

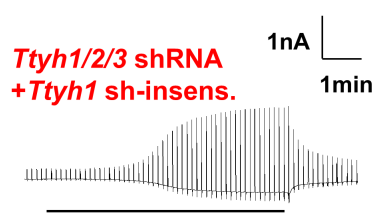

HOS
$\mathbf{F}$

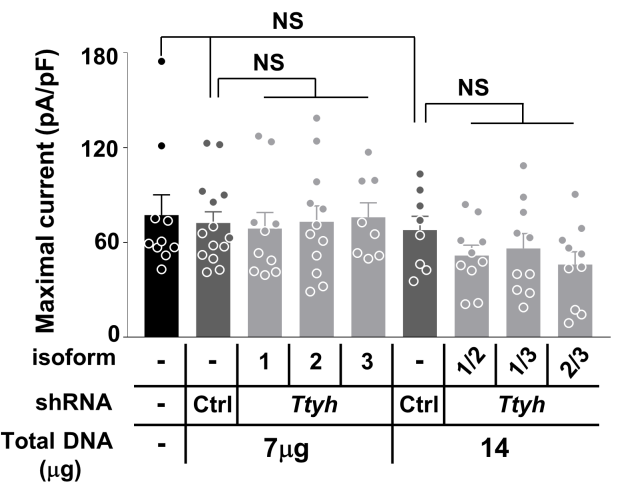

G

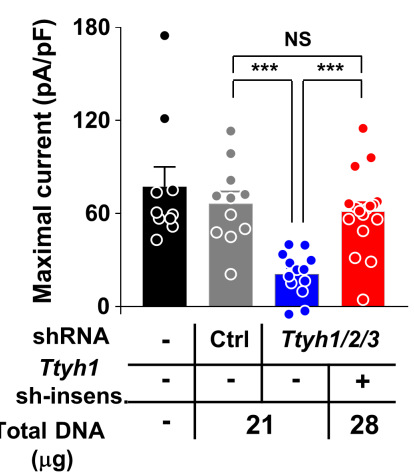

H

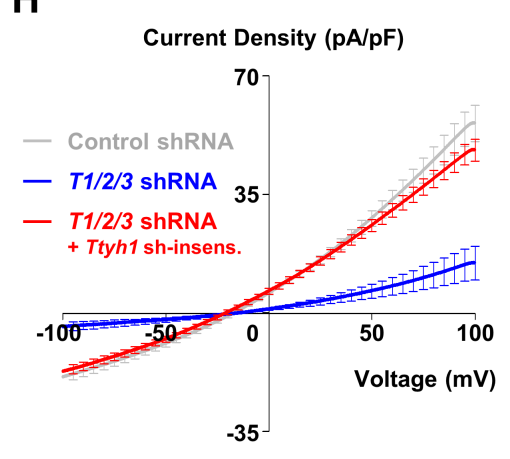

I

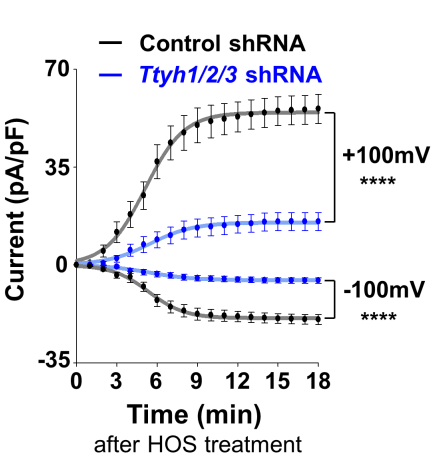

$\mathbf{J}$

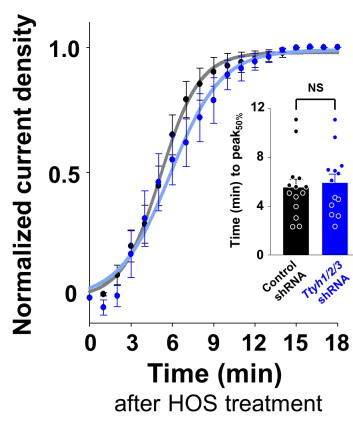

Fig. 2. Continued.

profoundly different from TTYH-mediated VRAC $\mathrm{Swell}_{\text {in }}$ its external-cation-dependence and that the astrocytic $\mathrm{VRAC}_{\text {swell }}$ is distinct from LRRC8A. This conclusion was further strengthened by the observations that TTYH-mediated VRAC $_{\text {swell }}$ and LRRC8Amediated $\mathrm{VRAC}_{\Gamma}$ showed profoundly different voltage-dependent inactivation (Fig. 4A and 4B) and relative permeability to various anions (Fig. 4D), although there was no difference in rectification index (Fig. 4C).

TTYH1/2/3 share the same biophysical, biochemical and pharmacological properties as astrocytic $\mathbf{V R A C}_{\text {swell }}$

The astrocytic $\mathrm{I}_{\mathrm{Cl}, \text { swell }}$ was reported to display an outwardly rectifying conductance [6] with a calculated rectification index to be less than one. The rectification index of each TTYH1/2/3-mediated $\mathrm{I}_{\mathrm{Cl} \text {,swell }}$ was also identical to that of $\mathrm{I}_{\mathrm{Cl} \text {,swell }}$ recorded from cultured astrocytes with a strong outward rectification (Fig. 4E). Crepel et
K

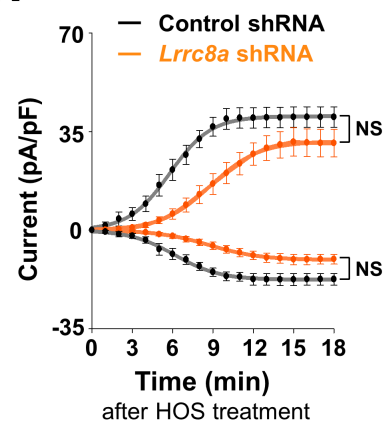

$\mathbf{L}$

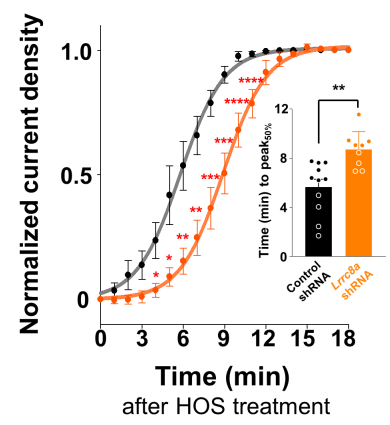

al. also showed that the $\mathrm{Ca}^{2+}$ is not essential for the activation of astrocytic VRAC $_{\text {swell }}$ [6]. We observed that each of the TTYH1/2/3mediated $\mathrm{I}_{\mathrm{Cl} \text { swell }}$ is also independent of $\mathrm{Ca}^{2+}$ as evidenced by the similar amplitude of $\mathrm{I}_{\mathrm{Cl} \text {,swell }}$ in low external $\mathrm{Ca}^{2+}(0.15 \mathrm{mM})$ and high internal $\mathrm{Ca}^{2+}$-chelator BAPTA (20mM) (Fig. 4F H). We next examined the pharmacological profiles of astrocytic $\mathrm{VRAC}_{\text {swell }}$ compared to TTYH1/2/3-mediated $\mathrm{I}_{\mathrm{Cl} \text {,swell }}$ in HEK293T cells. DCPIB is a known inhibitor for both $\mathrm{VRAC}_{\text {swell }}$ and $\mathrm{VRAC}_{\Gamma}$ recorded from various cell lines including cultured astrocytes [50,51]. We found that DCPIB rapidly blocked $\mathrm{I}_{\mathrm{Cl} \text { swell }}$ in cultured astrocytes (Fig. 4I K) and TTYH1/2/3-mediated $\mathrm{I}_{\mathrm{Cl} \text {,swell }}$ in HEK293T cells (Fig. 4L and $4 \mathrm{M}$ ). Taken together, these results indicate that TTYH1/2/3 share the same biophysical (outward rectification), biochemical $\left(\mathrm{Ca}^{2+}\right.$-independency) and pharmacological (sensitivity to DCPIB) properties as the astrocytic $\mathrm{VRAC}_{\text {swell. }}$. 
A

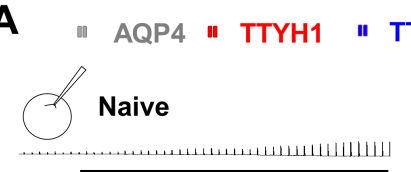

HOS

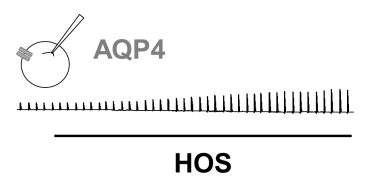

HOS

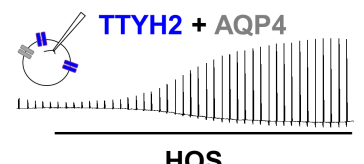

D

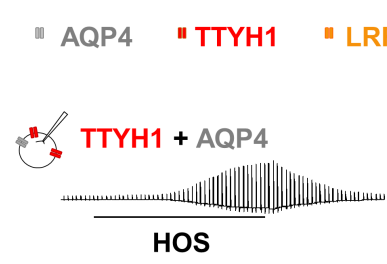

G

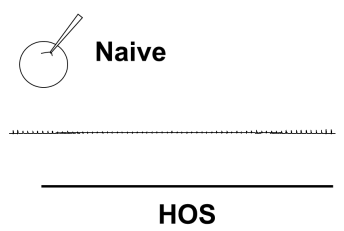

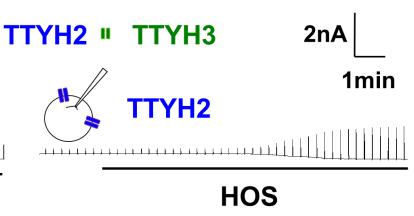

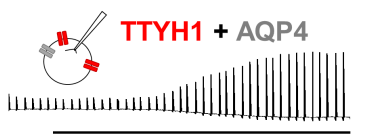

HOS

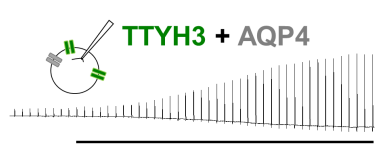

HOS
B

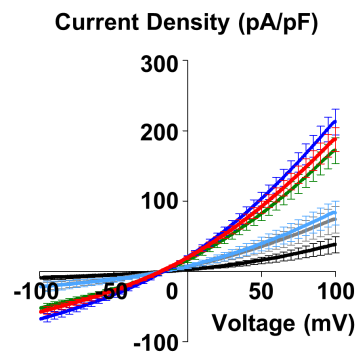

- Naive - TTYH1 + AQP4

- TTYH2 - TTYH2 + AQP4

- AQP4 - TTYH3 + AQP4

E

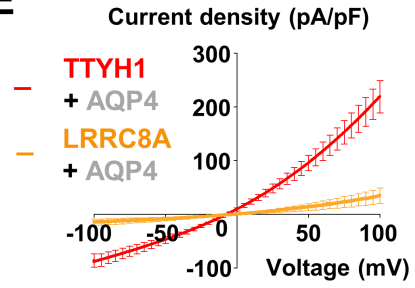

H

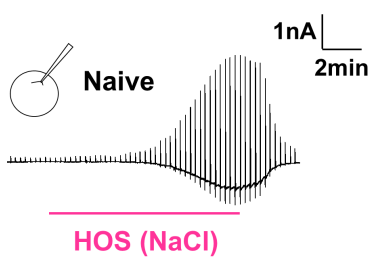

C

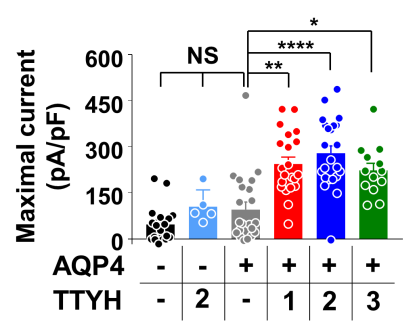

$\mathbf{F}$
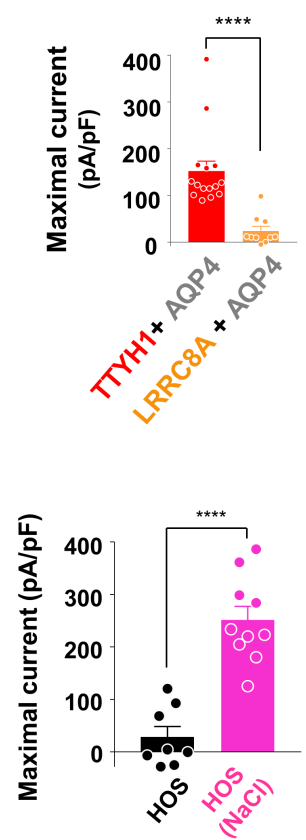

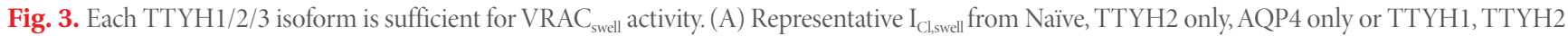
and TTYH3 with AQP4 co-expressing HEK293T cells. Inset: schematic diagram of whole-cell patch-clamp recording in AQP4 (grey), TTYH1 (red), TTYH2 (blue), TTYH3 (green) expressing HEK293T cells. (B) Averaged I-V curves for $\mathrm{I}_{\mathrm{Cl} \text { swell }}$ in Naïve (black), TTYH2 only (skyblue), AQP4 only (grey), and TTYH1 (red), TTYH2 (blue), TTYH3 (green) with AQP4 co-expressing HEK293T cells. (C) Summary bar graph showing the maximal amplitude of $\mathrm{I}_{\mathrm{Cl}, \text { swell }}$ from $+100 \mathrm{mV}$ to $-100 \mathrm{mV}$. Data are represented as mean $\pm \mathrm{SEM}$ ( $\mathrm{n}=18$ for Naïve HEK293T cells, $\mathrm{n}=5$ for TTYH2 over-expressing HEK293T cells, $\mathrm{n}=22$ for AQP4 over-expressing HEK293T cells, $\mathrm{n}=21,23$ and 13 for TTYH1, TTYH2 and TTYH3 with AQP4 co-expressing HEK293T cells; ${ }^{*}<0.05,{ }^{* *}<0.01,{ }^{* * * *}<0.0001$ and NS $>0.05$, Kruskal-Wallis test). (D F) Representative traces, averaged I V curves and summary bar graphs of maximal $\mathrm{I}_{\mathrm{Cl}, \mathrm{swell}}$ currents from either TTYH1 or LRRC8A with AQP4 co-expressed CHO-K1 cells ( $\mathrm{n}=15$ for TTYH1+AQP4, n=10 for LRRC8A+AQP4; ${ }^{* * * *} \mathrm{p}<0.0001$, Mann-Whitney test). (G) Representative traces of $\mathrm{I}_{\mathrm{Cl} \text { swell }}$ recording from naïve HEK293T cells during HOS (black bar) and NaCl-containing $\operatorname{HOS}(\mathrm{HOS}(\mathrm{NaCl}))$ treatment, respectively (pink bar). $(\mathrm{H})$ Averaged $\mathrm{I} \sim \mathrm{V}$ curves for maximal $\mathrm{I}_{\mathrm{Cl} \text { swell }}$ recorded from naïve HEK293T cells in response to HOS (black) and $\mathrm{HOS}(\mathrm{NaCl})$ (pink). (I) Summary bar graph showing the maximal amplitude for $\mathrm{I}_{\mathrm{Cl}, \mathrm{swell}}$ from $+100 \mathrm{mV}$ to $-100 \mathrm{mV}$ recorded from naïve HEK293T cells in response to HOS (black) and $\mathrm{HOS}(\mathrm{NaCl})$ (pink). Data are represented as mean $\pm \mathrm{SEM}(\mathrm{n}=8$ and 10 for $\mathrm{HOS}$ or $\mathrm{HOS}(\mathrm{NaCl})$; ${ }_{* * * *}<0.0001$, unpaired t-test). (J L) Representative traces, averaged $\mathrm{I} \sim \mathrm{V}$ curves, and summary bar graph of $\mathrm{I}_{\mathrm{Cl} \text { swell }}$ recorded from control shRNA (black), $\mathrm{m} / \mathrm{h}$ Lrrc8a shRNA (orange)-expressing and TTYH1 (red), AQP4 (grey) with $\mathrm{m} / \mathrm{h}$ Lrrc8a shRNA (orange)-expressing HEK293T cells in response to $\mathrm{HOS}(\mathrm{NaCl})$ (pink). Data are represented as mean \pm SEM ( $\mathrm{n}=10,11$, and 11 for Control shRNA, m/h Lrrc8a shRNA, and TTYH1+AQP4 with m/h Lr$\mathrm{rc} 8 \mathrm{a} ;{ }^{* * *}<0.001$, one-way ANOVA). (M O) Representative traces, averaged I V curves and summary bar graphs of maximal $\mathrm{I}_{\mathrm{Cl} \text {.swell }}$ currents from control shRNA or $m / h$ Lrrc8a shRNA expressing condition in cultured astrocytes ( $\mathrm{n}=9$ for control shRNA, $\mathrm{n}=9$ for $m / h$ Lrrc8a shRNA; NS: $\mathrm{p}>0.05$, unpaired $\mathrm{t}$ test). (P R) Representative traces, averaged $\mathrm{I} \sim \mathrm{V}$ curves and summary bar graphs of maximal $\mathrm{I}_{\mathrm{Cl} \text { swell }}$ currents from control shRNA expressing condition $(\mathrm{n}=10)$ or $\mathrm{m} / \mathrm{h}$ Lrrc8a shRNA expressing condition $(\mathrm{n}=13)$ in HEK293T cells with expression of TTYH1+AQP4. Statistical analysis was performed with (NS: $>>0.05$, Mann-Whitney test) Data are represented as mean \pm SEM for all averaged $\mathrm{I} \sim \mathrm{V}$ curves and summary bar graphs. 
J

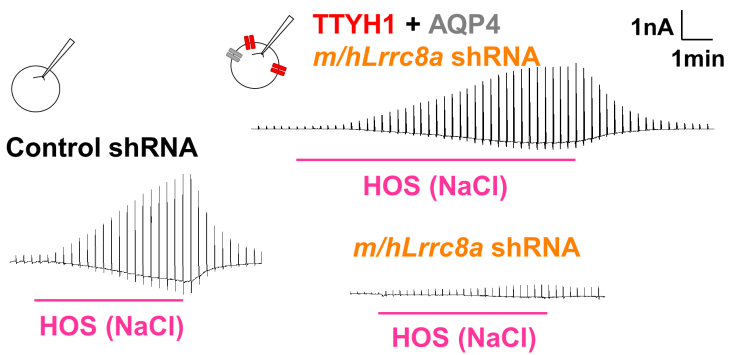

M

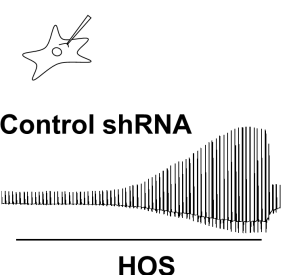

HOS

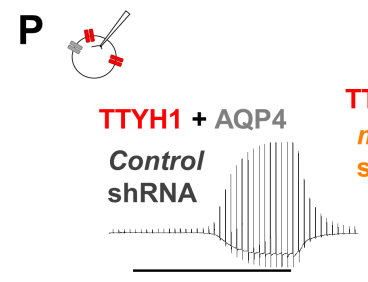

HOS

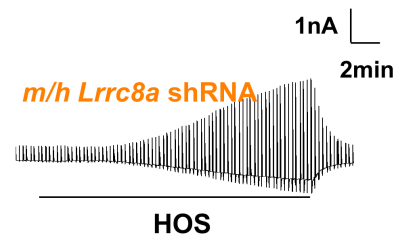

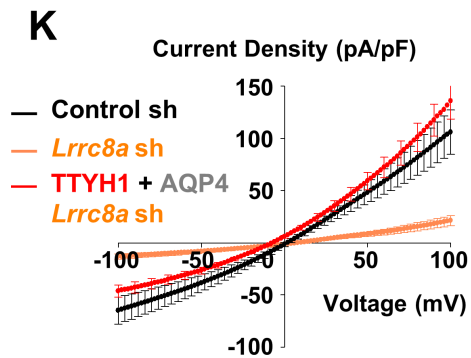

$\mathbf{L}$

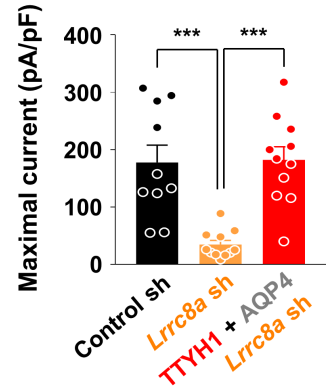

$\mathbf{N}$

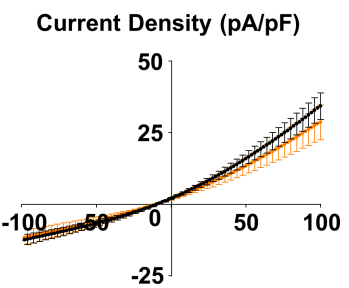

- Control sh $-m / h$ Lrrc8ash

Q

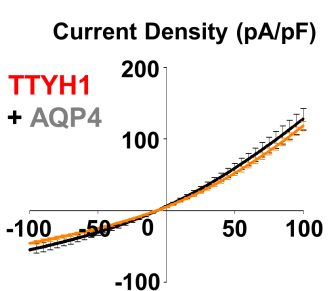

- Control sh - m/h Lrrc8ash

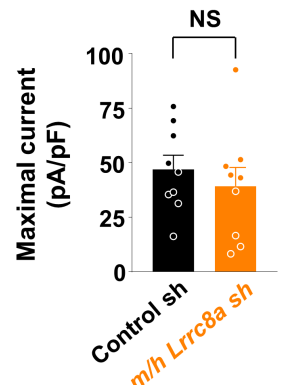

$\mathbf{R}$

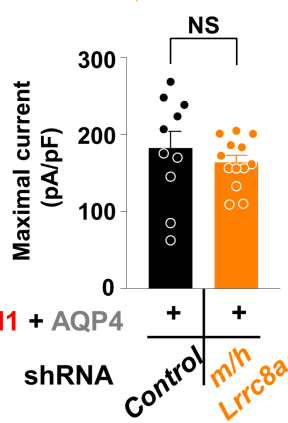

Fig. 3. Continued.

TTYH1/2/3 share the same kinase-dependency and glutamate-permeability as astrocytic VRAC $C_{\text {swell }}$

As previously reported, tyrosine kinase (TK) and mitogenactivated protein kinase (MAPK) are essential for activation of the astrocytic $V_{R A C} C_{\text {swell }}[6]$. We also confirmed that pre-treatment of TK inhibitor genistein (Fig. 5A C) and MAPK inhibitor PD98059 (Fig. 5E G) completely abolished $\mathrm{I}_{\mathrm{Cl}, \text { swell }}$ in cultured astrocytes. Each of the TTYH1/2/3-mediated $\mathrm{I}_{\mathrm{Cl}, \text { swell }}$ was similarly blocked by pre-treated genistein (Fig. 5A and 5D) or PD98059 (Fig. 5H J). In fact, the surface expression of TTYH1 was enhanced by HOS treatment, which was prevented by either TK or MAPK inhibitor (Fig. 5K). These results indicate that each TTYH isoform shares the identical kinase-dependency as the astrocytic $\mathrm{VRAC}_{\text {swell. }}$. In contrast, LRRC8A-mediated VRAC $\mathrm{C}_{\Gamma}$ showed a profoundly different sensitivity to MAPK inhibitor (Fig. 5L N).

Another unique property of the astrocytic $\mathrm{VRAC}_{\text {swell }}$ is its relatively high $\mathrm{P}_{\mathrm{Glu}} / \mathrm{P}_{\mathrm{Cl}}[8,32,52]$. To measure the $\mathrm{P}_{\mathrm{Glu}} / \mathrm{P}_{\mathrm{Cl}}$ of $\mathrm{I}_{\mathrm{Cl}, \mathrm{swell}}$, we exchanged the external solution from $\operatorname{HOS}\left(83 \mathrm{mM} \mathrm{Cl}^{-}\right)$to glutamate-containing HOS (gHOS: $70 \mathrm{mM}$ glutamate and $13 \mathrm{mM}$ $\mathrm{Cl}^{-}$) after reaching a maximal current amplitude of $\mathrm{I}_{\mathrm{Cl}, \text { swell }}$ (Fig. 5O). We found that in both cultured astrocyte (Fig. 5P and 5Q) and each TTYH1/2/3-expressing HEK293T cells (Fig. 5R), the reversal potential of $\mathrm{I}_{\text {Cl,swell }}$ shifted to a positive potential in gHOS treatment. Based on the reversal potential shift, we calculated the $\mathrm{P}_{\mathrm{Glu}} /$ $\mathrm{P}_{\mathrm{Cl}}$ according to Goldman-Hodgkin-Katz equation and found that $\mathrm{I}_{\mathrm{Cl}, \mathrm{swell}}$ in cultured astrocytes and each TTYH1/2/3-mediated $\mathrm{I}_{\mathrm{Cl} \text {,swell }}$ shared the similar high $\mathrm{P}_{\mathrm{Glu}} / \mathrm{P}_{\mathrm{Cl}}$ at around 0.26 (Fig. $5 \mathrm{~S}$ ). Taken together, these results indicate that kinase-dependency and glutamate-permeability of each TTYH-mediated $\mathrm{I}_{\mathrm{Cl}, \text { swell }}$ resemble those of the astrocytic VRAC swell.

\section{Arginine residue at 165 in TTYH1 and 164 in TTYH2 is the} pore-forming amino acid as evidenced by mutagenesisbased structure-activity analysis

If TTYH isoforms are the true channel-forming subunit of $\mathrm{VRAC}_{\text {swell }}$, we should be able to determine the channel-pore as 
A
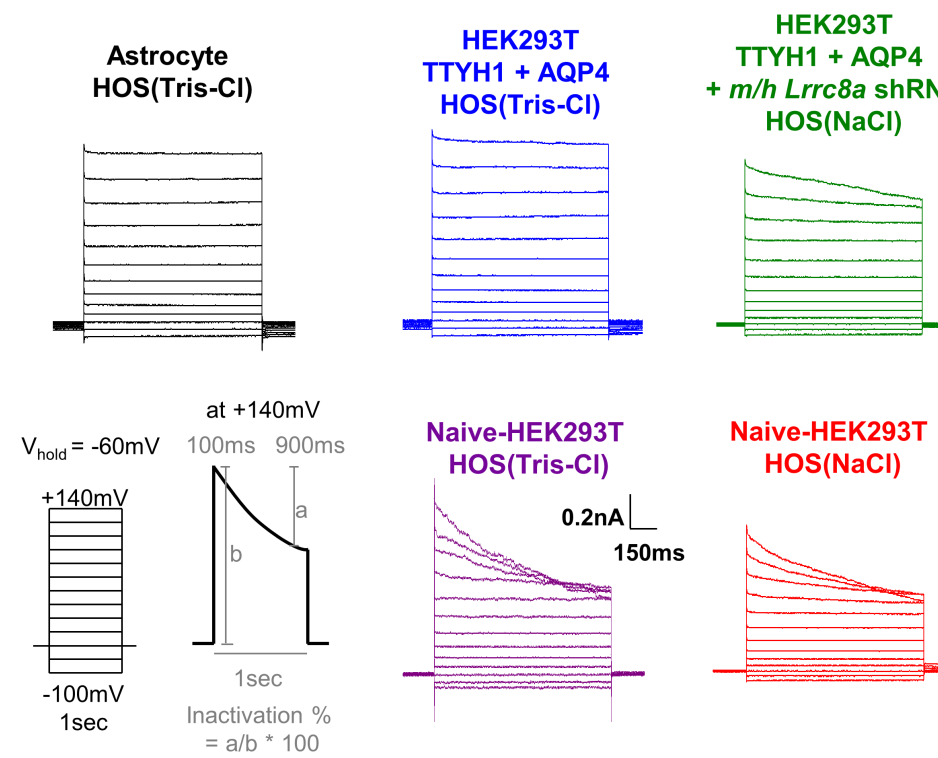
TTYH1 + AQP4
$+m / h$ Lrrc8a shRNA
$\mathrm{HOS}(\mathrm{NaCl})$

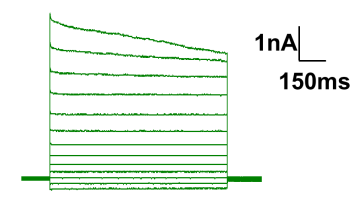

D

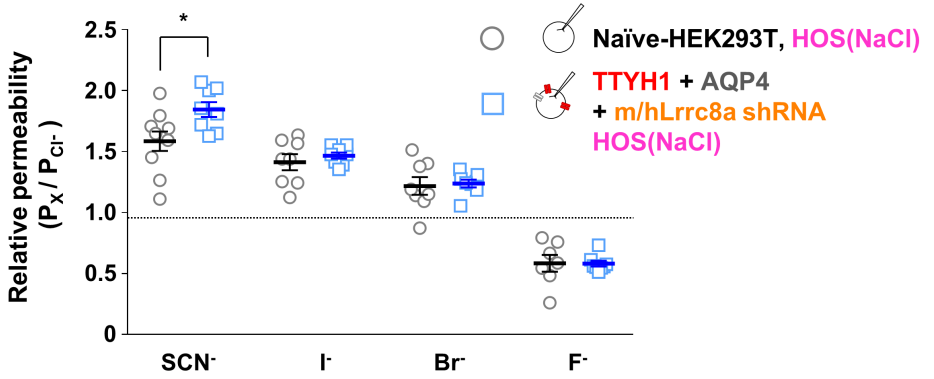

B

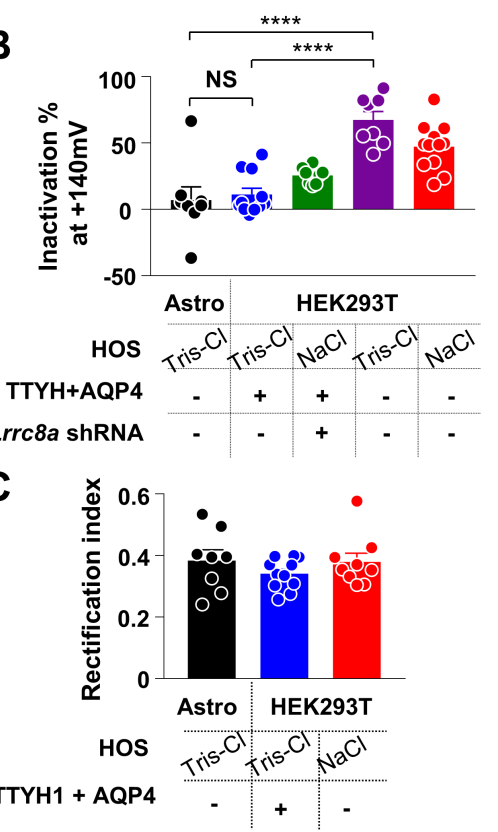

E

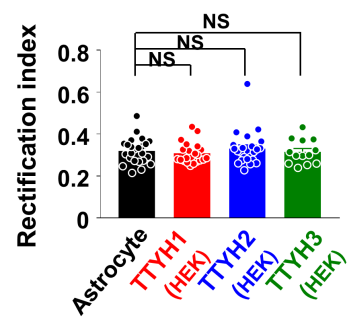

Fig. 4. Each TTYH1/2/3 isoform shares the same biophysical (voltage-dependent inactivation, outward rectification), biochemical (Ca ${ }^{2+}$-independency) and pharmacological properties (sensitivity to DCPIB) as astrocytic $\mathrm{VRAC}_{\text {swell }}$. (A) Representative current traces with voltage step protocol from - 100 $\mathrm{mV}$ to $+140 \mathrm{mV}$, which is recorded in cultured astrocytes (black), TTYH1+AQP4 (blue), TTYH1+AQP4 with m/h Lrrc8a shRNA (green) expressing HEK293T cells, and naïve HEK293T cells (purple and red). The major constituent of HOS is indicated in each traces, $(\mathrm{HOS}(\mathrm{Tris}-\mathrm{Cl})$ or $\mathrm{HOS}(\mathrm{NaCl})$. Bottom left, the schematic diagram of voltage step protocol and calculation of inactivation $\%$ (Inactivation \% is calculated by a/b $\mathrm{b}^{*} 100$, the a indicates the initial $10 \%$ of current amplitude at $+140 \mathrm{mV}$, and the ' b' indicates the last $90 \%$ of current amplitude at $+140 \mathrm{mV}$ ). (B) Summary bar graph showing inactivation $\%$ at $+140 \mathrm{mV}$. Data are represented as mean \pm SEM ( $\mathrm{n}=8$ for astrocytes by treating HOS(Tris-Cl), $\mathrm{n}=11$ for TTYH1+AQP4 expressing HEK293T by treating $\mathrm{HOS}($ Tris-Cl), $\mathrm{n}=9$ for TTYH1+AQP4 with $m / h$ Lrrc8a shRNA by treating HOS(NaCl), $\mathrm{n}=8$ for naïve HEK293T cells by treating HOS(Tris$\mathrm{Cl}$ ), and $\mathrm{n}=14$ for naïve HEK293T cells by treating $\mathrm{HOS}(\mathrm{NaCl}),{ }^{* * *}<0.0001$, one-way ANOVA). (C) Summary bar graph showing rectification index from cultured astrocyte and naïve HEK293T by treating HOS(Tris-Cl) (black and blue) and from naïve HEK293T cells by treating $\mathrm{HOS}(\mathrm{NaCl})(\mathrm{red})$. ( $\mathrm{n}=8$ for astrocyte by treating HOS(Tris-Cl), n=11 for TTYH1+AQP4 expressing HEK293T cells by treating HOS(Tris-Cl), n=9 for naïve HEK293T cells by treating $\mathrm{HOS}(\mathrm{NaCl}), \mathrm{ns}>0.05$, one-way ANOVA). (D) Summary scatter plot showing the relative permeability of various anions such as $\mathrm{SCN}$, I, $\mathrm{Br}$, and F recorded from naïe HEK293T cells by treating $\mathrm{Na}^{+}$containing HOS (grey circle) and recorded from TTYH1+AQP4 with $m / h$ Lrrc8a shRNA expressing HEK3293 cells by treating $\mathrm{Na}^{+}$containing HOS (skyblue square). ( $\mathrm{n}=9,8,8$, and 7 for naïve HEK293T cells for SCN', I', Br, and F, respectively, and $\mathrm{n}=8,8,8$, and 8 for TTYH1+AQP4 with $\mathrm{m} / \mathrm{h}$ Lrrc8a shRNA expressing HEK293T cells for SCN', I, Br, and F, respectively). (E) Summary bar graph showing rectification index $\left(\mid \mathrm{I}_{\mathrm{Cl} \text {.swell }}\right.$ at $-100 \mathrm{mV} / \mathrm{I}_{\mathrm{Cl} \text {.swell }}$ at $\left.+100 \mathrm{mV}\right)$ from whole-cell patch-clamp recording of cultured astrocyte and TTYH1/2/3 with AQP4 co-expressing HEK293T cells. Data are represented as mean \pm SEM ( $n=24$ for astrocytes and $n=21,23$ and 13 for TTYH1, TTYH2 and TTYH3 with AQP4 co-expressing HEK293T cells; NS >0.05, Kruskal-Wallis test). (F) Representative $\mathrm{I}_{\mathrm{Cl} \text {,swell }}$ from TTYH1, 2 and 3 with AQP4 overexpressing $\mathrm{CHO}-\mathrm{K} 1$ cells using $0.15 \mathrm{mM}$ external Ca2+ and $20 \mathrm{mM}$ BAPTA containing internal solution. Inset: schematic diagram of whole-cell patch-clamp recordings in TTYH1 (red), TTYH2 (blue) and TTYH3 (green) with AQP4 (grey) co-expressing CHO-K1 cells. (G) Averaged I V curves for I $\mathrm{Cl}_{1, \text { swell }}$ recorded at TTYH1 (red), TTYH2 (blue) and TTYH3 (green) with AQP4 (grey) co-expressing CHO-K1 cells. (H) Summary bar graph showing the maximal amplitude of $\mathrm{I}_{\mathrm{Cl}, \text { swell }}$ from $-100 \mathrm{mV}$ to $100 \mathrm{mV}$. Data are represented as mean $\pm \mathrm{SEM}$ ( $\mathrm{n}=10,8$ and 10 for TTYH1, TTYH2 and TTYH3 with AQP4 co-expressing CHO-K1 cells; NS>0.05, Kruskal-Wallis test). (I, L) Representative traces of $\mathrm{I}_{\mathrm{Cl}, \text { swell }}$ recording from cultured astrocytes and TTYH1/2/3 with AQP4 co-expressing HEK293T cells during treatment HOS (black bar) and DCPIB (10 $\mu$ M, sky blue bar). (J) Averaged I V curves for $\mathrm{I}_{\mathrm{Cl}, \text { swell }}$ from cultured astrocytes in control (black) and DCPIB (sky blue). (K, M) Summary bar graph showing the maximal amplitude for $\mathrm{I}_{\mathrm{Cl} \text { swell }}$ from $+100 \mathrm{mV}$ to $-100 \mathrm{mV}$ in cultured astrocytes and TTYH1/2/3 with AQP4 co-expressing HEK293T cells, respectively. Data are represented as mean \pm SEM ( $\mathrm{n}=10$ and 8 for control or DCPIB treatment in astrocytes; ${ }^{* * * *}<0.0001$, Mann-Whitney test; $\mathrm{n}=8,15$ and 8 for control or DCPIB treatment in each TTYH1, TTYH2 and TTYH3 with AQP4 co-expressing HEK293T cells; ${ }^{* * * *}<0.0001,2$ way ANOVA). 
F

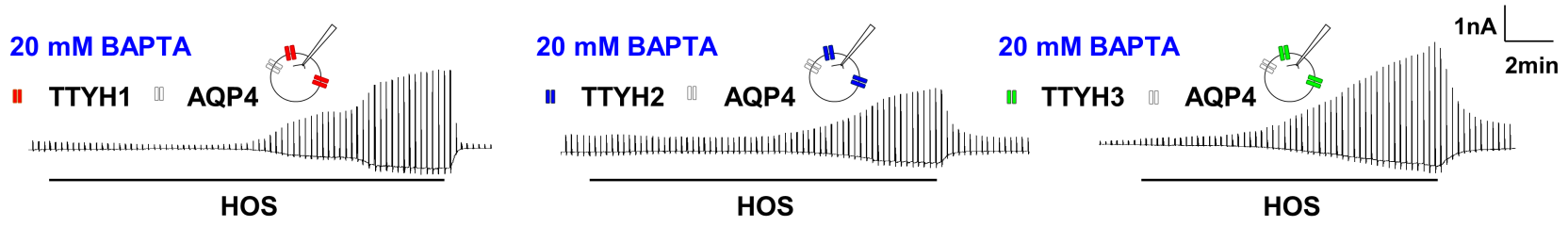

G

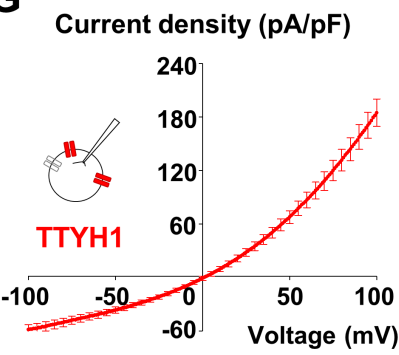

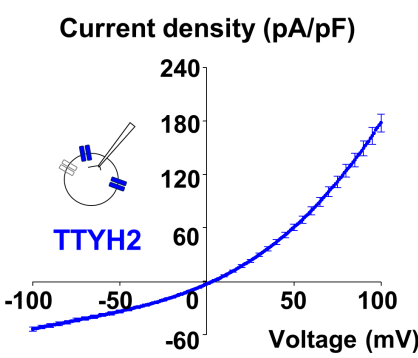

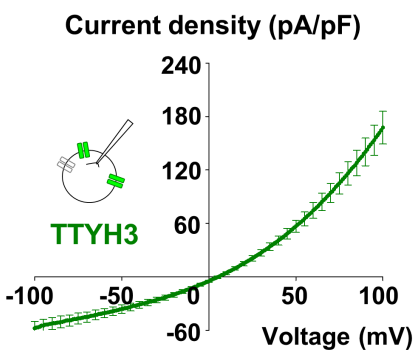

H

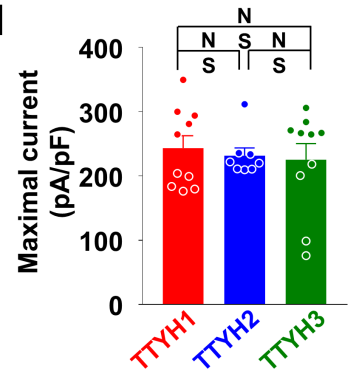

I

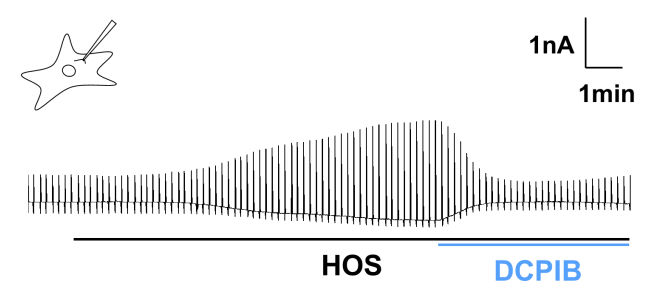

L
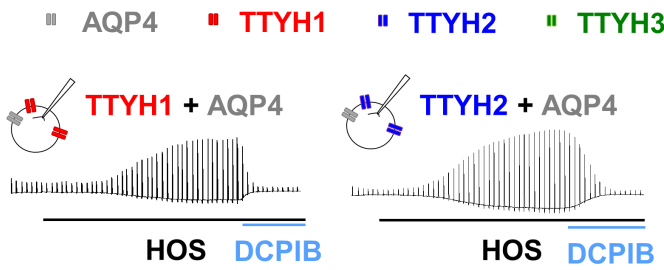

$\mathbf{J}$

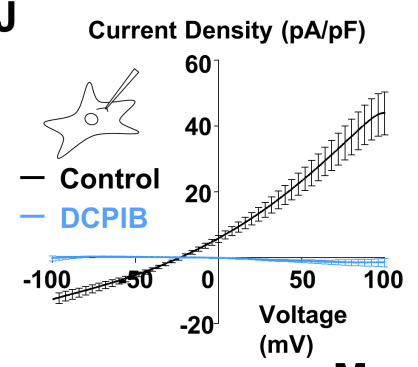

K

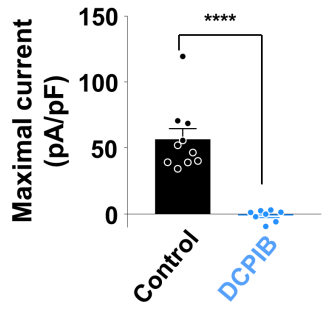

M
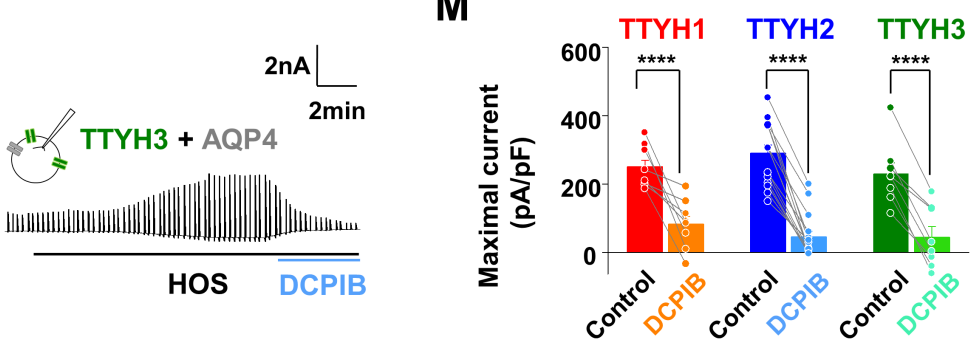

Fig. 4. Continued.

a single amino acid residue. To identify the exact pore-forming amino acid residue, we first utilized bioinformatical approaches to predict the membrane topology of TTYH isoforms. Based on the dendrogram analysis (Fig. 6A) and sequence alignment (Fig. 7) of TTYH1/2/3 isoforms across different species, we found that TTYH1, which is the most abundantly expressed isoform in astrocytes (Fig. 1D), showed the order of sequence homology: TTYH1 > TTYH2>TTYH3 >> Drosophila Tweety homologs. The hydrophobicity-based sequence analysis predicted a membrane topology with four highly-conserved trans-membrane domains (TM) and additional intra-membrane domain (IM) in TTYH1 or TM domain in TTYH2 and TTYH3 near the C-terminus (Fig. $6 \mathrm{~B})$. To validate the predicted topology, we over-expressed the chimeric clone of TTYH1-GFP (GFP attached to the C-terminus of
TTYH1) in HEK293T cells. We performed immunocytochemistry with either the antibody recognizing the N-terminus of TTYH1 $\left(A b_{\mathrm{N} \text {-term }}\right)$ or the GFP-antibody $\left(A b_{\mathrm{GFP}}\right)$ which should bind to the C-terminus of TTYH1-GFP (Fig. 8A). The intracellular or extracellular topology of each terminus was determined by the presence of the membrane detergent Triton X-100, which allowed the access of antibodies to the cytosolic compartment. We found that both $\mathrm{Ab}_{\mathrm{N} \text {-term }}$ and $\mathrm{Ab}_{\mathrm{GFP}}$ showed positive immunoreactivity only when Triton X-100 was present (Fig. 8A). These results indicate that contrary to the previous suggestion [53], TTYH1 has four TM domains and one IM domain with cytosolic N- and C-termini (Fig. 8C). In support of this topology, we found that the location of Loop1 between TM1 and TM2 (Fig. 8C) is in the extracellular region (Fig. 8B). 
A

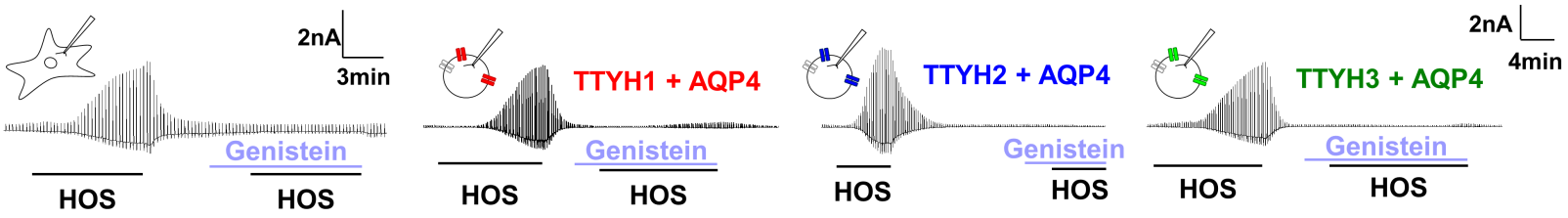

B

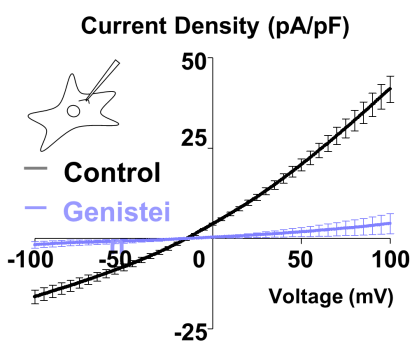

C
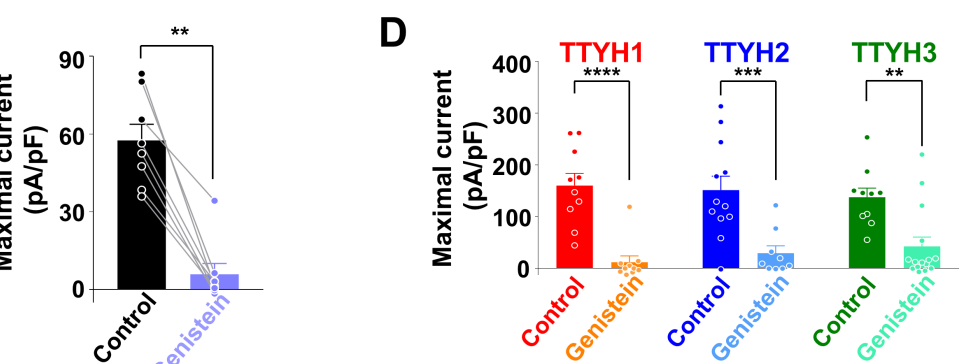

E
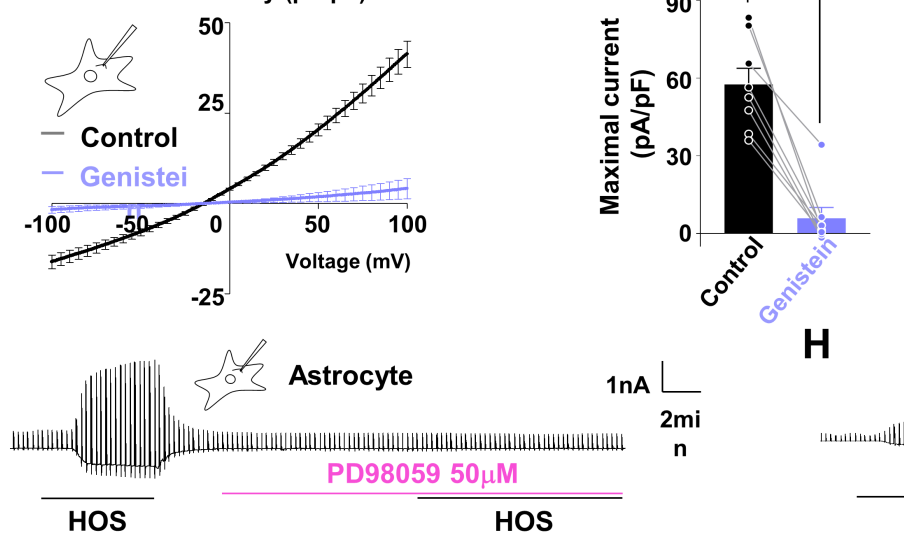

D

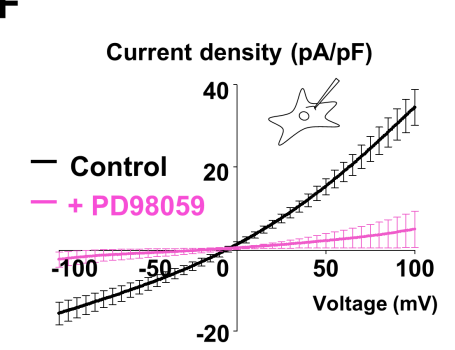

G

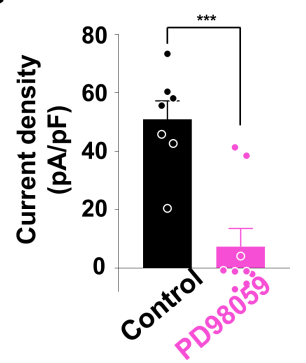

H

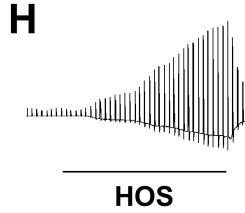

I

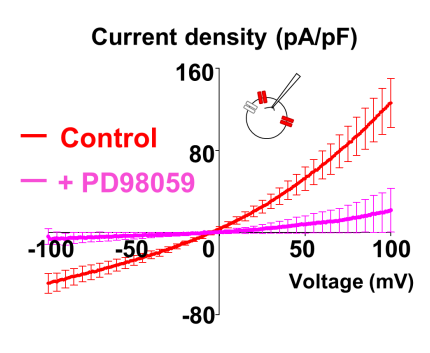

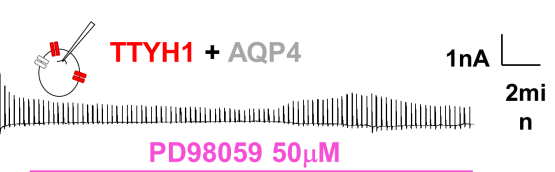

PD98059 50 $\mu \mathrm{M}$

HOS

J

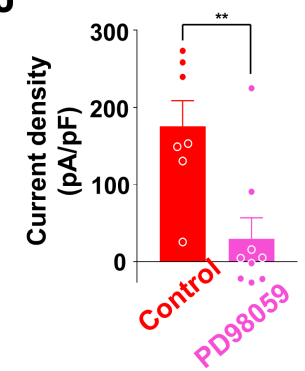

Fig. 5. Each TTYH1/2/3 shares the same pharmacological properties (sensitive to both genistein and PD98059) as astrocytic VRAC swell. $_{\text {(A) }}$ Representative traces of $\mathrm{I}_{\mathrm{Cl}, \text { swell }}$ recording from cultured astrocytes and TTYH1/2/3 with AQP4 co-expressing HEK293T cells during treatment HOS (black bar) in the presence or absence of Genistein $(50 \mu \mathrm{M}$, sky blue bar). Right upper insets represent cultured astrocytes and TTYH1/2/3 (red, blue and green, respectively) with AQP4 (grey) over-expressing HEK293T cells. (B) Averaged I V curves for $\mathrm{I}_{\mathrm{Cl} \text { swell }}$ in control (grey) and genistein-treated group (sky blue) recorded from cultured astrocytes. (C, D) Summary bar graph showing the maximal amplitude of $\mathrm{I}_{\text {Clswell }}$ from $+100 \mathrm{mV}$ to $-100 \mathrm{mV}$ recorded from cultured astrocytes and TTYH1/2/3 with AQP4 co-expressing HEK293T cells, respectively. Data are represented as mean \pm SEM ( $\mathrm{n}=8$ for both control and genistein treatment in astrocytes; ${ }^{* *}<0.01$, Wilcoxon test; $\mathrm{n}=10$ for both control and genistein treatment in TTYH1 with AQP4 co-expressing HEK293T cells, $\mathrm{n}=12$ and 9 for control and genistein treatment in TTYH2 with AQP4 co-expressing HEK293T cells, and $\mathrm{n}=10$ and 15 for control and genistein treatment in TTYH2 with AQP4 co-expressing HEK293T cells; ${ }^{* *}<0.01,{ }^{* * *}<0.001,{ }^{* * * *}<0.0001,2$ way ANOVA). (E) Representative traces of $\mathrm{I}_{\mathrm{Cl} \text { swell }}$ from cultured astrocytes during treatment hypo-osmotic solution (black bar) and then PD98059 (50 $\mu \mathrm{M}$, pink bar). Inset: schematic diagram of whole-cell patch-clamp recording in primary cultured astrocyte. (F) Averaged I V curves for HOS induced current responses in control (black) and PD980959 (pink) recorded at cultured astrocytes. (G) Summary bar graph showing the maximal amplitude of HOS induced current density from -100mV to $100 \mathrm{mV}$. Data are represented as mean $\pm \mathrm{SEM}$ ( $\mathrm{n}=7$ and 9 for control and PD98059; ${ }^{* * *} \mathrm{p}<0.001$; Mann-Whitney test). (H) Representative traces of $\mathrm{I}_{\mathrm{Cl}, \text { swell }}$ from TTYH1 with AQP4 co-expressing CHO cells during treatment HOS and then PD98059 (50 $\mu \mathrm{M})$. Inset: schematic diagram of whole-cell patchclamp recording in TTYH1 (red) with AQP4 (grey) co-expressing CHO cells. (I) Averaged I V curves for HOS induced current responses in control (red) and PD98059 (pink) recorded at TTYH1 with AQP4-co-expressing CHO cells. (J) Summary bar graph showing the maximal amplitude of $\mathrm{I}_{\mathrm{Cl}, \text { swell }}$ from $-100 \mathrm{mV}$ to $100 \mathrm{mV}$. Data are represented as mean \pm SEM ( $\mathrm{n}=7$ and 9 for control and PD98059; ${ }^{* *} \mathrm{p}<0.01$; Mann-Whitney test). (K) Surface expression of TTYH1 in response to HOS(Tris-Cl) in cultured astrocytes, which were prevented by either TK and MAPK inhibitor. (L, M) Representative traces and summary bar graph of $\mathrm{I}_{\mathrm{Cl}, \text { swell }}$ recording from naïve HEK293T in the absence of drug (black bar) or in the presence of genistein (TK inhibitor, light purple) or PD98059 (MAPK inhibitor, green) induced by $\mathrm{HOS}(\mathrm{NaCl}$, Pink line). For $\mathrm{G}, \mathrm{n}=10,4,7$ for in the absence or presence of drug, genistein or PD98059 in HEK293T cells, ${ }^{* *}<0.01$, one-way ANOVA). (N) Summary bar graph showing block \% of kinase inhibitor in cultured astrocytes (black, induced by HOS(Tris-Cl)), TTYH1+AQP4 overexpressed HEK293T cells (red, induced by HOS(Tris-Cl)), and naïve HEK293T cells (pink, induced by $\operatorname{HOS}(\mathrm{NaCl}))$. $(\mathrm{n}=8,10$, and 4 for recorded from astrocyte, TTYH+AQP4 overexpressed, and naïve HEK293T cells after genistein treatment, and $\mathrm{n}=9$, 9, and 6 for recorded from astrocyte, TTYH+AQP4 overexpressed HEK293T cells, and naïve HEK293T cells after PD98059 treatment, ${ }^{* *}<0.01$, Two-way ANOVA). 


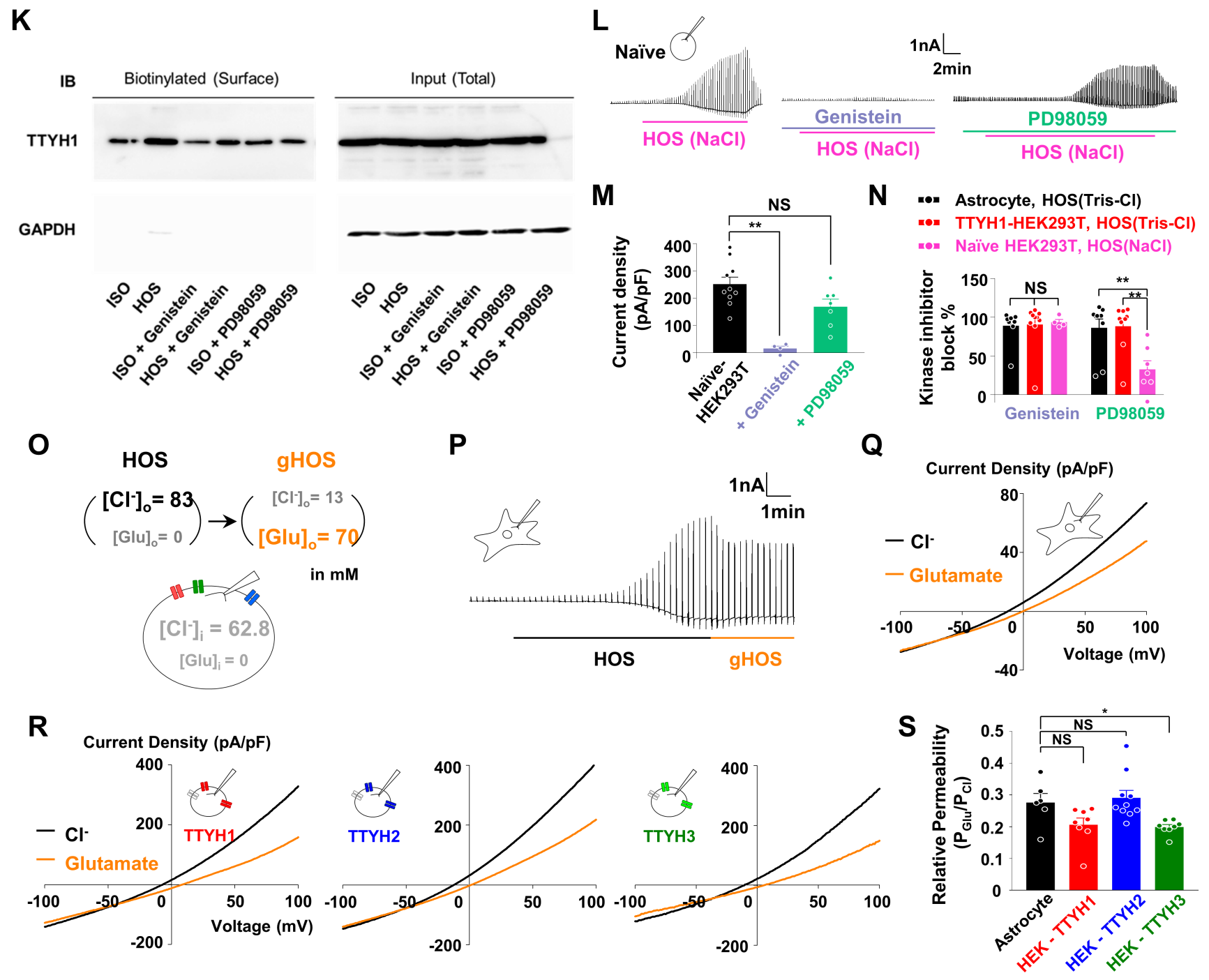

Fig. 5. Continued. (O) Schematic diagram for experimental conditions to record glutamate permeability of $\mathrm{I}_{\mathrm{Cl}, \mathrm{swell}}$. $\mathrm{HOS}$ (black) is standard $83 \mathrm{mM} \mathrm{Cl}^{\circ}$ containing the hypo-osmotic solution. gHOS (orange) is $70 \mathrm{mM}$ glutamate and $13 \mathrm{mM} \mathrm{Cl}^{-}$containing the hypo-osmotic solution. (P) Representative trace for glutamate permeability recording in cultured astrocytes. gHOS (orange) was treated at the peak of $\mathrm{I}_{\text {Cl.swell }}$ induced by standard HOS (black). (Q) Representative I V curves for $\mathrm{I}_{\mathrm{Cl} \text {,swell }}$ were recorded under whole-cell patch-clamp in cultured astrocytes firstly in $\mathrm{HOS}(83 \mathrm{mM} \mathrm{Cl}$; black) and switched to gHOS (70 mM glutamate and $13 \mathrm{mM} \mathrm{Cl}$, orange) in the same cell. (R) Representative I V curve for $\mathrm{I}_{\text {Cl.swell }}$ in AQP4 (grey), TTYH1 (red), TTYH2 (blue), TTYH3 (green) with AQP4 co-expressing HEK293T cells, with standard HOS (black) changed to gHOS (orange) in the same cell. (S) Glutamate permeability ratio relative to $\mathrm{Cl}^{-}\left(\mathrm{P}_{\mathrm{Glu}} / \mathrm{P}_{\mathrm{Cl}}\right)$ of $\mathrm{I}_{\mathrm{Cl} \text { swell }}$ are summarized. $\mathrm{P}_{\mathrm{Glu}} / \mathrm{P}_{\mathrm{Cl}}$ was calculated from the Goldman-Hodgkin-Katz equation (see in methods). Data are represented as mean \pm SEM ( $n=6$ for astrocytes and $n=8,10$ and 8 for TTYH1, TTYH2 and TTYH3 with AQP4 co-expressing HEK293T cells; NS $>0.05,{ }^{*}<0.05$, Kruskal-Wallis test).

Because channel-pores usually reside within a loop between two transmembrane domains, we next closely examined the loopsequences of Loop1-4 of TTYH1 (Fig. 8C) and found that Loop2 and Loop 4 were highly conserved across different species but not Loop1 (Fig. 7). Loop3 appeared to be too short for a pore. Therefore, we focused on Loop2 and Loop4 to search for the channelpore. We generated a series of truncation mutants $(\Delta)$ with a 20 amino-acid-deletion for each loop 2 and 4 and also recorded $\mathrm{I}_{\mathrm{Cl} \text { swell- }}$. We identified potential candidates, $\Delta 2 \mathrm{~A}$ (S116-T135) and $\Delta 2 \mathrm{C}$
(T156-A175) in Loop2 and $\Delta 4 \mathrm{~B}$ (L289-N304) in Loop4, which all showed an elimination of $\mathrm{I}_{\mathrm{Cl}, \text { swell }}$ (Fig. 8D). Then, we performed surface biotinylation assay for each candidate to eliminate the possibility that the disappearance of $\mathrm{I}_{\mathrm{Cl} \text { swell }}$ is due to an impaired surface expression of the channel protein. We eliminated $\triangle 4 \mathrm{~B}$ in Loop4 and $\Delta Y Y(\Delta Y 299, Y 300)$ in Loop4B as a potential pore because of the lack of surface expression of $\Delta 4 \mathrm{~B}$ and $\Delta \mathrm{YY}$ (Fig. $8 \mathrm{E}$ ). We made additional truncation mutants with $\Delta 2 \mathrm{~A}$ and $\Delta 2 \mathrm{C}$ into 5-aminoacid-deletions and narrowed down to $\Delta 2 \mathrm{~A} 4, \Delta 2 \mathrm{C} 2$, and $\Delta 2 \mathrm{C} 3$, 
A

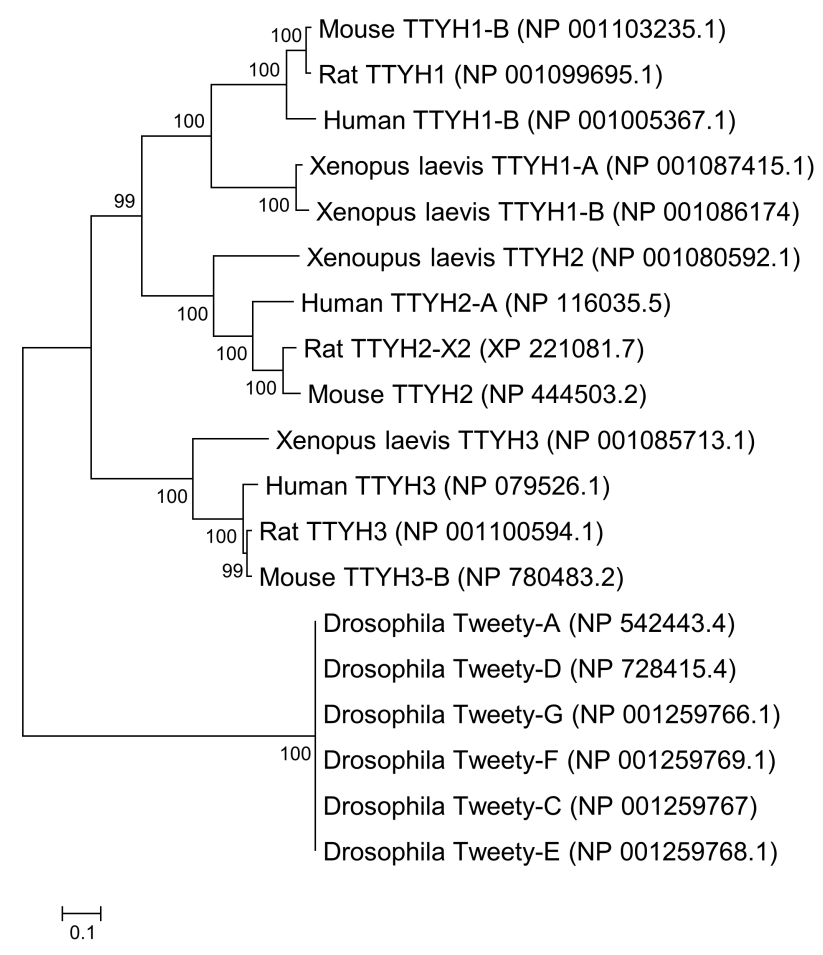

B

\section{TMHMM posterior probabilities}
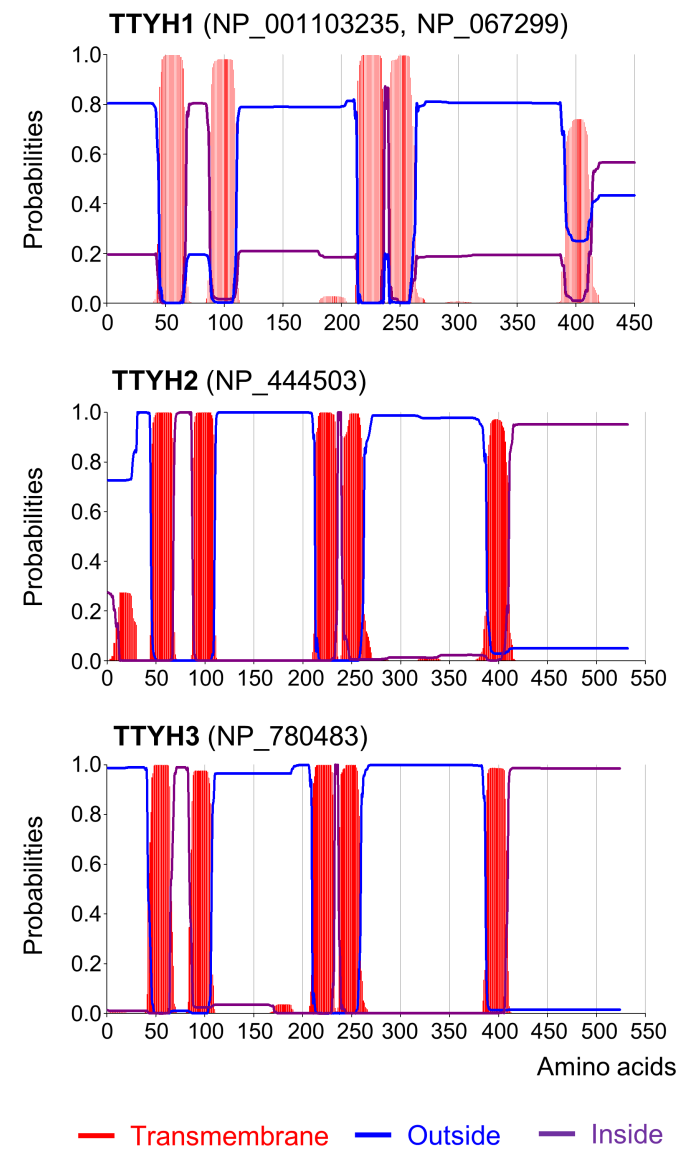

Fig. 6. Dendrogram with various species of TTYH family and the prediction of trans-membrane (TM) domains in TTYH1, 2 and 3 based on hydrophobicity with TMHMM software. (A) Phylogenetic tree indicates the genetic relationship of various species of TTYH family such as mouse, rat, human, xenopus laevis and drosophila TTYH family. The tree was constructed using maximum likelihood method with the bootstrap values at 1000 replicates by MEGA5. The evolutionary distances were computed using the Poisson correction method and are in the units of the number of amino acid substitutions per site. (B) Prediction results of hydrophobic trans-membrane (TM) domain (red) and hydrophilic-intracellular (purple) and extracellular (blue) part of TTYH1, 2 and 3.

which showed significantly reduced $\mathrm{I}_{\mathrm{Cl} \text {.swell }}($ Fig. 8D). After examining the surface biotinylation results (Fig. 8E), we found that the positively charged arginine residue at 165 position (R165) satisfied the definition of putative single amino acid pore residue, displaying a signficant reduction of $\mathrm{I}_{\text {Cl.swell }}$ (Fig. $8 \mathrm{~F}$ and $8 \mathrm{G}$ ) and a positive shift in the reversal potential of about $+7 \mathrm{mV}$ (Fig. 8G) without affecting the surface expression after substitution with alanine (R165A) (Fig. 8E). This result suggests that the TTYH1-R165A is less permeable to $\mathrm{Cl}^{-}$compared to TTYH1-WT. The substitution at the homologous residue, R164A in TTYH2 similarly showed significantly reduced $\mathrm{I}_{\mathrm{Cl}, \text { swell }}$ (Fig. $8 \mathrm{H}$ and $8 \mathrm{I}$ ) indicating that the arginine residue (R165 for TTYH1 and R164 for TTYH2) is the key pore-forming residue. We further found that R165A mutant of shRNA-insensitive TTYH1, when co-expressed with all Ttyh1/2/3
shRNA, failed to rescue the $\mathrm{I}_{\mathrm{Cl}, \text { swell }}$ in astrocytes (Fig. 8J and 8K), confirming that R165 is the putative pore residue. Taken together, R165 in TTYH1 and R164 in TTYH2 are the pore-forming amino acids located between TM2 and TM3.

\section{Arginine residue at 165 in TTYH1 and 164 in TTYH2 is the pore-forming amino acid as evidenced by substituted cyste- ine accessibility methods (SCAM)}

To determine whether R165 and neighboring residues in TTYH1 are located at the pore lining vestibule, we performed the SCAM with cysteine substituted mutants of each of 10 amino acids from V161 to A170 (Fig. 9A D). The control TTYH1-WT mediated $\mathrm{I}_{\mathrm{Cl} \text {,swell }}$ was reduced by $9.01 \%$ with $100 \mathrm{mM}$ of MTSES which has no permeability through the plasma membrane, sug- 


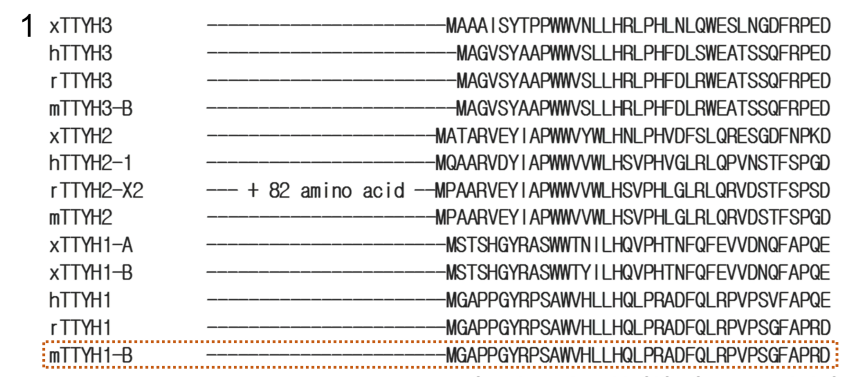

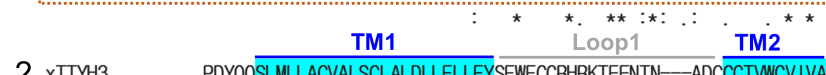

2 xTTYH3 PDYQQSLMLLACVALSCLALDLLFLLFYSFWFCCRHRKTEENTN--ADCCCTVWCVIVA hTTYH3 TDYQQALLLLGAAALACLALDLLFLLFYSFWLCCRRRKSEEHLD--ADCCCTAWCVI IA ITTYH3 ADYQQALLLLGAAALACLALDLLFLLFYSFWLCCRRRKTDEHLD-ADCCCTAWCVIIA mTTYH3-B ADYQQALLLLGATALACLALDLLFLLFYSFWLCCRRRKTDEHLD--ADCCCTAWCVI IT xTTYH2 PGYQQTLLFVALFIALCAAVNLLFVSGYLICLCCCKKEDETETKM--TSSCCVTWTAAVS hTTYH2-1 ESYQESLLFLGLVAAVCLGLNLIFLVAYLVCACHCRRDDAVQTKQ- HHSCCITWTAVVA rTTYH2-X2 ETYQESLLFLGMLAAIGLGLNLIFLAIYLVCTCCCRRDHTVQTKQ-PDSCCVTWTAVMA ITTYH2 ETYQESLLFLGVLAAIGLGLNLIFLTVYLVCTCCCRRDHTVQTKQ--QESCCVTWTAVA XTTYH1-A WPYQQALLFLASIAGLCLAISLILICVY IRFCCCASQEDDDSKN-HRVCCVTWSCVAA XTTYH1-B WSYQQALLFLASIAGLCLAISLVLICWL IKFCCCASQEDDDSKS- HRVCCVTWSCVAA hTTYH1 QEYQQALLLVAALAGLGLGLSLIFIAVYLIRFCCCRPPEPPGSKIPSPGGGCVTWSCIVA ITTYH1 QEYQQALLLVAALAGLGLGLSLIFIAVYLIRFCCCRPPEPPGAKSPPPGGGCVTWSCIAA mTTYH1 B Q QEYQQALELVALAGLG GLSLIFIAVY IRFCCCRPPEPHGAKSPPPGGCVTWSCIAA

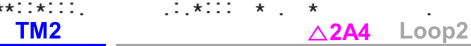

3 хTTYH3 $\overline{\text { TLVCSAGIAVGFYGNGETSDGIHRVTYSIRHVNRTMAGIHDRVSDTTISLNQTVEPCLQN }}$ hTTYH3 TLVCSAGIAVGFYGNGETSDGIHRATYSLRHANRTVAGVQDRVWDTAVGLNHTAEPSLQT ITTYH3 TLVCSAGI AVGFYGNGETSDGVHRATYSLRHANRTVAGVQDRVWDTAAALNRTAEPNLQS mTTYH3-B TLVCSAGI AVGFYGNGETSDG I HRATYSLRHANRTVAGVQDRVWDTAAALNRTAEPNLQS XTTYH2 GLLCCAAVGI GFYGNSETNDGVYQLTYSLDNANHTLAGIDSLVSNTNAKMKEDLDQHLFR hTTYH2-1 GLICCAAVGVGFYGNSETNDGAYQLMYSLDDANHTFSGIDALVSGTTQKMKVDLEQHLAR rTTYH2-X2 GLLCCAAVGVGFYGNSETNDGVHQLIYSLDNANHTFSGMDEL VSGNTQKMKVDLEQHLAR ITTYH2 GLLCCAAVGVGFYGNSETNDGMHQLIYSLDNANHTFSGMDELVSANTQRMKVDLEQHLAR XTTYH1-A VI ICCAGI GI GFYGNSETNDGVYQVTYSLMNTNHTLTSI ILLVSDTVELLSSWKSDLTQ XTTYH1-B VI ICCAGI GI GFYGNSETNDGVYQVTYSLMNANHTLTSI NLLVSDTVELLSSWKSDLTQ hTTYH1 LLAGCTGIGIGFYGNSETSDGVSQLSSALLHANHTLSTIDHLVLETVERLGEAVRTELTT ITTYH1 LLVGCAGIGI GFYGNSETSDGVSQLSSALQHANHTLSTIDDLVLETVERLGEAVRTELTT

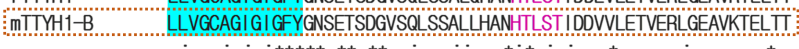
$\triangle 2 \mathrm{C} 2 / 3$ $\ddot{2}$

4 XTTYH3 LEVMETWTDYLRIVQRLOSLYTLVQQTSE hTTYH3 LERQLAGRPEPLRAVQRLQGLLETLLGYTAAIP-FWRNTAVSLEVLAEQVDLYDWYRWL ITTYH3 LEKQLAGRPEPLRAVQRLQTLLGTLLGYTAAIP-FWRNPGVSLEVLAEQVDLYDWYRW ITTYH3-B LEROLAGRREPLRAVQRLQTLLGTLLGYTAAIP-FWRNPGVSLEVLAEQVDLYDWYRW XTTYH2 LNEIFAARGDYIQSLRFMQQMAGN I IQQLTSLP-NWQGTSVNFSEI ARNASI IEYYRWL hTTYH2-1 LSEIFAARGDYLQTLKFI QQMAGSVVVQLSGLP--WRREVTMEL TKLSDQTGYVEYYRIL ITTYH2-X2 LSEIFAARGDYMQTLKFMQQMAGNIVNQLSGLP--VWREVTEELTALSHQTAYVEHYRWL mTTYH2 LSEI IAARGDYIQTLKFMQQMAGNVVSQLSGLP-VWREVTTQLTKLSHQTAYVEYYRWL XTTYH1-A LEEIFSKRTEFLVMIRNTRRQVESVAQQLAEIS--FWKGTELNPNVLAEQVNFIEDYRWL xTTYH1-B LEEIFSTRTEFVVMIRNTRRQVESVAQQLTEI SSFFWKGAELNPSALAEQVNFIEDYRM hTTYH1 LEEVLEPRTELVAAARGARRQAEAAAQQLQGLA-FWQGVPLSPLQVAENVSFVEEYRWL ITYH1 LEEVLSER RELVAATRGARRQAEAAAQHLQGLA- FWQGVSLSPVQVAEDVTFVEEYRWI MTYH1-B LEEVISY BMELVAATRGARROAEAAQYLQGLA-FWQGVSLSPVQVAEDVTFVEEYRW R165*.

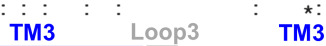

5 xTTYH3 GYLGLLFHVFICLLVLFGLIRNSKTLICVCFLGMMALI ISWASMGLELAVAVGSSDFC hTTYH3 GYLGLLLLDVI ICLLVLVGLIRSSKGILVGVCLLGVLALVISWGALGLELAVSVGSSDFC ITTYH3 GYLGLULDVI ICLLVLVGLIRSSKGILVGVCLL GVLALVISWGALGLELAVSVGSSDFC mTTYH3-B GYLGLLLLDVIICLLVLVGLIRSSKGILVGVCLLGVLALVISWGALGLELAVSVGSSDFC XTTYH2 SYLILFITDVVICLVTCLGLAKKSKCLLLTMLCCGLIALMLSWASLALETSSAVGTSDFC hTTYH2-1 SYLLLFILDLVICLIACLGLAKRSKCLLASMLCCGALSLLLSWASLAADGSAAVATSDFC ITTYH2-X2 SYLLLFILDLVICLVTCLGLARRSKCLLASMLCCGILALVLSWASLAADAAAAVGTSDFC $\mathrm{mTTYH} 2$ SYLLLFILDLVICLVTCLGLARRSKCLLASMLCCGILTLILSWASLAADAAAAVGTSDFC XTTYH1-A AYILLLLLDLIICLFTLLGLAKRIKWLVIVMTVSFFVLLLSWGSMGLEMATAVGLSDFC XTTYH1-B AYIUUUDLIICLFTLLSLAKQIKWLVIVMTVSFFVUUSWGSMGLEMATAVGLSDFC hTTYH1 AYVLLLLLELLVCLFTLLGLAKQSKMLVIVMTVMSLLVLVLSWGSMGLEAATAVGLSDFC ITYH1 AYVLLLLLVLLVLFTLLGLAKQSKWLVWMTAMSLLVLVLSWGSMGLEAATAVGLSDFC

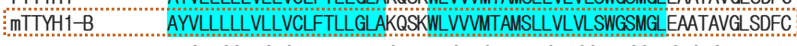

$\triangle$ 4B Loop4

6 VNPDTFVSKMVEEKSVI RADILNYY VVCNTGSPNPFOQMLSSGHKALVEMQDDVRDLRS VDPDAYVTKMVEEYSVLSGDILQYYLACSPRAANPFQQKLSGSHKALVEMODWAELLRT IDPDTFVTKMVEEYSVLSGDILQYYLACSPRATNPFQOKLSGSHKALVEMQDWAELLKN VDPDTFVTKMVEEHSVLSGDILQYYLACSPRATNPFQOKLSGSHKALVEMQDWAELLRN VAPDKFILNMTPD - QITADVVHYYLYCSQSQRNPFQQALTVFORSLTTMQIQIOGULF VAPDTFILNVTEG - QISTEVTRYYLYCSQSGSSPFQQTLTTFQRALTTMQI QVAGLLQF MVPDVYILNNTQN-QISSEVTRYYLHCSQSQISPFQQSLTIFQRSLTTMQIQVVGLLQF MAPDIYILNNTGS - QINSEVTRYYLHCSQSLISPFQQSLTTFQRSLTTMQ IQVGGLLQF SNPDGYVMNQTQMITN INPDILQYYI SCNQDVVANPFRORLTTSQRALSNIHSQLHGLERE SDPDAYVMNQTOMITN INPDILQYYI SCNQDVTNPFRORLTMSQRALSNIHSQLHGLERE SNPDPYVLNLTQEETGLSSDILSYYLLCNRAVSNPFQQRLTLSQRALANIHSQLLGLERE SNPDTYVLNLTQEETGI SSDILNYYFLCNQAVSNPFQQRLTLSQRALASIHSQLQGLERE SNPDTYVLNLTQEETGLSSDIISYYFLCNQAVSNPFQORITISQRALASIHSOLQGLERE

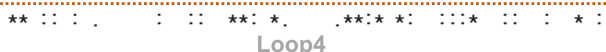

7 AVKEYPNSKDYLVCIQGVLNSTEINLOHLTALVDCRGLHLDYVQSLTGFCYDGVEGLIYL VPWEQPATKDPLLRVQEVLNGTEVNLQHLTALVDCRSLHLDYVQALTGFCYDGVEGLIYL VPREHPATKDPLLRVQEVLNGTEVNLQHLTALVDCRSLHLDYVQALTGFCYDGVEGLIYL VPREHPATKDPLLRVQEVLNGTEVNLQHLTALVDCRSLHLDYVQALTGFCYDGVEGL IYL AVPLFPTAOKDLLGIQLLLNTSESNLHQITALLDCRGLHKDYLEALIGICYDGVEGLLYL AVPLFSTAEEDLLAIQLLLNSSESSLHQLTAMVDCRGLHKDYLDALAGICYDGLQGLLYL AVPLFPTAEKDLLGIQLLLNNSETSLHQLTAMLDCRGLHKDYLDALTGICYDGIEGLLFL AVPLFPTAEKDLLGIQLLLNNSE ISLHQLTAMLDCRGLHKDYLDALTGICYDGIEGLFL AVPQFPTAEKNLLAVQGMLNTTEGNFHHLVALLNCRGLHKDYVDALKGLCYDGMEGILFL AVPQFPTAERNVLWQGMLNTTEGNFHHLVALLNCRGLHKDYVDALKGLCYDGMEGILFL AVPQFPSAQKPLLSLEETLNVTEGNFHQLVALLHCRSLHKDYGAALRGLCEDALEGLLFL ASPQFPAAOKPLLSLEETLNVTERSFHQLVALLHCRSLHKDYGSALRGLCEDALEGLLFL AIPQFSAAOKPLISLEETLNVTERSFHOLVALIHCRS HKDYGSALRGLCEDALEGLLFL

IM or TM

8 VLFSFVTALMFSSIVCSVPHTWQQRRANYEEGD-E-EE-TTTPGTRQTHDNLYRVHM ALFSFVTALMFSSIVCSVPHTWQOKRGPDEDGE- E-EAAPGPRQAHDSLYRVHM ALFSFVTALMFSSIVCSIPHTWQOKRGADEDGE-E-ETAPGPRQAHDSLYRVHM ALFSFVTALMFSSIVCSIPHTWQQKRGPDDDGE- ——E-ETAPGPRQAHDSLYRVHM SLFSLLAAVAFTAMVCAMPRAWKHLAARDRD--YNDVDDEDPFNPQARRIAVHNPNRGQL GLFSFLAALAFSTMI CAGPRAWKHFTTRNRD-Y YDDIDDDDPFNPQAWRMAAHSPPRGQL GLFSLLAALAFSTLTCAGPRAWKHFINRDRD--YDDIDDDDPFNPQARRIAAHNPARGQL GLFSLLAALAFSTLTCAGPRAWKYFINRDRD--YDDIDDDDPFNPQARRIAAHNPTRGQL LLFSFLSALSFTAAVCSLPRAWKRFQNRDLD-YODDDEDDPFNPQESKRLLFSFLSALSFTAAVCSLPRAWKRFRNRDLD-YYDDMDEDDPFNPQESKRLLFSLLSAGALATALCSLPRAWALFPPRNPSALCSGSRLSEPLLPAGLEPGSP MLFSLLSAGALATTLCSLPRAWALFPPSDDYDDTDDD-DPFNPQESKR MLFSLLSAGALATTLCSLPRAWALFPPSDOYDDTDODD-.-DPFNPQESKR$\star \star \star:: \star \star \quad:: * \star *: *: \star \star$

9 PSLYSCGSSYGSETSIPAAAHTVSNAPVTEYMSQNANF-QNPRCENTPLIGRESPPPSYT PSLYSCGSSYGSETSIPAAAHTVSNAPVTEYMSQNANF-QNPRCENTPLI GRESPPPSYT PSLYSCGSSYGSEASIPAAAHTVSNAPVTEYMSQNANF-QNPRCENTPLI GRESPPPSYT PSLYSCGSSYGSEASIPAAAHTVSNAPVTEYMSONANF-ONPRCENTPLI GRESPPPSYT RSFCSYSSSLGSQASLQPPAQTVSNAQAAEYMNQAALFGGNPRYENVPLIGRGSPPPTYS HSFCSYSSGLGSQTSLQPPAQT I SNAPVSEYMNQAMLFGRNPRYENVPLI GRASPPPTYS HSFCSYSSGLGSQCSL OPPTOTISNAPVSEYMNOAILFGGNPRYENVPL I GRGSPPPTYS HSFCSYSSGLGSQCSLQPPSQT I SNAPVSEYMNQAILFGGNPRYENVPLIGRGSPPPTYS -FVQWQSSI

FVQWQSSI-

- - LRSFPGCRRR - - PH

-FVQWOSSI-

-.......WWOSSI!*

10 SSMRAKYLATNRPETDPVH-_SSMRAKYLATSQPRPDSSGSH-SSMRAKYLATSQPRPDSSGSGHSSMRAKYLATSQPRPDSSGSGH*PTMRATYLSMNEESPNIYSNVFPA PSMRATYLSVADEHLRHYGNQFPA PSMRATYMSVADEHLRHYEFPSPSMRPTYMSVADEHLRHYEFPS*-

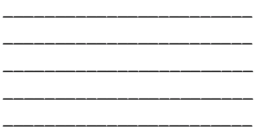

Fig. 7. Multiple amino acids alignment of for various species of TTYH family. Multiple amino acids alignment for various species of TTYH family represents 4 strong hydrophobic and conserved trans-membrane (TM) domain (sky blue), 1 weak hydrophobic and conserved intra-transmembrane (IM) domain or TM (yellowish green) across the species and isoforms of TTYH. Loop1-4 are located between TM domains. The possible candidates of the pore regions which are decided by the recording of $\mathrm{I}_{\mathrm{Cl} \text {,swell }}$ in Fig. $8 \mathrm{D}$ are $\Delta 2 \mathrm{~A} 4$ (pink letter), 2C2 (yellowish green letter), 2C3 (green letter) and 4B (sky blue letter). The 165 arginine residue (R165, red letter) is in between $\Delta 2 \mathrm{C} 2$ and 3. mTTYH1-B is indicated with dark-red box. 
A TTYH1-GFP, $A b_{\text {-term }}$
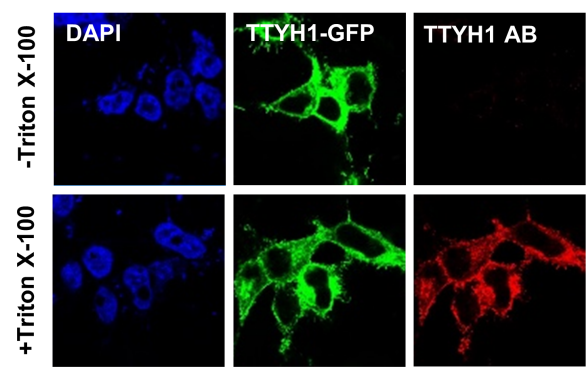

B

TTYH1-GFP (Loop1-Flag), Ab Flag $_{\text {}}$
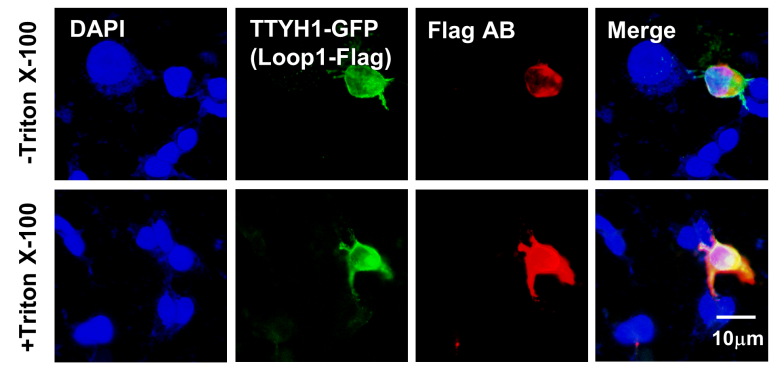

C

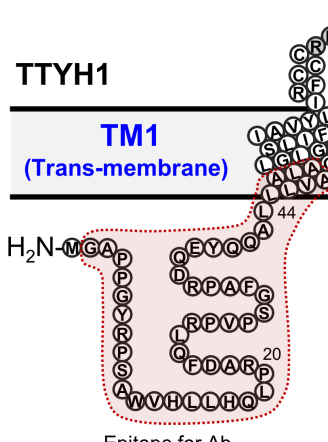

D

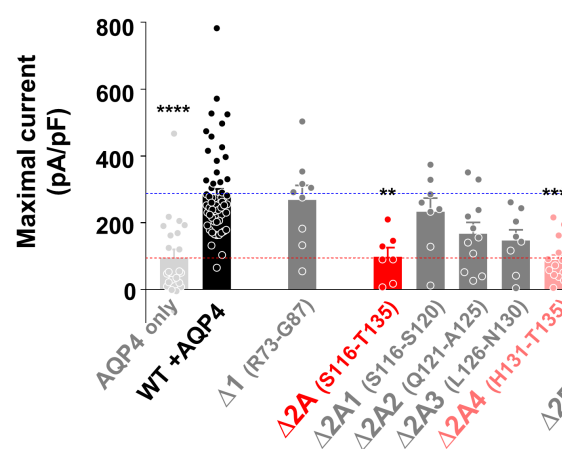

FLAG-tag
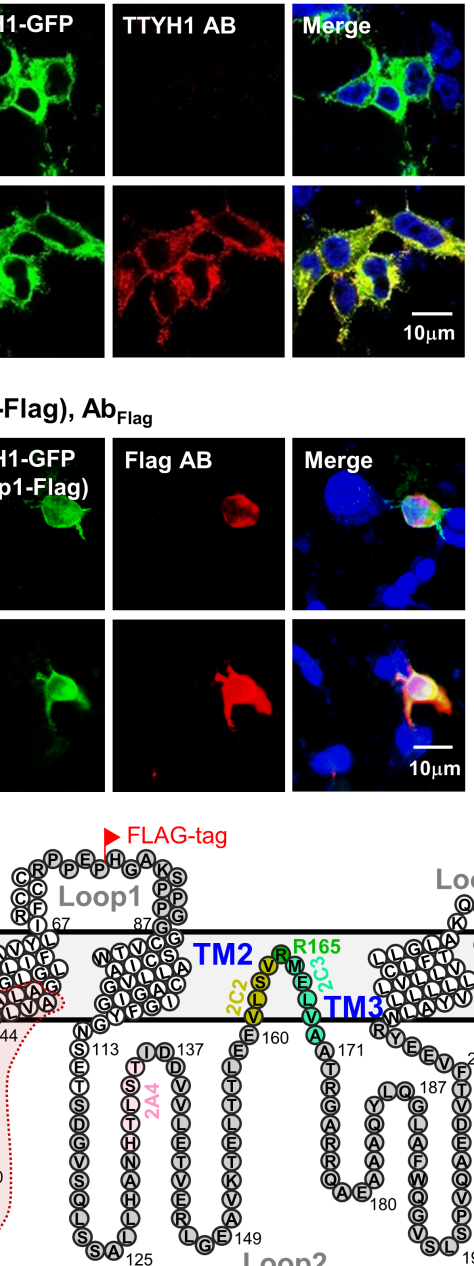

Loop2
TTYH1-GFP, Ab $b_{\text {GFP }}$
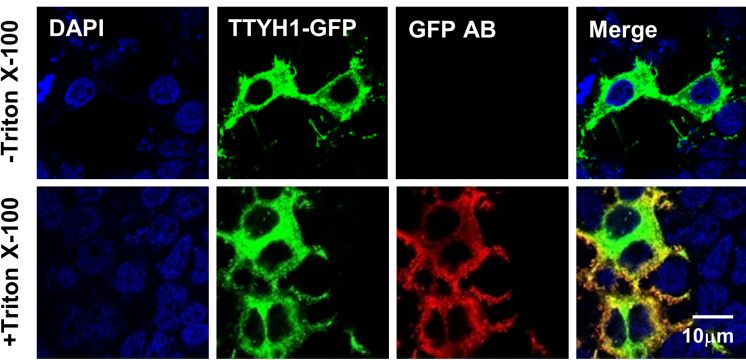

E
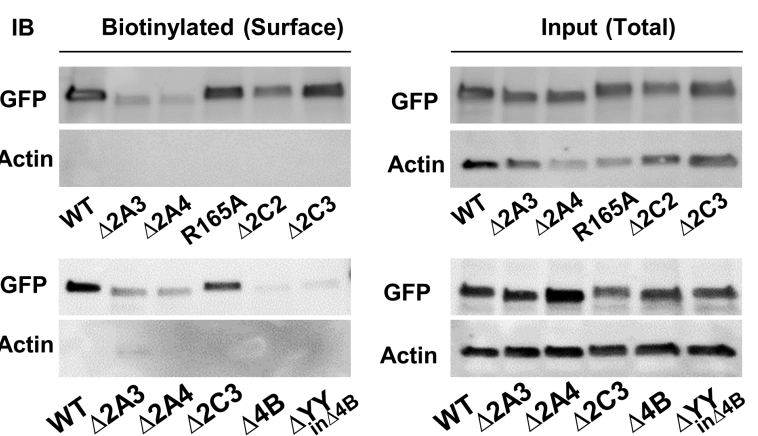

Loop3

(1) 24000

Outside

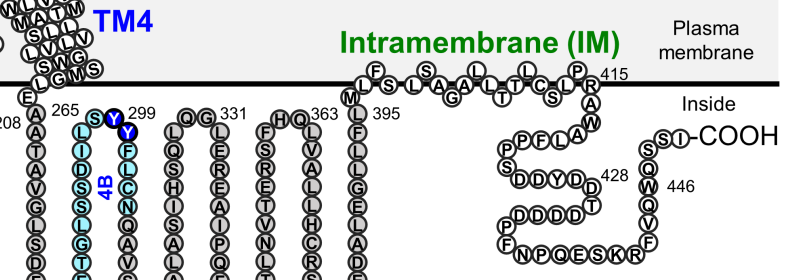

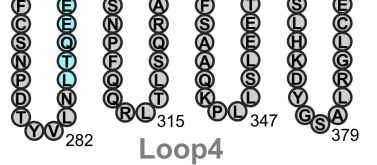

ENDQESRE

Fig. 8. R165 in TTYH1 is the pore-forming amino acid as evidenced by mutagenesis-based structure-activity analysis. (A, B) Non-permeabilized (-Triton X-100) and permeabilized (+Triton X-100) HEK293T cells expressing TTYH1-GFP were immunostained with N terminus of TTYH1 by anti-TTYH1 antibody, C terminus of TTYH1 by anti-GFP antibody and Loop1-FLAG-tagged-TTYH1 clone by anti-FLAG-tag antibody. (C) The prediction of membrane topology of TTYH1 based on permeabilization staining results and topology prediction software (TMHMM). Epitope for Ab $\mathrm{N}_{\mathrm{N} \text {-term }}$ antibody (red box), $\Delta 2 \mathrm{~A} 4$ (H131-T135, pink circle), $\Delta 2 \mathrm{C} 2$ (V161-R165, yellow-green circle), $\Delta 2 \mathrm{C} 3$ (M166-A170, green circle), $\Delta 4 \mathrm{~B}(\mathrm{~L} 285-\mathrm{N} 304, \mathrm{sky}$ blue), $\Delta \mathrm{YY}$ (Y299-Y300, blue circle) and R165 (which was the pore of TTYH1) were also indicated. (D) Summary bar graph showing the maximal amplitude of $\mathrm{I}_{\mathrm{Cl}, \text { swell }}$ from $+100 \mathrm{mV}$ to $-100 \mathrm{mV}$ recorded with WT or several truncation mutants of TTYH1 co-expressing HEK293T cells. Data are represented as mean \pm SEM ( $\mathrm{n}=22$ for AQP4 expressing HEK293T cells, $\mathrm{n}=57$ for WT-TTYH1 with AQP4 co-expressing HEK293T cells, $\mathrm{n}=9$ for loop1-TTYH1, $\mathrm{n}=7,8$, 11,8 and 15 for related to loop2A-TTYH1, n=9 for loop2B-TTYH1, n=8, 6, 9, 10, 16, 11 for related to loop2C-TTYH1, n=7 for both loop2D and loop2ETTYH1, $\mathrm{n}=8$ for loop4A, $\mathrm{n}=8$ and 15 for related to loop4B-TTYH1, and $\mathrm{n}=9,11,8,9$ and 8 for loop4C, D, E, F and G of TTYH1; ${ }^{* *}<0.01$, ${ }^{* * *}<0.001$, ${ }^{* * * *}<0.0001$, Kruskal-Wallis test). 
$\mathbf{F}$

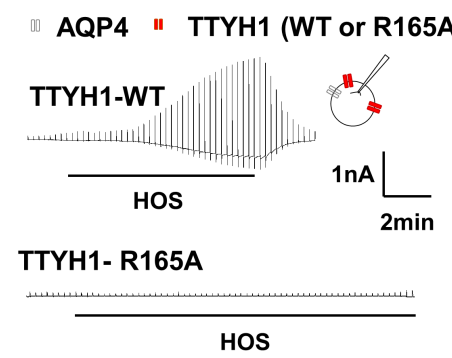

J

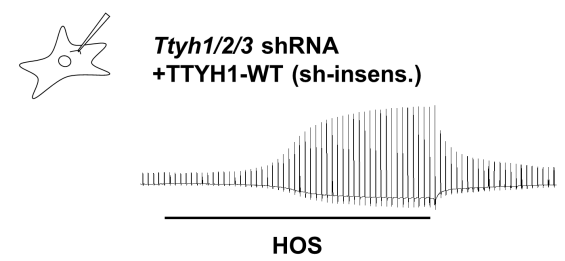

G

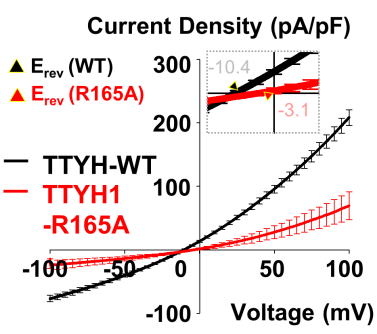

H

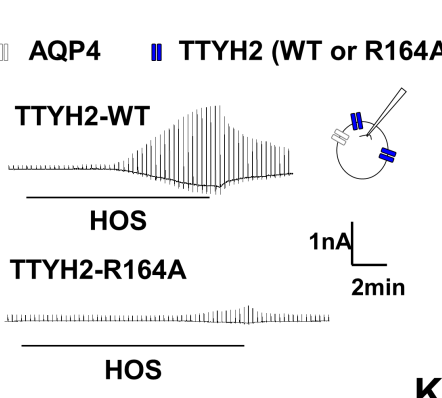

K
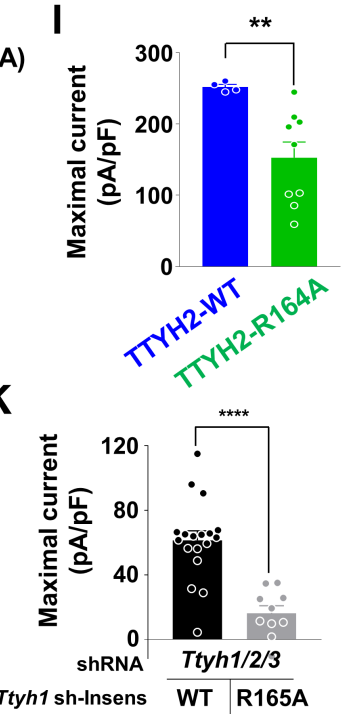

\begin{tabular}{ll|l} 
Ttyh1 sh-Insens & WT & R165A
\end{tabular}
Ttyh1/2/3 shRNA

+TTYH1-R165A (sh-insens.)

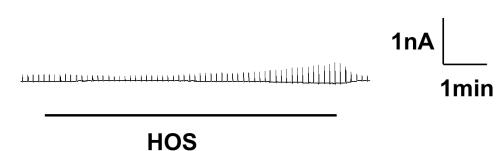

Fig. 8. Continued. (E) Surface expression of truncation mutants of TTYH1 that showed significant reduction of $\mathrm{I}_{\mathrm{Cl} \text { swell }}$ by biotinylation assay. (F, G) Representative traces and averaged I V curve for $\mathrm{I}_{\text {Cl,swell }}$ from wild-type (WT) and R165A-TTYH1 with AQP4 co-expressing HEK293T cells. (H) Representative traces for $\mathrm{I}_{\mathrm{Cl} \text { swell }}$ from TTYH2-R164A with AQP4 compared to TTYH2-WT with AQP4 overexpressing CHO cells. Inset: schematic diagram of whole-cell patch-clamp recording in R164A or WT-TTYH2 with AQP4 expressing CHO cells. (I) Summary bar graph showing the maximal amplitude of $\mathrm{I}_{\mathrm{Cl} \text {,swell }}$ from $-100 \mathrm{mV}$ to $100 \mathrm{mV}$. Date are represented as mean \pm SEM ( $\mathrm{n}=4$ and 9 for TTYH2-WT with AQP4 and TTYH2-R164A with AQP4 coexpressing HEK293T cells, ${ }^{* *} \mathrm{p}<0.01$; Mann-Whitney test). (J) Representative $\mathrm{I}_{\mathrm{Cl} \text { swell }}$ recordings from Ttyh 1/2/3 shRNAs with shRNA-insensitive clone of TTYH1-WT and Ttyh1/2/3 shRNAs with shRNA-insensitive clone of TTYH1-R165A-expressing cultured astrocytes. Inset: schematic diagram of whole-cell patch-clamp recording in primary cultured astrocyte. (K) Summary bar graph showing the maximal amplitude of $\mathrm{I}_{\text {Cl.swell }}$ from $+100 \mathrm{mV}$ to $-100 \mathrm{mV}$ in the presence of the Ttyh 1/2/3 shRNAs with shRNA-insensitive clone of TTYH1-WT (Ttyh1 sh-insens.) or with shRNA-insensitive clone of TTYH1-R165A -expressing cultured astrocytes. Data are represented as mean \pm SEM ( $\mathrm{n}=18$ and 10 for Ttyh1/2/3 shRNAs with shRNA-insensitive form of WT-TTYH1 and R165A-TTYH1 expressing astrocytes, respectively; ${ }^{* * * *}<0.0001$, unpaired t-test).

gesting that there is a basal level sensitivity of TTYH1 for $100 \mathrm{mM}$ of MTSES (Fig. 9A C). Among 10 amino acids, R165C was most significantly blocked by $100 \mathrm{mM}$ of MTSES with the highest block percentage (36.58\%) (Fig. 9A C), suggesting that R165 is the bona fide pore-forming amino acid residue, but not an amino acid involved in channel gating. The V164C was also substantially blocked by $100 \mathrm{mM}$ of MTSES (28.85\%, Fig. 9C). These results suggest that R165 might be located at the apex of the outer vestibule of the pore in TTYH1, whereas V164 might be partially buried in the outer vestibule (Fig. 9D). Finally, to investigate whether one R165 functions as one pore in a multi-subunit complex or a collection of multiple R165 functions as an assembly of one pore, we recorded $\mathrm{I}_{\mathrm{Cl} \text {,swell }}$ when the relative abundance of TTYH1-R165A and TTYH1-WT was varied in co-expression system (Fig. 9E). Intriguingly, the $\mathrm{I}_{\text {Clswell }}$ was linearly reduced according to the relative abundance of TTYH1-R165A (Fig. 9E), which fitted well with a straight line $\left(\mathrm{R}^{2}=0942, \mathrm{p}=0.006\right)$ but not with a dominance model of tetramer or pentamer [54]. These results suggest that, instead of an assembly of several R165's to form one functional pore, each R165 in a multi-subunit complex of TTYH1 homomeric channel constitutes an individual functional conducting pore as a part of a large conducting pore.

\section{The $I_{C l, \text { swell }}$ is mediated by TTYH family in ex-vivo hippo- campal astrocytes}

Due to the lack of molecular identity, the brain distribution and in-vivo function of $\mathrm{VRAC}_{\text {swell }}$ have remained unknown. Using the antibody against TTYH1, which is the most abundant isoform, we found that the protein expression pattern of TTYH1 was exclusively in GFAP-expressing astrocytes in the hippocampus and cortex (Fig. 10A). The astrocyte-specific expression and antibody specificity were verified by the use of adeno-associatedvirus carrying Ttyh 1 -specific shRNA (Fig. 10B and 10C). Then, we recorded $\mathrm{I}_{\mathrm{Cl}, \mathrm{swell}}$ from ex-vivo astrocytes in acute hippocampal slices infected with either all Ttyh1/2/3 shRNAs or control shRNA. After making a whole-cell patch configuration under the conventional artificial cerebrospinal fluid, we exchanged the external bath solution to the Tris- $\mathrm{Cl}$ based isotonic solution which contained $5 \mathrm{mM} \mathrm{TEA}$ and $5 \mathrm{mM} \mathrm{BaCl}_{2}$ to eliminate the $\mathrm{K}^{+}$conductance of astrocytes and found that the reversal potential of the membrane current shifted from $-80 \mathrm{mV}$ to near $-10 \mathrm{mV}$, which was the equilibrium potential for $\mathrm{Cl}^{-}$. Under these recording conditions, the HOS- 


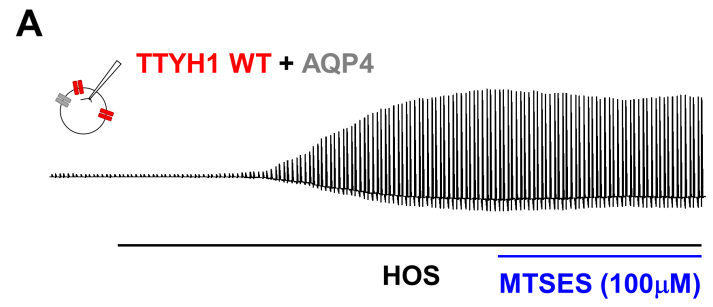

B

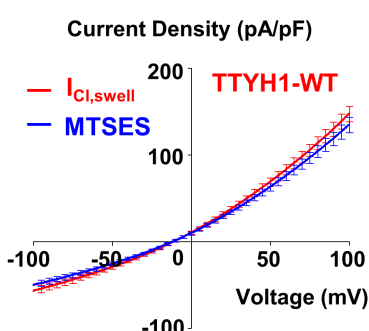

$-100$

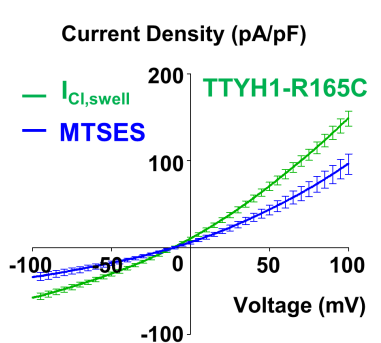

$-100$

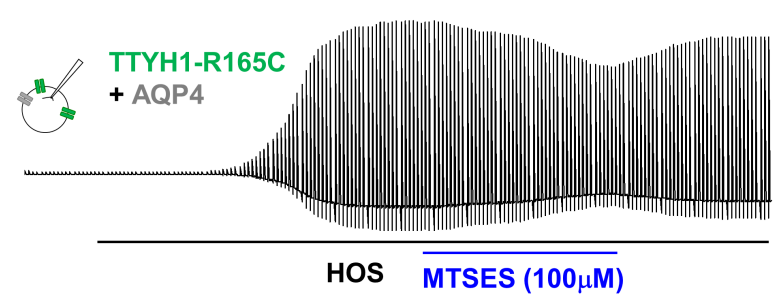

C

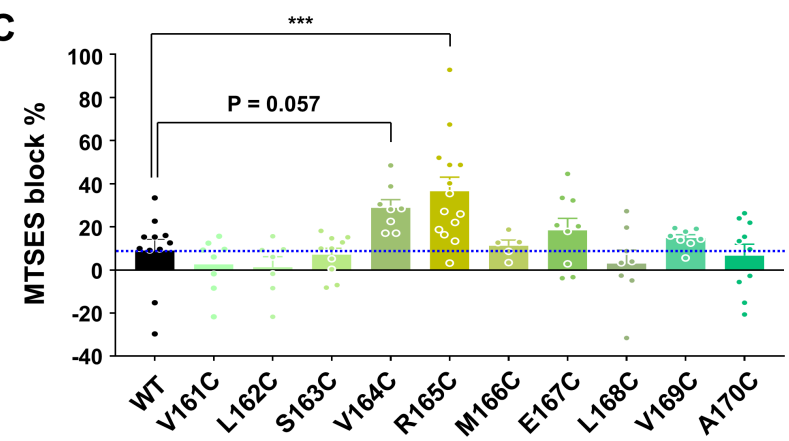

D

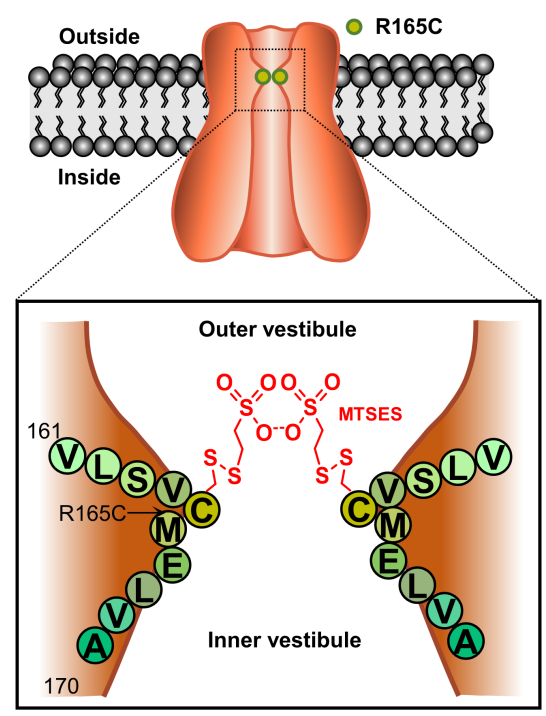

E

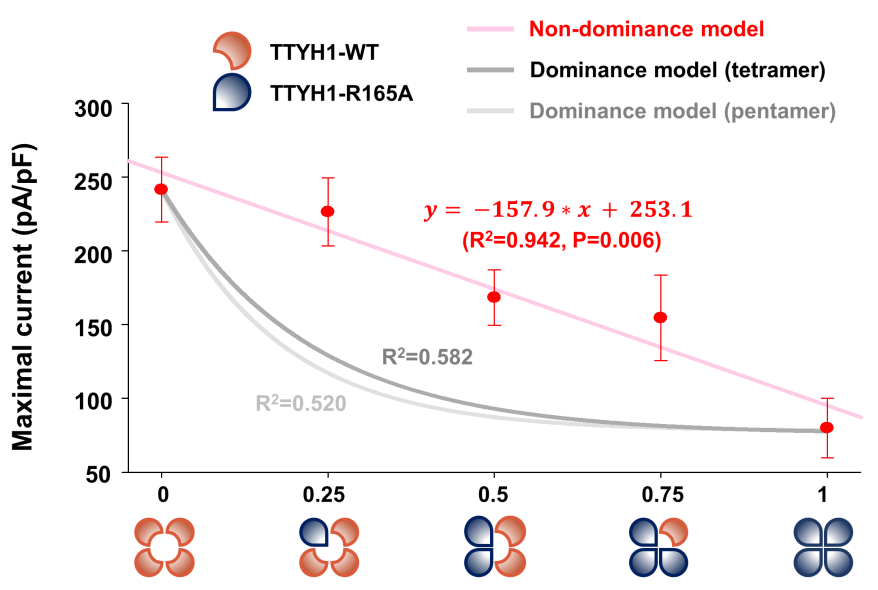

Relative abundance of TTYH1-R165A

Fig. 9. R165 in TTYH1 is the pore-forming amino acid as evidenced by SCAM. (A) Representative traces of $\mathrm{I}_{\mathrm{Cl} \text { swell }}$ recording from TTYH1-WT and TTYH1-R165C with AQP4 co-expressing HEK293T cells during treatment HOS (black bar) in the presence or absence of MTSES (100 mM, blue bar). Left upper insets represent TTYH1-WT (red) and TTYH1-R165C (green) with AQP4 (grey) co-expressing HEK293T cells. (B) Averaged I V curves for $\mathrm{I}_{\mathrm{Cl} \text { swell }}$ recording from TTYH1-WT and TTYH1-R165C with AQP4 co-expressing HEK293T cells in the absence of MTSES (red and green, respectively) or presence of MTSES (100 mM, blue). (C) Summary bar graph showing the MTSES block percentage (\%) recorded from TTYH1-V161C to TTYH1-A170C compared to TTYH1-WT with AQP4 co-expressing HEK293T cells. Data are represented as mean \pm SEM ( $\mathrm{n}=11$ for TTYH1-WT with AQP4 co-expressing HEK293T cells, $\mathrm{n}=8,7,10,8,14,5,9,8,8$, and 10 for from TTYH1-V161C to TTYH1-A170C with AQP4 co-expressing HEK293T cells; ${ }^{* * *}<0.001$, Ordinary one-way ANOVA). (D) Schematic diagram of pore-forming subunit of TTYH1 predicted by results from mutagenesis-based structure-activity analysis and SCAM experiment. (E) Summary graph showing the maximal current of $\mathrm{I}_{\mathrm{Cl} \text {,swell }}($ red, $\mathrm{n}=12,10$, 16, 9 and 11, respectively) according to the relative abundance of TTYH1-R165A, fitted with linear-regression (pink line, $\mathrm{R}^{2}=0.942, \mathrm{p}=0.006$ ). The non-dominance model for tetramer and pentamer is indicated with dark-grey and grey lines $\left(\mathrm{R}^{2}\right.$ between the experimental results and the dominance model of tetramer and pentamer were 0.582 and 0.520 , respectively). 
A
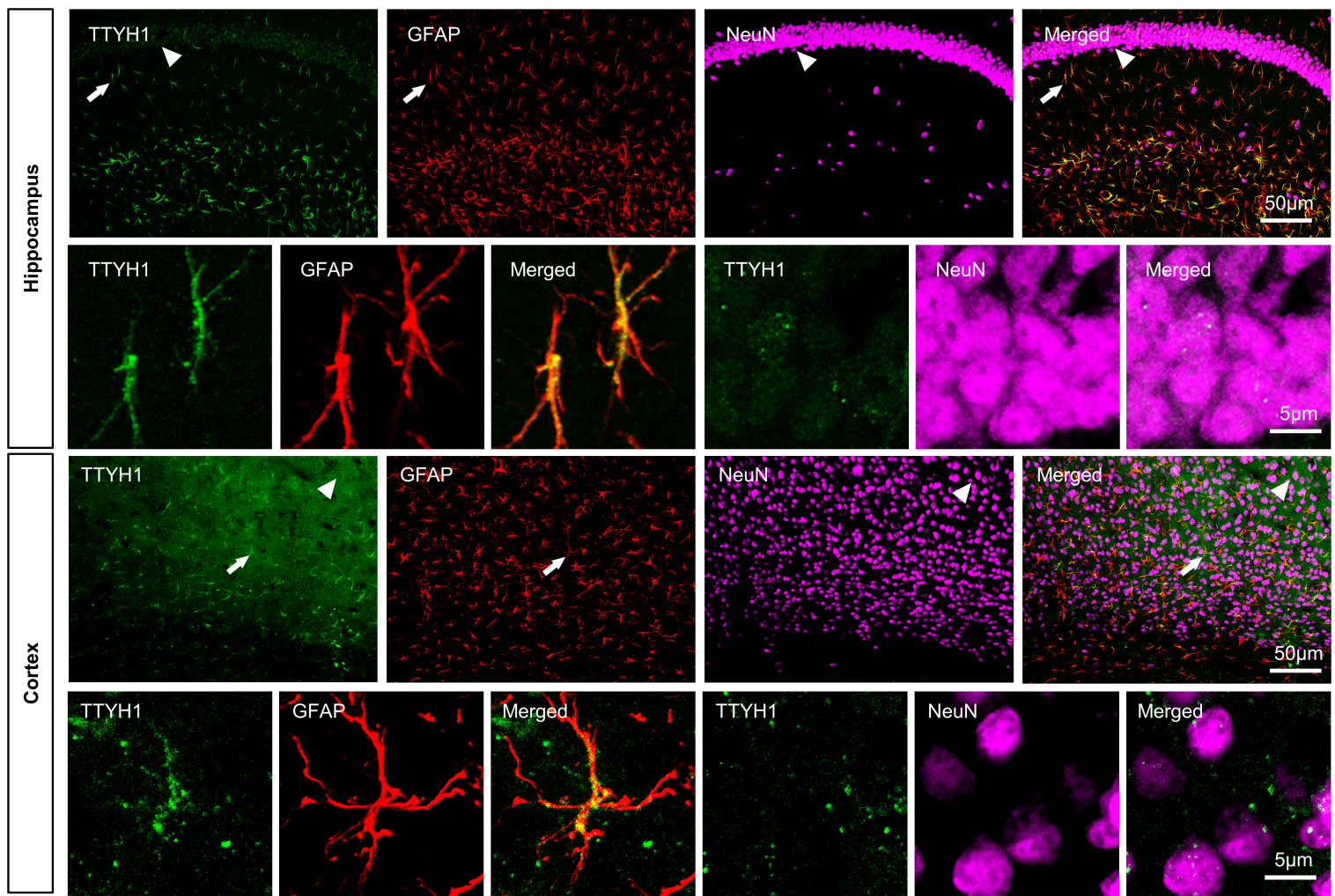

GFAP
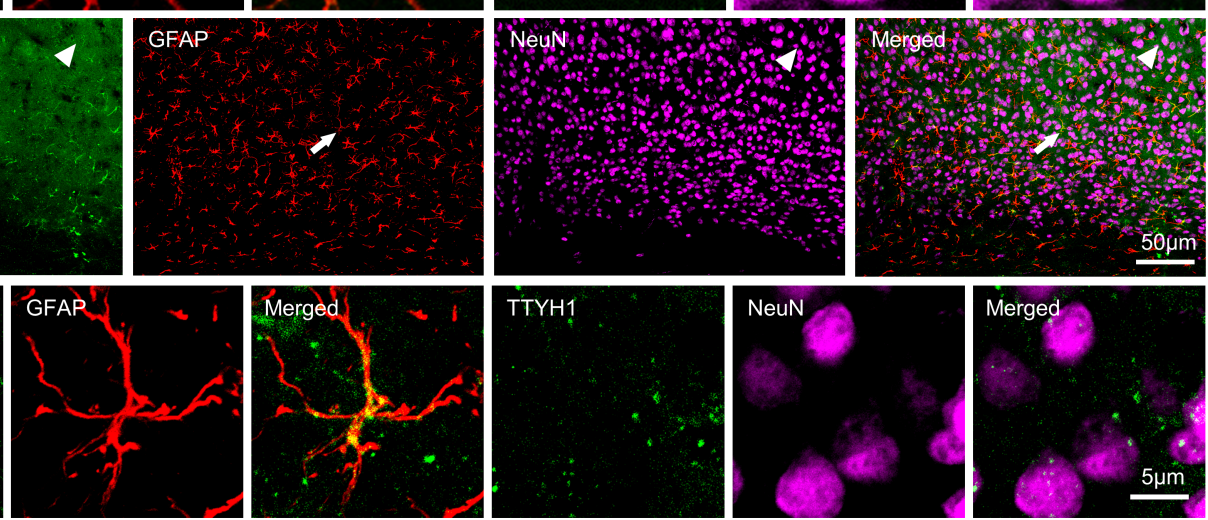

B
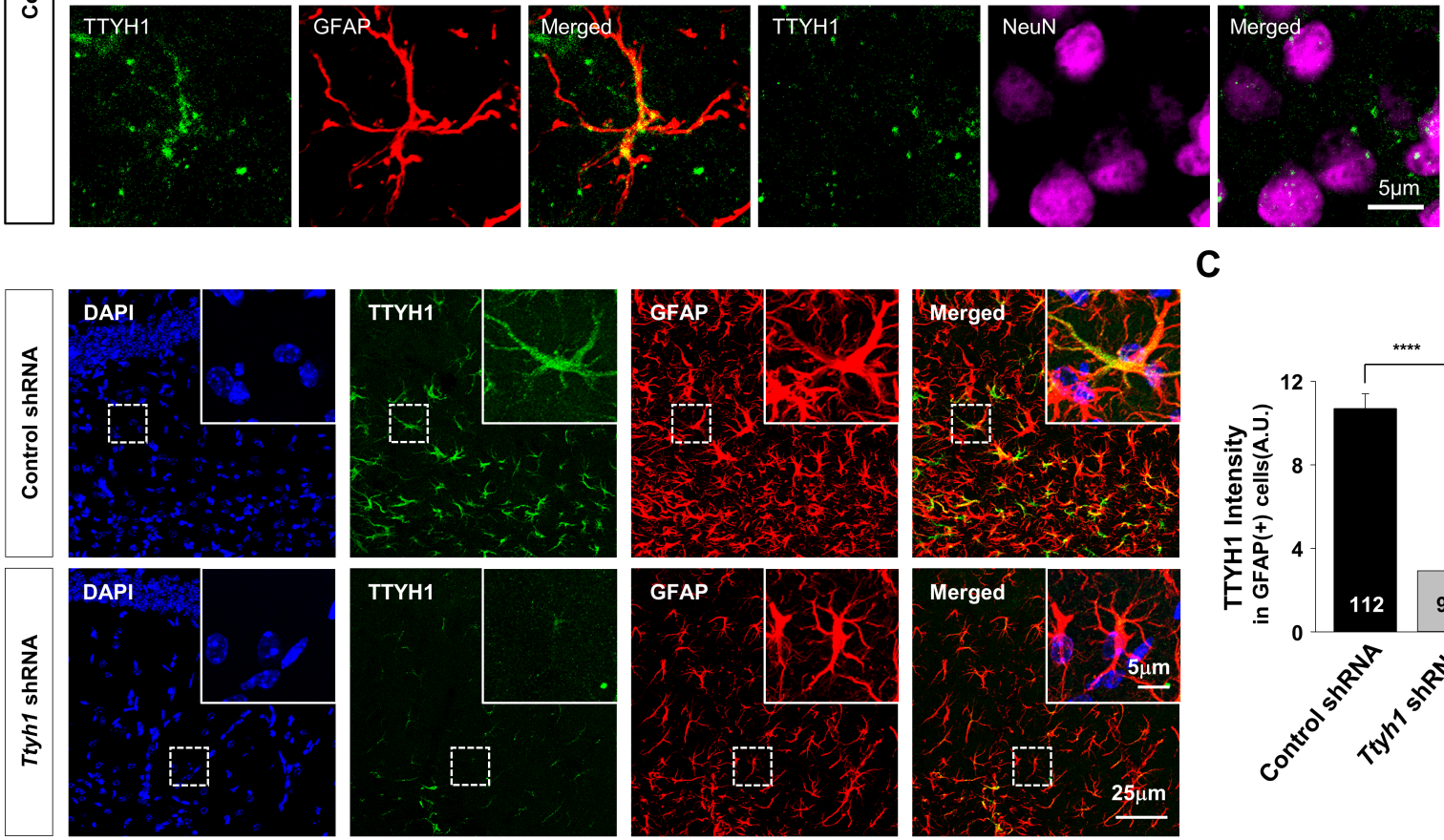

C

Fig. 10. The $\mathrm{I}_{\mathrm{Cl} \text {.swell }}$ is mediated by TTYH family in eX-vivo hippocampal astrocytes. (A) Upper panels in the hippocampus show immunostaining for TTYH1 expression in GFAP-positive (arrow) and NeuN-positive cells (arrowhead) in the hippocampal CA1 region. The lower panel in the hippocampus shows higher magnification images of TTYH1 expression in GFAP-positive (left) and NeuN-positive (right) cells. Upper panels in the cortex show immunostaining for TTYH1 expression in GFAP-positive (arrow) and NeuN-positive (arrowhead) in the cortex. Lower panel in the cortex show higher magnification images of TTYH1 expression in GFAP-positive (right) and NeuN-positive (arrowhead) cells. (B) Immunostaining images from the hippocampus of C57BL/6J mouse injected with AAV-control shRNA (top) or AAV-Ttyh1 shRNA (bottom) stained with DAPI (blue), TTYH1 (green), GFAP (red) and merged images by confocal microscope. Inset: High magnification images focusing on single GFAP-positive cells from the mouse injected with AAV-control shRNA or Ttyh1 shRNA stained with DAPI (blue), TTYH1 (green), GFAP (red) and merged images. (C) Quantification of TTYH1 intensity in astrocytes (GFAP-positive cells) from hippocampal CA1 stratum radiatum (SR) injected with AAV-virus containing control or all Ttyh1/2/3 shRNAs. Data are represented as mean \pm SEM ( $\mathrm{n}=112$ and 94 for control and Ttyh1/2/3 shRNAs; ${ }^{* * * *}<0.0001$, unpaired t-test). (D) Top: schematic diagram of whole-cell patch-clamp recordings in SR (left) and representative images for bright-field and fluorescence images showing Ttyh1/2/3 shRNAs-expressing astrocytes (right). Bottom: representative traces of $\mathrm{I}_{\mathrm{Cl}, \mathrm{swell}}$ in naïve, control and Ttyh1/2/3 shRNAs expressing astrocytes in SR. (E) Averaged I V curves for $\mathrm{I}_{\text {Cl,swell }}$ in naive (black), control shRNA (blue) and Ttyh1/2/3 shRNAs (red). (F) Summary bar graph showing the maximal amplitude of $\mathrm{I}_{\mathrm{Cl}, \text { swell }}$ from $+100 \mathrm{mV}$ to $-100 \mathrm{mV}$ in the naïve, control and Ttyh1/2/3 shRNAs. Data are represented as mean \pm SEM ( $\mathrm{n}=10,10$ and 12 for naïve, control shRNA and Ttyh1/2/3 shRNA; ${ }^{* *}<0.01$, unpaired t-test). 
D
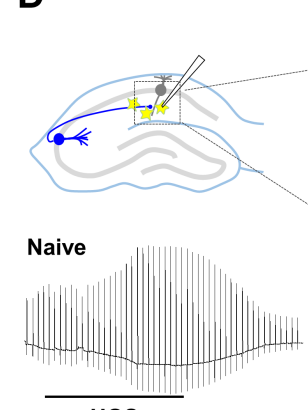

HOS

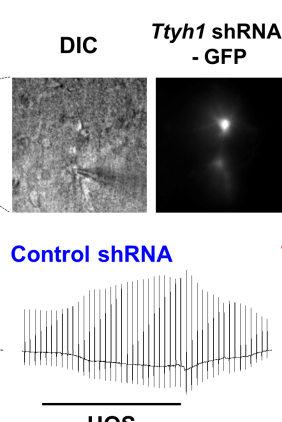

HOS

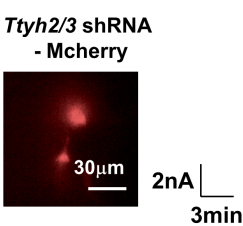

Ttyh1/2/3 shRNA

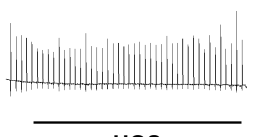

E

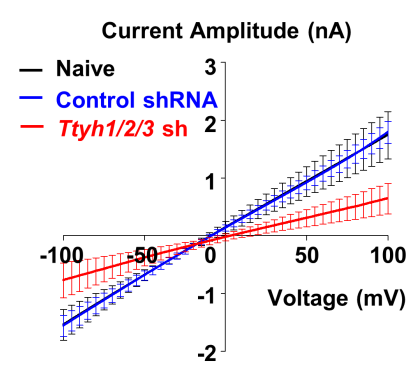

$\mathbf{F}$

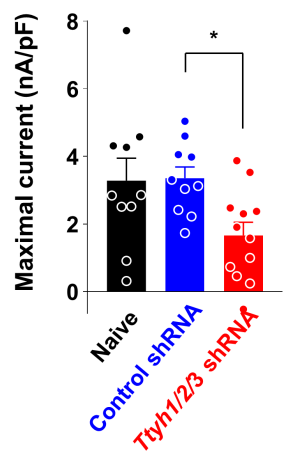

Fig. 10. Continued.

induced astrocytic $\mathrm{I}_{\mathrm{Cl}, \text { swell }}$ was significantly reduced by all Ttyhl/2/3 shRNAs compared to control shRNA (Fig. 10D F), indicating that $\mathrm{I}_{\mathrm{Cl}, \text { swell }}$ of hippocampal astrocyte is mediated by TTYH1/2/3. Taken together, these results indicate that TTYH family function as the astrocytic $\mathrm{VRAC}_{\text {swell }}$ ex vivo.

\section{The astrocytic TTYH1/2/3 is necessary and sufficient for RVD in the hippocampus}

The primary role of $\mathrm{VRAC}_{\text {swell }}$ in volume regulation is its participation during RVD. To recapitulate RVD in hippocampal slices, we performed intrinsic optical signal (IOS) imaging which represents the astrocytic volume change through water movement via AQP4 upon repetitive neuronal activity $[2,55]$. Among various stimulation protocols, we found that low-frequency stimulation (LFS; 1 $\mathrm{Hz}$ ) for $30 \mathrm{~min}$ at Schaffer-collateral pathway caused an RVD with a continuous increase in IOS, which peaked at around $15 \mathrm{~min}$, followed by a steady decrease in IOS until the end of $30 \mathrm{~min}$ stimulation period (Fig. $11 \mathrm{~A} \sim \mathrm{C}$, and $11 \mathrm{E} \sim \mathrm{G}$ ). In contrast, a brief $20 \mathrm{~Hz}$ or $100 \mathrm{~Hz}$ stimulation only casued a transient IOS, but not DCPIBsensitive RVD (Fig. 11D). The LFS-induced RVD was completely blocked by DCPIB and genistein treatments (Fig. 11E G), raising a possibility that the LFS-induced RVD might be mediated by TTYH1/2/3.

To test whether LFS-induced RVD is mediated by TTYH isoforms, we injected lentivirus carrying all Ttyh1/2/3 shRNAs into CA1 hippocampus (Fig. 11J) and found that the RVD was eliminated by all Ttyh1/2/3 shRNAs (Fig. 11J L). The eliminated RVD by all Ttyh1/2/3 shRNAs was fully rescued by tamoxifendependent flanking of shRNAs, which are under the cre/loxP control (pSicoR system [44]) in hGFAP-CreERT2 mice (Fig. 11H L). These results demonstrate that astrocytic TTYH1/2/3 are necessary and sufficient for RVD in the hippocampus.

\section{DISCUSSION}

Our study elucidates for the first time that TTYH family of genes encode the pore-forming subunits of $\mathrm{VRAC}_{\text {swell }}$ in the brain. Several lines of evidence support this conclusion: (1) The gene-silencing experiments using all three Ttyh1/2/3 shRNAs reveal that expression of TTYH family is necessary for endogenous $\mathrm{I}_{\mathrm{Cl}, \text { swell }}$ in astrocytes from both primary culture and hippocampal slice and for RVD in hippocampal slice; (2) Overexpression of each TTYH isoforms with AQP4 in HEK293T or CHO-K1 cells is sufficient for further increase of $\mathrm{I}_{\mathrm{Cl} \text {,swell }}$ even in the absence of LRRC8A and this TTYH1/2/3-mediated $\mathrm{I}_{\mathrm{Cl}, \text { swell }}$ shares the same biophysical (outward-rectification, glutamate permeability), biochemical $\left(\mathrm{Ca}^{2+}-\right.$ independency, kinase-dependency) and pharmacological (sensitivity to DCPIB) properties as astrocytic VRAC; (3) The arginine residue at position 165 of TTYH1 and 164 of TTYH2 is the poreforming amino acid of astrocytic VRAC as evidenced by a complete elimination of $\mathrm{I}_{\mathrm{Cl}, \mathrm{swell}}$ without any disturbance of surface expression by the pore-mutant of either TTYH1-R165A or TTYH2R164A. This was further strengthened by the failure to rescue $\mathrm{I}_{\mathrm{Cl}, \mathrm{swell}}$ by overexpression of shRNA-insensitive TTYH1-R165A as opposed to the full rescue by overexpression of shRNA-insensitive TTYH1-WT when co-expressed with all three TTYH1/2/3 shRNAs. The most striking evidence for R165 as the pore-forming amino acid residue comes from the significant block of TTYH1R165C-mediated $\mathrm{I}_{\mathrm{Cl} \text { swell }}$ by MTSES in SCAM experiment. These lines of evidence provide unequivocal proof that TTYH family is the bona fide $\mathrm{VRAC}_{\text {swell }}$ of the brain.

\section{TTYH family can function as a homomeric channel}

One of the unique properties of an ion channel family is its ability to assemble as a homomeric or heteromeric complex to form a functional channel. For TTYH family there are three possible 
A

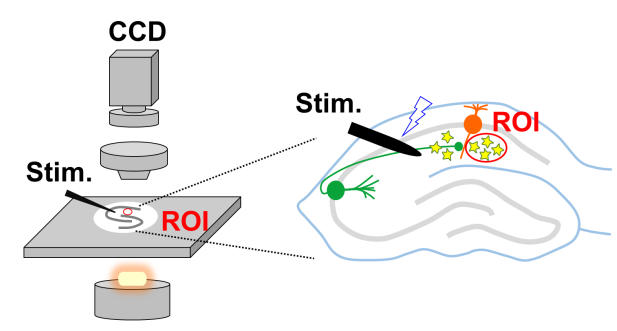

B

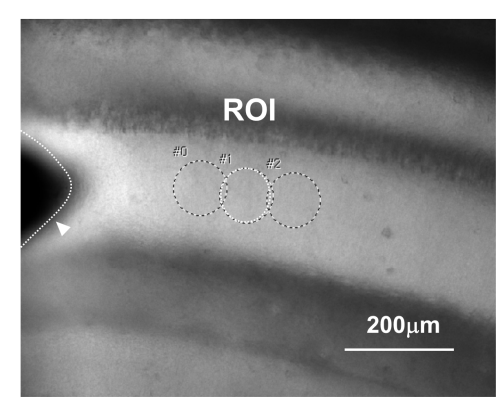

E
C

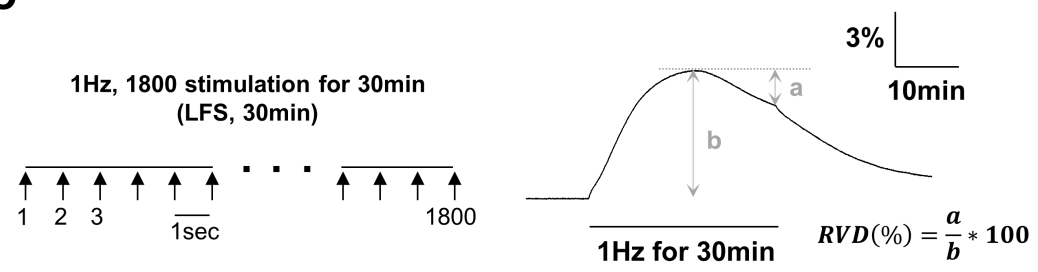

D

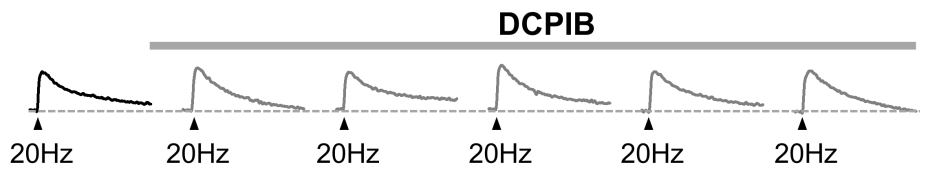

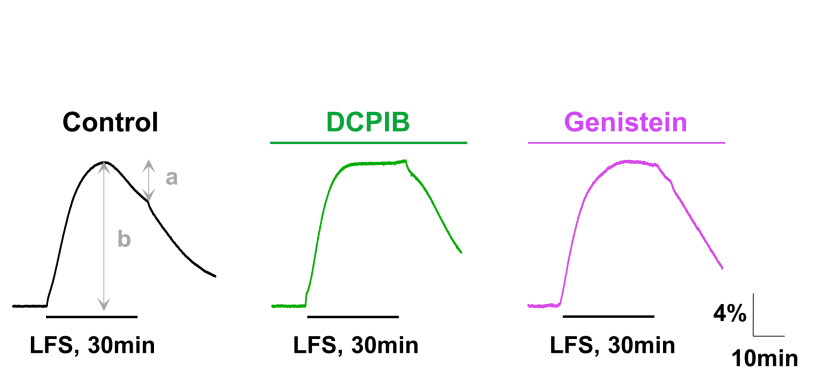

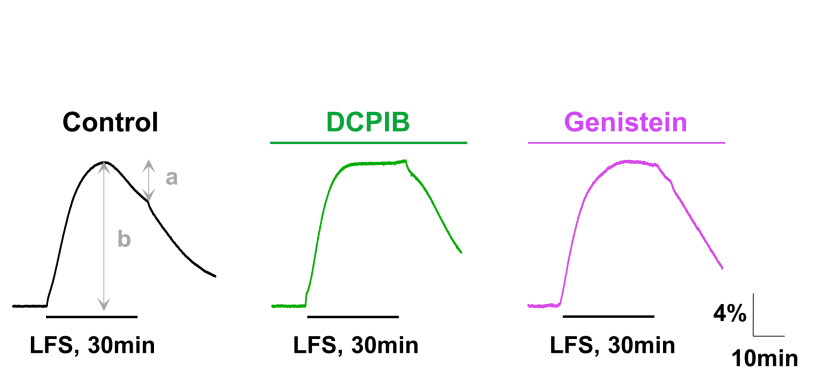

$\mathbf{F}$

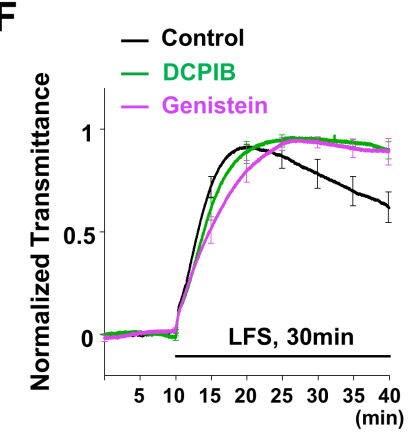

G

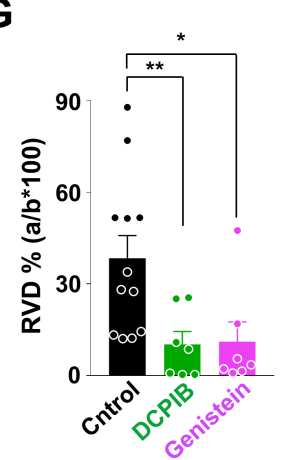

Fig. 11. The astrocytic TTYH $1 / 2 / 3$ is necessary and sufficient for RVD in the hippocampus. (A) Schematic diagram of intrinsic optical signal (IOS) imaging experiment in SR of the hippocampus. (B) Representative bright-field image for IOS recording in SR after stimulating the Schaffer-collateral pathway. A white arrowhead indicates an electrical stimulation electrode in the Schaffer-collateral pathway. A white dotted lined circle indicates regions of interest (ROI). (C) (Left) Schematic diagram for electrical stimulation protocol for inducing RVD in SR of the hippocampus. (Right) The representative trace of IOS change by prolonged $1 \mathrm{~Hz}$ for 30 min electrical stimulation on the Schaffer-collateral pathway in CA1 hippocampus. The percentage of RVD is calculated with a portion of decreased transmittance (a) from the peak transmittance (b) during $1 \mathrm{~Hz}, 30 \mathrm{~min}$ stimulation. (D) Upper panels for the representative traces for IOS change indicated as astrocytic volume change before and after treatment of DCPIB (grey line) by brief $20 \mathrm{~Hz}$ for 1 sec electrical stimulation on the Schaffer-collateral pathway in CA1 hippocampus. Lower representative trace for IOS change by $100 \mathrm{~Hz}$ for 1 sec electrical stimulation on the Schaffer-collateral pathway in CA1 hippocampus. (E) Representative traces of IOS induced by low-frequency stimulation (LFS) for $30 \mathrm{~min}$ in control (black), with $10 \mathrm{mM}$ DCPIB (green) and with $50 \mathrm{mM}$ Genistein (pink). The à indicates the difference between the peak of response and the value of end of stimulation. The ' $b$ ' indicates the value of the peak for calculating RVD \% (as described in Fig. 11C, a/ $b^{*} 100$ ). (F) Averaged traces for normalized transmittance by the peak of each trace. (G, L) Averaged bar graph of RVD percentage (\%). RVD\% is calculated by a/b 100 . Data are represented as mean \pm SEM $\left(n=12,7\right.$ and 7 for control and after DCPIB and Genistein treatment; ${ }^{*}<0.05,{ }^{* *}<0.01$, Kruskal-Wallis test; $\mathrm{n}=10,10$ and 9 for control and Ttyh1/2/3 shRNA injected C57BL/6J mice and pSicoR Ttyh1/2/3 shRNA injected in tamoxifen-treated hGFAP-creERT2 mouse, respectively; ${ }^{*}<0.05,{ }^{* *}<0.01, \mathrm{NS}>0.05$, Kruskal-Wallis test) $(\mathrm{H})$ Timeline from tamoxifen injection to IOS imaging. Tamoxifen was into hGFAP-CreERT2 by intraperitoneal (i.p.) injection for 6 days. On 7 day, lentivirus containing pSicoR Ttyh1/2/3 shRNA were injected into CA1 stratum radiatum of the hippocampus. IOS imaging was done 2 weeks after virus injection. (I) In the presence of tamoxifen, the inactivated Cre (CreER) were converted to the activated form of Cre (CreERT), which were translocated into Nucleus. CreERT recognized loxP sites in pSicoR Ttyh1/2/3 shRNA construct and cleaved the shRNA sequence. (J) Representative fluorescence images of lenti-viral carrying control or Ttyh1/2/3 shRNA injected into SR of CA1 hippocampus (upper panel). Representative traces of 30 min LFS-induced IOS recording from control shRNA (black), Ttyh1/2/3 shRNAs (red) injected C57BL/6J mice and glial rescue condition by pSicoR Ttyh1/2/3 shRNAs injected in tamoxifen-treated hGFAP-creERT2 mouse (blue) (bottom panel). (K) Averaged traces for $30 \mathrm{~min}$ LFS-induced IOS recording. 
H

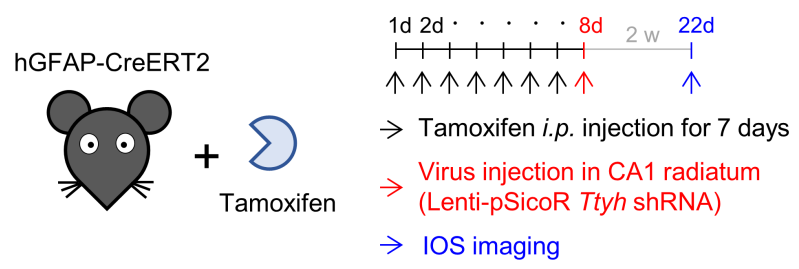

J

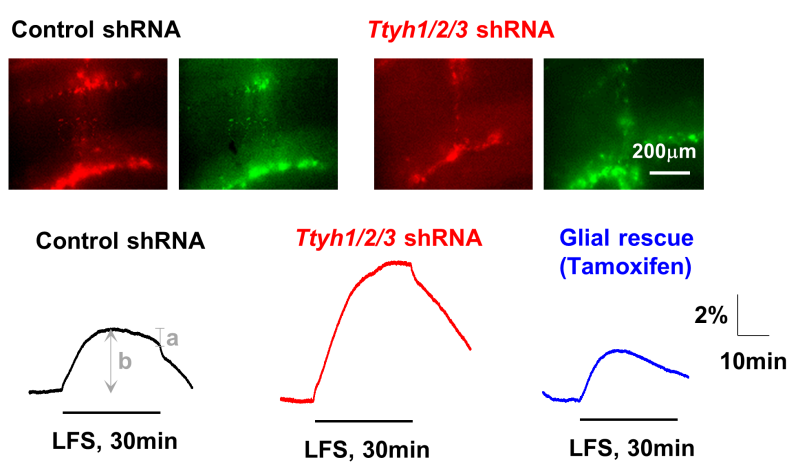

I

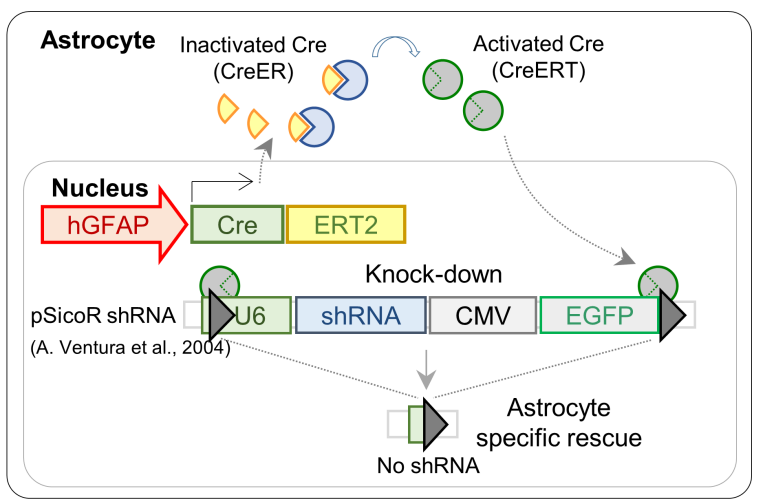

K
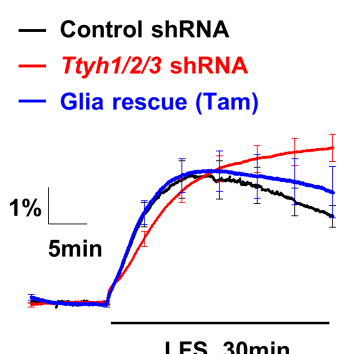

LFS, $30 \mathrm{~min}$
$\mathbf{L}$

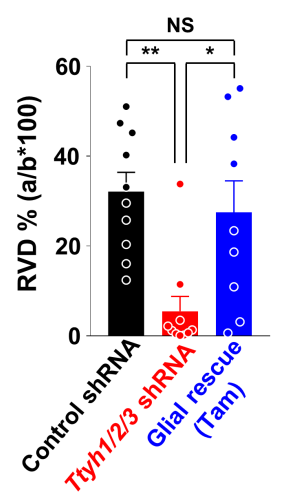

Fig. 11. Continued.

scenarios: (1) each TTYH subunits can assemble as a homomer; (2) TTYH subunits can assemble as a heteromer within TTYH family; and (3) TTYH subunits can assemble as a heteromer with other unknown proteins. Although we cannot completely rule out the possibilities of TTYH subunits assembling as heteromers, our results support the possibility that TTYH subunits can assemble and function as a homomer. If TTYH subunits were assembled only as a heteromer within TTYH family, gene-silencing by the combination of two shRNAs should have been effective to reduce the $\mathrm{I}_{\mathrm{Cl}, \mathrm{swell}}$ in astrocytes. However, this was not the case: Only the combination of all three shRNAs (Fig. 2E, 2G and 2H), but not the combinations of two shRNAs (Fig. 2E and 2F), was able to significantly and fully silence the $\mathrm{I}_{\text {Cl.swell }}$ in astrocytes. These strongly suggest that TTYH subunits can assemble and function at least as a homomer. It is also unlikely that TTYH subunits assemble with other unknown protein to form a functional channel because heterologous overexpression of each TTYH subunits produced an equal magnitude of $\mathrm{I}_{\mathrm{Cl}, \text { swell }}$ in HEK293T and CHO-K1 cells, which are originated from human kidney and hamster ovary, respectively. The chance of such unknown protein to be expressed at high level in those two seemingly different cell lines and astrocytes is very low. More importantly, the strongest evidence for homomeric assembly of TTYH in astrocytes comes from the observation that co-expression of shRNA-insensitive TTYH1-WT with all three TTYH1/2/3 shRNAs fully rescued $\mathrm{I}_{\mathrm{Cl}, \text { swell }}$ (Fig. 2E, 2G and $2 \mathrm{H}$ ), whereas co-expression of the pore-mutant TTYH1-R165A (shRNA-insensitive) and all three Ttyh $1 / 2 / 3$ shRNAs caused a complete impairment of $\mathrm{I}_{\mathrm{Cl}, \text { swell }}$ (Fig. $8 \mathrm{~J}$ and $8 \mathrm{~K}$ ). Therefore, we propose that astrocytic $\mathrm{VRAC}_{\text {swell }}$ is composed of mostly homomers of all three TTYH1/2/3 subunits. Nevertheless, further studies are needed to clarify the exact subunit composition of the TTYH channel.

\section{The relationship between TTYH family and LRRC8A}

In this study, we provide unprecedented evidence that each TTYH1/2/3 isoform acts as a pore-forming subunit of $\mathrm{VRAC}_{\text {swell, }}$ while LRRC8A acts as a pore-forming subunit of $\mathrm{VRAC}_{\Gamma}$, which modulates the speed of cell swelling and subsequent activation kinetics of $V_{R A C} C_{\text {swell }}$. These ideas are derived from the detailed analysis of activation kinetics of $\mathrm{I}_{\mathrm{Cl}, \text { swell }}$ recorded from both $\operatorname{Lrrc} 8 \mathrm{a}$ 
and Ttyh1/2/3 shRNAs expressing cultured astrocytes (Fig. 2I L). The observations that the peak amplitude of $\mathrm{I}_{\mathrm{Cl}, \text { swell }}$ was almost completely eliminated by Ttyh1/2/3 shRNAs without affecting the activation kinetics (Fig. 2I and 2J), while there was no change in peak amplitude of $\mathrm{I}_{\mathrm{Cl}, \text { swell }}$ with significantly slower activation kinetics by Lrrc8a shRNA (Fig. $2 \mathrm{~K}$ and 2L), implying that TYH1/2/3 and LRRC8A might directly or indirectly interact with each other and have distinct roles on activation of $\mathrm{I}_{\mathrm{Cl} \text {,swell }}$ in astrocytes. In support of the possibility of a direct interaction, a recent report demonstrated that LRRC8A directly binds to other ion channels such as TMEM16A (ANO1) in response to swelling by coimmunoprecipitation assay [56], raising a possibility that LRRC8A might also interact with TTYH family.

In support of the possibility of an indirect interaction between TTYH-mediated VRAC $_{\text {swell }}$ and LRRC8-mediated VRAC , a $_{\text {, }}$ recent report provided a crystal structure of the pore-forming subunits of LRRC8 family [29]. In this report, the authors clearly demonstrated that activation of LRRC8 requires reduced cytosolic ionic strength, but not swelling or membrane stretch [27,29]. Based on this report and our findings, we now propose a mechanistic model (Fig. 12A) to give a more comprehensive view and to explain the observed difference in activation kinetics of $\mathrm{I}_{\mathrm{Cl}, \text { swell }}$ after Lrrc8a shRNA and the maximal current density of $\mathrm{I}_{\mathrm{Cl}, \text { swell }}$ by Ttyh shRNA in astrocytes. When HOS(Tris-Cl) is applied in cultured astrocytes, water permeates the astrocytic plasma-membrane through the abundant AQP4 water channel, down the gradient of osmotic pressure. At the intracellular vicinity of $\mathrm{AQP} 4$, the ionic strength is instantaneously lowered by the influx of water (due to a dilution of ionic concentration by water). This lowering of ionic strength at the local region activates and opens nearby LRRC8Amediated $\mathrm{VRAC}_{\Gamma}$, allowing the $\mathrm{Cl}^{-}$ions to initially influx through $\mathrm{VRAC}_{\Gamma}$. The influx of $\mathrm{Cl}^{-}$ions is ensured and potentiated particularly during the current recording by the ramp protocol (a periodic voltage step to $+100 \mathrm{mV}$ and ramping down to $-100 \mathrm{mV}$ ). This influx of $\mathrm{Cl}^{-}$ions through $\mathrm{VRAC}_{\Gamma}$ further accelerates the water influx via AQP4 and subsequently induces a cell-swelling. This cell swelling eventually activates and open TTYH-mediated VRAC swell- $_{\text {- }}$ By this time the intracellular $\mathrm{Cl}^{-}$concentration would have been significantly accumulated, and the opening of $\mathrm{VRAC}_{\text {swell }}$ allows efflux of $\mathrm{Cl}^{-}$ions. And the water efflux through AQP4 follows the $\mathrm{Cl}^{-}$ efflux via VRAC $_{\text {swell }}$, causing a regulatory volume decrease (RVD). Based on this mechanistic model, we propose that TTYH family constitute the pore-forming subunits of astrocytic $\mathrm{VRAC}_{\text {swell }}$ which senses the cell swelling, and LRRC8 family constitutes a modulatory channel, $V_{R A C}$ which senses the low cytosolic ionic strength to boost anionic influx, water influx, and cell-swelling, facilitating the activation of $\mathrm{VRAC}_{\text {swell }}$. This model now explains how the gene-
A

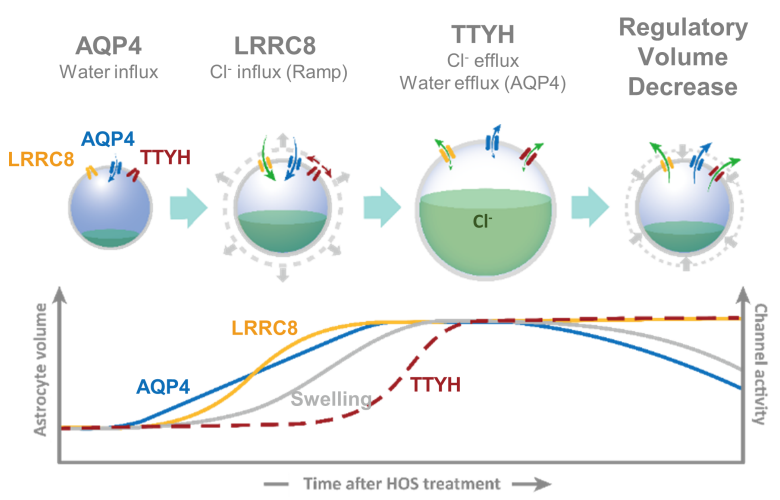

B
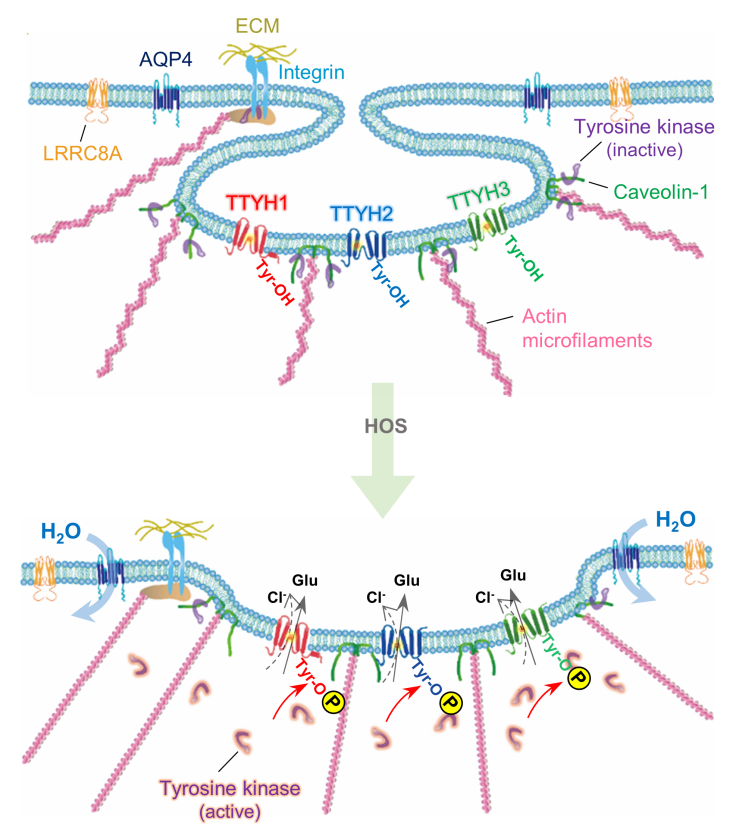

Fig. 12. A mechanistic model of volume regulation. (A) A mechanistic model for the sequence of events after HOS treatment. LRRC8 (yellow), AQP4 (blue), TTYH (red) were indicated in astrocytes (circle). Water or $\mathrm{Cl}^{-}$fluxes were indicated as a blue and green arrow, respectively. Bottom panel, the graphical diagram of cell swelling (grey) and channel activity (AQP4 indicated as blue, Lrrc8a indicated as yellow, and TTYH indicated as red) with the time after HOS treatment. (B) The schematic model for volume sensing and $\mathrm{VRAC}_{\text {swell }}$ activation upon inducing cell swelling by HOS. TTYH1, 2 and 3 might be located in the caveolae, which is the structure of the complex including caveolin-1 (green), Integrin (sky blue), and cytoskeleton (pink). After cell swelling, the inactive form of tyrosine kinase (purple) might be activated (orange, active TK).

silencing of LRRC8A by Lrrc8a shRNA slows the activation kinetics of $\mathrm{I}_{\mathrm{Cl} \text {,swell }}$ without affecting the maximal current density of $\mathrm{I}_{\mathrm{Cl} \text { swell }}$. Taken together, the precise relationship between TTYH1/2/3 and LRRC8A and the molecular mechanisms of activation and modulation of $\mathrm{I}_{\mathrm{Cl} \text { swell }}$ by the association of both TTYH-mediated VRAC- 
swell and LRRC8-mediated $\mathrm{VRAC}_{\Gamma}$ remain undetermined. Future investigations are needed to test those exciting possibilities.

\section{Molecular mechanisms of volume sensing and VRAC acti- vation}

The precise molecular mechanisms of sensing the cell swelling induced by hypo-osmotic shock, leading to an opening of $\mathrm{VRAC}_{\text {swell }}$ are poorly understood. Several hypothetical models for sensing the cell-swelling have been proposed [57-59]; (1) direct sensing of membrane stretch, (2) direct or indirect tethering to the cytoskeleton, (3) alterations in membrane curvature such as caveolae complex by mechanical or membrane-compositional changes, and (4) via interaction with integrins activated by the cell volume perturbation, and (5) via swelling-induced interaction between actin-binding protein (ACTN4) and a cytosolic member of $\mathrm{ABC}$ transporter superfamily (ABCF2) prevents ABCF2 from suppressing $\mathrm{VRAC}_{\text {swell }}$. Previous studies supporting these models have identified caveolin-1 and caveolin-related proteins that form a membrane curvature called caveolae in astrocytes [60]. This caveolin-1 is tethered to actin microfilaments [61] and positively modulates the activity of VRAC via c-Src tyrosine kinase [62]. Meanwhile, integrins are known to be associated with not only the extracellular matrix but also caveolin and positively regulate VRAC activation via various kinases such as FAK tyrosine kinase [63]. It has been previously demonstrated that a5-integrin is co-localized with TTYH1 in TTYH1-GFP over-expressing HEK293T cells [64]. We have demonstrated that TTYH1/2/3-mediated $\mathrm{I}_{\mathrm{Cl}, \text { swell }}$ is fully blocked by genistein and PD98059, which are the inhibitors of tyrosine kinase and MAP kinase, respectively (Fig. 5A, 5D and Fig. $5 \mathrm{H} \sim \mathrm{J})$. Based on these results, we can propose a mechanistic insight that there exists a complex of caveolin, integrin, cytoskeleton, and TTYH channels at astrocytic membrane curvature called caveolae, and hypo-osmotic shock somehow transduces through the integrin-caveolin-cytoskeleton complex to activate MAP kinase and tyrosine kinase to phosphorylate TTYH channels, which is required for either activation or surface expression of TTYH channels (Fig. 12B). In support of this possibility, we have observed that the surface expression of TTYH1 is enhanced by HOS treatment and prevented by either TK or MAPK inhibitor (Fig. 5K). These exciting possibilities await future investigations.

\section{The physiological and pathological roles of TTYH family in the brain}

In addition to the fundamental role of $\mathrm{VRAC}_{\text {swell }}$ in cellular volume regulation, $\mathrm{VRAC}_{\text {swell }}$ is also implicated in many other functions including regulation of cell proliferation, apoptosis and motility, which occur during an early developmental stage in the embryonic neural stem cells $[17,18]$. Consistently, TTYH1 has been shown to be prominently expressed in embryonic stem cells during developmental stages and various brain structures in developing and adult brain, while limited expression was detected in non-neural tissues and cell types [65]. In the brain, TTYH1 appears to be associated with the general functions of $\mathrm{VRAC}_{\text {swell }}$ such as proliferation, apoptosis, and motility. For example, TTYH1 expression was shown to be increased at the edge of extending processes of the migrating cultured astrocytes after a scratch injury [66], suggesting its role in migration. TTYH1 expression is also increased in hypertrophied reactive astrocytes following status epilepticus [66], alluding to its role in morphogenesis. In glioma cells, TTYH1 was implicated as a potent regulator of tumor microtubule morphology, tumor-cell invasion, and proliferation [41], which are the putative functions of $\mathrm{VRAC}_{\text {swell }}$.

We have demonstrated that TTYH channels are highly permeable to glutamate $\left(\mathrm{P}_{\mathrm{Glu}} / \mathrm{P}_{\mathrm{Cl}}=0.2 \sim 0.3\right)$ (Fig. 5O S), as VRAC $\mathrm{Cwell}_{\text {il }}$ has been already shown to release glutamate and other osmolytes [8$10,15,51]$. We have also demonstrated that $1 \mathrm{~Hz}$ stimulation in the Schaffer-collateral pathway in the hippocampus causes a profound volume increase and eventual TTYH1-mediated RVD (Fig. $11 \mathrm{~J} \sim \mathrm{L})$. It is possible that glutamate released through TTYH channels during RVD might regulate synaptic transmission as well as synaptic plasticity. Consistent with this idea, it has been previously shown that taurine, released through DCPIB-sensitive VRAC $_{\text {swell, }}$, can mediate glycinergic neurotransmission in the hypothalamus [11]. We show that there is no contribution of DCPIB-sensitive RVD after a brief $20 \mathrm{~Hz}$ or $100 \mathrm{~Hz}$ stimulation at Schaffer-collateral pathway in the hippocampus (Fig. 11D). In contrast, a prolonged $1 \mathrm{~Hz}$ stimulation, which is a conventional protocol for long-term depression (LTD) at this synapse, causes a profound increase in volume and initiation of RVD (Fig. 11C, Fig. 11E G, J L). During such RVD, glutamate and other osmolytes are expected to be released through TTYH channels and affect synaptic transmission as well as NMDA receptor- or mGluR-dependent synaptic plasticity, in particular, LTD. These exciting possibilities should be explored in the future.

In conclusion, with the advent of molecular identification of TTYH family as the VRAC $_{\text {swell }}$ of the brain, the putative functions of VRAC $_{\text {swell }}$ can be systematically addressed at the molecular, cellular and systemic levels in the future. Furthermore, our study should provide novel therapeutic targets for cerebral edema following ischemic stroke, brain trauma, and brain cancer, which are known to be associated with $\mathrm{VRAC}_{\text {swell }}[14,67]$. 


\section{ACKNOWLEDGEMENTS}

This study was supported by the Creative Research Initiative Program, Korean National Research Foundation (2015R1A3A2066619), and IBS institutional Grant (IBS-R001D1).

\section{REFERENCES}

1. Papadopoulos MC, Verkman AS (2013) Aquaporin water channels in the nervous system. Nat Rev Neurosci 14:265277.

2. Woo J, Kim JE, Im JJ, Lee J, Jeong HS, Park S, Jung SY, An H, Yoon S, Lim SM, Lee S, Ma J, Shin EY, Han YE, Kim B, Lee EH, Feng L, Chun H, Yoon BE, Kang I, Dager SR, Lyoo IK, Lee CJ (2018) Astrocytic water channel aquaporin-4 modulates brain plasticity in both mice and humans: a potential gliogenetic mechanism underlying language-associated learning. Mol Psychiatry 23:1021-1030.

3. Nilius B, Eggermont J, Voets T, Buyse G, Manolopoulos V, Droogmans G (1997) Properties of volume-regulated anion channels in mammalian cells. Prog Biophys Mol Biol 68:69119.

4. Parkerson KA, Sontheimer H (2004) Biophysical and pharmacological characterization of hypotonically activated chloride currents in cortical astrocytes. Glia 46:419-436.

5. Hazama A, Okada Y (1988) $\mathrm{Ca}^{2+}$ sensitivity of volume-regulatory $\mathrm{K}^{+}$and $\mathrm{Cl}^{-}$channels in cultured human epithelial cells. J Physiol 402:687-702.

6. Crépel V, Panenka W, Kelly ME, MacVicar BA (1998) Mitogen-activated protein and tyrosine kinases in the activation of astrocyte volume-activated chloride current. J Neurosci 18:1196-1206.

7. Kimelberg HK, Macvicar BA, Sontheimer H (2006) Anion channels in astrocytes: biophysics, pharmacology, and function. Glia 54:747-757.

8. Takano T, Kang J, Jaiswal JK, Simon SM, Lin JH, Yu Y, Li Y, Yang J, Dienel G, Zielke HR, Nedergaard M (2005) Receptormediated glutamate release from volume sensitive channels in astrocytes. Proc Natl Acad Sci U S A 102:16466-16471.

9. Liu HT, Tashmukhamedov BA, Inoue H, Okada Y, Sabirov RZ (2006) Roles of two types of anion channels in glutamate release from mouse astrocytes under ischemic or osmotic stress. Glia 54:343-357.

10. Liu HT, Akita T, Shimizu T, Sabirov RZ, Okada Y (2009) Bradykinin-induced astrocyte-neuron signalling: glutamate release is mediated by ROS-activated volume-sensitive out- wardly rectifying anion channels. J Physiol 587:2197-2209.

11. Choe KY, Olson JE, Bourque CW (2012) Taurine release by astrocytes modulates osmosensitive glycine receptor tone and excitability in the adult supraoptic nucleus. J Neurosci 32:12518-12527.

12. Tucker B, Olson JE (2010) Glutamate receptor-mediated taurine release from the hippocampus during oxidative stress. J Biomed Sci 17 Suppl 1:S10.

13. Kimelberg HK (1995) Current concepts of brain edema. Review of laboratory investigations. J Neurosurg 83:1051-1059.

14. Kimelberg HK (2005) Astrocytic swelling in cerebral ischemia as a possible cause of injury and target for therapy. Glia 50:389-397.

15. Zhang Y, Zhang H, Feustel PJ, Kimelberg HK (2008) DCPIB, a specific inhibitor of volume regulated anion channels (VRACs), reduces infarct size in MCAo and the release of glutamate in the ischemic cortical penumbra. Exp Neurol 210:514-520.

16. Ransom CB, O'Neal JT, Sontheimer H (2001) Volume-activated chloride currents contribute to the resting conductance and invasive migration of human glioma cells. J Neurosci 21:7674-7683.

17. Okada Y, Sato K, Numata T (2009) Pathophysiology and puzzles of the volume-sensitive outwardly rectifying anion channel. J Physiol 587:2141-2149.

18. Hoffmann EK, Holm NB, Lambert IH (2014) Functions of volume-sensitive and calcium-activated chloride channels. IUBMB Life 66:257-267.

19. Shimizu T, Lee EL, Ise T, Okada Y (2008) Volume-sensitive $\mathrm{Cl}^{-}$channel as a regulator of acquired cisplatin resistance. Anticancer Res 28:75-83.

20. Lee EL, Shimizu T, Ise T, Numata T, Kohno K, Okada Y (2007) Impaired activity of volume-sensitive $\mathrm{Cl}$ - channel is involved in cisplatin resistance of cancer cells. J Cell Physiol 211:513521.

21. Okada Y (1997) Volume expansion-sensing outward-rectifier $\mathrm{Cl}^{-}$channel: fresh start to the molecular identity and volume sensor. Am J Physiol 273:C755-C789.

22. Clapham DE (1998) The list of potential volume-sensitive chloride currents continues to swell (and shrink). J Gen Physiol 111:623-624.

23. Nilius B, Droogmans G (2003) Amazing chloride channels: an overview. Acta Physiol Scand 177:119-147.

24. Hoffmann EK, Lambert IH, Pedersen SF (2009) Physiology of cell volume regulation in vertebrates. Physiol Rev 89:193277.

25. Qiu Z, Dubin AE, Mathur J, Tu B, Reddy K, Miraglia LJ, Re- 
inhardt J, Orth AP, Patapoutian A (2014) SWELL1, a plasma membrane protein, is an essential component of volumeregulated anion channel. Cell 157:447-458.

26. Voss FK, Ullrich F, Münch J, Lazarow K, Lutter D, Mah N, Andrade-Navarro MA, von Kries JP, Stauber T, Jentsch TJ (2014) Identification of LRRC8 heteromers as an essential component of the volume-regulated anion channel VRAC. Science 344:634-638.

27. Syeda R, Qiu Z, Dubin AE, Murthy SE, Florendo MN, Mason DE, Mathur J, Cahalan SM, Peters EC, Montal M, Patapoutian A (2016) LRRC8 proteins form volume-regulated anion channels that sense ionic strength. Cell 164:499-511.

28. Okada T, Islam MR, Tsiferova NA, Okada Y, Sabirov RZ (2017) Specific and essential but not sufficient roles of LRRC8A in the activity of volume-sensitive outwardly rectifying anion channel (VSOR). Channels (Austin) 11:109-120.

29. Deneka D, Sawicka M, Lam AK, Paulino C, Dutzler R (2018) Structure of a volume-regulated anion channel of the LRRC8 family. Nature 558:254-259.

30. Sirianant L, Ousingsawat J, Wanitchakool P, Schreiber R, Kunzelmann K (2016) Cellular volume regulation by anoctamin 6: $\mathrm{Ca}^{2+}$, phospholipase A2 and osmosensing. Pflugers Arch 468:335-349.

31. Sirianant L, Wanitchakool P, Ousingsawat J, Benedetto R, Zormpa A, Cabrita I, Schreiber R, Kunzelmann K (2016) Non-essential contribution of LRRC8A to volume regulation. Pflugers Arch 468:805-816.

32. Akita T, Okada Y (2014) Characteristics and roles of the volume-sensitive outwardly rectifying (VSOR) anion channel in the central nervous system. Neuroscience 275:211-231.

33. Gaitán-Peñas H, Gradogna A, Laparra-Cuervo L, Solsona C, Fernández-Dueñas V, Barrallo-Gimeno A, Ciruela F, Lakadamyali M, Pusch M, Estévez R (2016) Investigation of LRRC8-mediated volume-regulated anion currents in Xenopus oocytes. Biophys J 111:1429-1443.

34. Park H, Han KS, Oh SJ, Jo S, Woo J, Yoon BE, Lee CJ (2013) High glutamate permeability and distal localization of Best1 channel in CA1 hippocampal astrocyte. Mol Brain 6:54.

35. Lee S, Yoon BE, Berglund K, Oh SJ, Park H, Shin HS, Augustine GJ, Lee CJ (2010) Channel-mediated tonic GABA release from glia. Science 330:790-796.

36. Milenkovic A, Brandl C, Milenkovic VM, Jendryke T, Sirianant L, Wanitchakool P, Zimmermann S, Reiff CM, Horling F, Schrewe H, Schreiber R, Kunzelmann K, Wetzel CH, Weber BH (2015) Bestrophin 1 is indispensable for volume regulation in human retinal pigment epithelium cells. Proc Natl Acad Sci U S A 112:E2630-E2639.
37. Fujii Y, Maekawa S, Morita M (2017) Astrocyte calcium waves propagate proximally by gap junction and distally by extracellular diffusion of ATP released from volume-regulated anion channels. Sci Rep 7:13115.

38. Sabirov RZ, Okada Y (2009) The maxi-anion channel: a classical channel playing novel roles through an unidentified molecular entity. J Physiol Sci 59:3-21.

39. Suzuki M (2006) The Drosophilatweety family: molecular candidates for large-conductance $\mathrm{Ca}^{2+}$-activated $\mathrm{Cl}^{-}$channels. Exp Physiol 91:141-147.

40. Okada Y, Okada T, Islam M R, Sabirov RZ (2018) Molecular identities and ATP release activities of two types of volumeregulatory anion channels, VSOR and Maxi-Cl. Curr Top Membr 81:125-176.

41. Jung E, Osswald M, Blaes J, Wiestler B, Sahm F, Schmenger T, Solecki G, Deumelandt K, Kurz FT, Xie R, Weil S, Heil O, Thomé C, Gömmel M, Syed M, Häring P, Huber PE, Heiland S, Platten M, von Deimling A, Wick W, Winkler F (2017) Tweety-homolog 1 drives brain colonization of gliomas. J Neurosci 37:6837-6850.

42. Zhang Y, Chen K, Sloan SA, Bennett ML, Scholze AR, O'Keeffe S, Phatnani HP, Guarnieri P, Caneda C, Ruderisch N, Deng S, Liddelow SA, Zhang C, Daneman R, Maniatis T, Barres BA, Wu JQ (2014) An RNA-sequencing transcriptome and splicing database of glia, neurons, and vascular cells of the cerebral cortex. J Neurosci 34:11929-11947.

43. Woo DH, Han KS, Shim JW, Yoon BE, Kim E, Bae JY, Oh SJ, Hwang EM, Marmorstein AD, Bae YC, Park JY, Lee CJ (2012) TREK-1 and Best 1 channels mediate fast and slow glutamate release in astrocytes upon GPCR activation. Cell 151:25-40.

44. Ventura A, Meissner A, Dillon CP, McManus M, Sharp PA, Van Parijs L, Jaenisch R, Jacks T (2004) Cre-lox-regulated conditional RNA interference from transgenes. Proc Natl Acad Sci U S A 101:10380-10385.

45. Park H, Oh SJ, Han KS, Woo DH, Park H, Mannaioni G, Traynelis SF, Lee CJ (2009) Bestrophin-1 encodes for the $\mathrm{Ca}^{2+}$-activated anion channel in hippocampal astrocytes. J Neurosci 29:13063-13073.

46. Benfenati V, Nicchia GP, Svelto M, Rapisarda C, Frigeri A, Ferroni S (2007) Functional down-regulation of volumeregulated anion channels in AQP4 knockdown cultured rat cortical astrocytes. J Neurochem 100:87-104.

47. Oh SJ, Lee CJ (2017) Distribution and function of the bestrophin-1 (Best1) channel in the brain. Exp Neurobiol 26:113121.

48. Marmorstein LY, Wu J, McLaughlin P, Yocom J, Karl MO, Neussert R, Wimmers S, Stanton JB, Gregg RG, Strauss O, 
Peachey NS, Marmorstein AD (2006) The light peak of the electroretinogram is dependent on voltage-gated calcium channels and antagonized by bestrophin (best-1). J Gen Physiol 127:577-589.

49. Wang R, Lu Y, Gunasekar S, Zhang Y, Benson CJ, Chapleau MW, Sah R, Abboud FM (2017) The volume-regulated anion channel (LRRC8) in nodose neurons is sensitive to acidic $\mathrm{pH}$. JCI Insight 2:e90632.

50. Decher N, Lang HJ, Nilius B, Brüggemann A, Busch AE, Steinmeyer K (2001) DCPIB is a novel selective blocker of $\mathrm{I}(\mathrm{Cl}$,swell $)$ and prevents swelling-induced shortening of guinea-pig atrial action potential duration. Br J Pharmacol 134:1467-1479.

51. Abdullaev IF, Rudkouskaya A, Schools GP, Kimelberg HK, Mongin AA (2006) Pharmacological comparison of swellingactivated excitatory amino acid release and $\mathrm{Cl}$ - currents in cultured rat astrocytes. J Physiol 572:677-689.

52. Jackson PS, Morrison R, Strange K (1994) The volume-sensitive organic osmolyte-anion channel VSOAC is regulated by nonhydrolytic ATP binding. Am J Physiol 267:C1203-C1209.

53. He Y, Ramsay AJ, Hunt ML, Whitbread AK, Myers SA, Hooper JD (2008) N-glycosylation analysis of the human Tweety family of putative chloride ion channels supports a pentaspanning membrane arrangement: impact of $\mathrm{N}$-glycosylation on cellular processing of Tweety homologue 2 (TTYH2). Biochem J 412:45-55.

54. Geiger JR, Melcher T, Koh DS, Sakmann B, Seeburg PH, Jonas P, Monyer H (1995) Relative abundance of subunit mRNAs determines gating and $\mathrm{Ca}^{2+}$ permeability of AMPA receptors in principal neurons and interneurons in rat CNS. Neuron 15:193-204.

55. MacVicar BA, Hochman D (1991) Imaging of synaptically evoked intrinsic optical signals in hippocampal slices. J Neurosci 11:1458-1469.

56. Benedetto R, Sirianant L, Pankonien I, Wanitchakool P, Ousingsawat J, Cabrita I, Schreiber R, Amaral M, Kunzelmann K (2016) Relationship between TMEM16A/anoctamin 1 and LRRC8A. Pflugers Arch 468:1751-1763.

57. Pedersen SF, Kapus A, Hoffmann EK (2011) Osmosensory mechanisms in cellular and systemic volume regulation. J Am Soc Nephrol 22:1587-1597.

58. Ando-Akatsuka Y, Shimizu T, Numata T, Okada Y (2012) Involvements of the $\mathrm{ABC}$ protein $\mathrm{ABCF} 2$ and alpha-actinin- 4 in regulation of cell volume and anion channels in human epithelial cells. J Cell Physiol 227:3498-3510.

59. Okada Y, Okada T, Sato-Numata K, Islam MR, AndoAkatsuka Y, Numata T, Kubo M, Shimizu T, Kurbannazarova RS, Marunaka Y, Sabirov RZ (2019) Cell volume-activated and volume-correlated anion channels in mammalian cells: their biophysical, molecular, and pharmacological properties. Pharmacol Rev 71:49-88.

60. Cameron PL, Ruffin JW, Bollag R, Rasmussen H, Cameron RS (1997) Identification of caveolin and caveolin-related proteins in the brain. J Neurosci 17:9520-9535.

61. Stahlhut M, van Deurs B (2000) Identification of filamin as a novel ligand for caveolin-1: evidence for the organization of caveolin-1-associated membrane domains by the actin cytoskeleton. Mol Biol Cell 11:325-337.

62. Trouet D, Carton I, Hermans D, Droogmans G, Nilius B, Eggermont J (2001) Inhibition of VRAC by c-Src tyrosine kinase targeted to caveolae is mediated by the Src homology domains. Am J Physiol Cell Physiol 281:C248-C256.

63. Browe DM, Baumgarten CM (2003) Stretch of beta 1 integrin activates an outwardly rectifying chloride current via FAK and Src in rabbit ventricular myocytes. J Gen Physiol 122:689-702.

64. Matthews CA, Shaw JE, Hooper JA, Young IG, Crouch MF, Campbell HD (2007) Expression and evolution of the mammalian brain gene Ttyh1. J Neurochem 100:693-707.

65. Kleinman CL, Gerges N, Papillon-Cavanagh S, Sin-Chan P, Pramatarova A, Quang DA, Adoue V, Busche S, Caron M, Djambazian H, Bemmo A, Fontebasso AM, Spence T, Schwartzentruber J, Albrecht S, Hauser P, Garami M, Klekner A, Bognar L, Montes JL, Staffa A, Montpetit A, Berube P, Zakrzewska M, Zakrzewski K, Liberski PP, Dong Z, Siegel PM, Duchaine T, Perotti C, Fleming A, Faury D, Remke M, Gallo M, Dirks P, Taylor MD, Sladek R, Pastinen T, Chan JA, Huang A, Majewski J, Jabado N (2014) Fusion of TTYH1 with the C19MC microRNA cluster drives expression of a brainspecific DNMT3B isoform in the embryonal brain tumor ETMR. Nat Genet 46:39-44.

66. Wiernasz E, Kaliszewska A, Brutkowski W, Bednarczyk J, Gorniak M, Kaza B, Lukasiuk K (2014) Ttyh1 protein is expressed in glia in vitro and shows elevated expression in activated astrocytes following status epilepticus. Neurochem Res 39:2516-2526.

67. Raslan A, Bhardwaj A (2007) Medical management of cerebral edema. Neurosurg Focus 22:E12. 